\title{
WestVirginiaUniversity
}

THE RESEARCH REPOSITORY @ WVU

Graduate Theses, Dissertations, and Problem Reports

2013

\section{A Study of Determinants of Coping in Childhood Cancer Survivors}

Lea Helene Mallett

West Virginia University

Follow this and additional works at: https://researchrepository.wvu.edu/etd

\section{Recommended Citation}

Mallett, Lea Helene, "A Study of Determinants of Coping in Childhood Cancer Survivors" (2013). Graduate Theses, Dissertations, and Problem Reports. 4978.

https://researchrepository.wvu.edu/etd/4978

This Dissertation is protected by copyright and/or related rights. It has been brought to you by the The Research Repository @ WVU with permission from the rights-holder(s). You are free to use this Dissertation in any way that is permitted by the copyright and related rights legislation that applies to your use. For other uses you must obtain permission from the rights-holder(s) directly, unless additional rights are indicated by a Creative Commons license in the record and/ or on the work itself. This Dissertation has been accepted for inclusion in WVU Graduate Theses, Dissertations, and Problem Reports collection by an authorized administrator of The Research Repository @ WVU.

For more information, please contact researchrepository@mail.wvu.edu. 


\title{
A Study of Determinants of Coping in Childhood Cancer Survivors
}

\author{
Lea Helene Mallett \\ Dissertation submitted to the \\ Davis College of Agriculture, Natural Resources, and Design \\ at West Virginia University \\ in partial fulfillment of the requirements \\ for the degree of
}

\author{
Doctor of Philosophy \\ in \\ Animal and Food Science
}

\author{
Susan Partington, Ph.D., Chair \\ Robert Dailey, Ph.D. \\ Jacek Jaczynski, Ph.D. \\ Kristen Matak, Ph.D. \\ Lesley Cottrell, Ph.D.
}

Department of Animal and Nutritional Science

Morgantown, West Virginia
2013

Keywords: Childhood Cancer Survivors; Coping; Stressors; Kidcope; Risk Factors 


\section{ABSTRACT \\ A Study of Determinants of Coping in Childhood Cancer Survivors}

Lea Helene Mallett

OBJECTIVES: The purposes of this research were to (1) determine the association between time since the completion of cancer treatment and the type of stressor (cancerrelated versus non-cancer-related) identified; (2) determine whether the stressor identified (cancer-related or non-cancer-related) and strategies utilized to cope with that stressor change over time; (3) determine whether type of cancer and treatment are associated with specific coping strategies, and (4) determine if family characteristics (household structure, median household income, and presence of siblings) impact the endorsement and efficacy of coping strategies utilized to cope with a stressor.

BACKGROUND: Cancer alters children's lives in many ways, beginning at diagnosis and continuing well after therapy ends. As a result, survivors of childhood cancer may face psychological problems, adjustment problems, or depression. Certain combinations of demographic variables, disease and treatment factors, and family structure factors have been suggested as predictors of more difficult psychological adjustment in childhood cancer survivors. These risk factors influence the child's coping strategies, which, in turn, affect their overall adjustment.

METHODS: Data from 270 surveys from 139 participants from the Medical University of South Carolina Follow-up After Cancer Treatment clinic were analyzed. Hierarchical regression modeling was used to examine treatment length, time since completion of treatment to assessment, and demographic variables as a predictor of stressor reporting. Change in stressor reporting and coping strategy use over time also was evaluated.

Logistic regression and linear regression analyses were performed to examine demographic, family, diagnosis and treatment variables, alone and in combination, as predictors of coping strategy endorsement and efficacy.

RESULTS: Hierarchical regression analyses revealed age at assessment and time since completion of treatment to assessment significantly predicted type of stressor reported (Wald $\chi^{2}(5)=13.07, \mathrm{p}<.05$ ). Stressor reporting and coping strategy use changed over time, while controlling for age, race, and gender $(\mathrm{p}<.05)$. Female participants had a significant increased odds of using approach coping (OR=2.27; 95\% CI: 1.04, 4.93) and participants with a diagnosis of leukemia had a greater likelihood using withdrawal coping (OR=2.91; 95\% CI: 1.07, 7.87), controlling for treatment and treatment length. Furthermore, participants from a two parent household (OR=2.13; 95\% CI: 1.06, 7.19), and those participants who had a median household income of $\geq \$ 50,000$ (OR=1.88; 95\% CI: 1.06, 2.65) had a greater likelihood of using approach coping. Results of the linear regression revealed that median household income, age at assessment, household structure, and siblings significantly $(\mathrm{p}<.05)$ predicated mean coping efficacy.

CONCLUSIONS: Overall, this research demonstrated that stressors and coping strategy use in childhood cancer survivors changes over time to give way to non-cancer-related stressors and adaptive coping strategies. The interrelationships detected among demographic, diagnosis, treatment, household variables and coping identified characteristics of childhood cancer survivors at increased risk of psychological adjustment issues and in need of psychosocial interventions. 


\section{ACKNOWLEDGEMENTS}

I wish to acknowledge and express my appreciation to those who provided me the opportunity and support to complete this dissertation.

I would like to thank Dr. Lesley Cottrell, Dr. Robert Dailey, Dr. Jacek Jaczynski, and Dr. Kristen Matak for serving on my dissertation committee. I am grateful for your time, expertise, and support. I cannot begin to express my gratitude to my advisor, Dr. Susan Partington, for your constant encouragement and support. Your guidance has been invaluable. You inspired me to pursue a Ph.D., and without you, I would not be where I am today.

I would also like to thank Michelle Vandermaas for the data that inspired this dissertation and for allowing me to be a part of the data collection process which gave me invaluable insight for this research.

Finally, I would like to thank my family and friends. To my parents, Dr. Victor and Joy Soderstrom, thank you for the support throughout all of my education and for the confidence you have inspired in me. Your constant love and encouragement is immeasurable and I am forever grateful. A special thank you to my siblings and friends for all the love and support you have given me throughout the years has been priceless. Lastly, to my loving husband, Drew, thank you for your unwavering love, support, and incredible patience throughout the years. 


\section{TABLE OF CONTENTS}

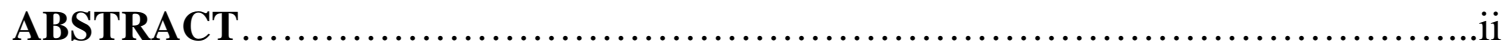

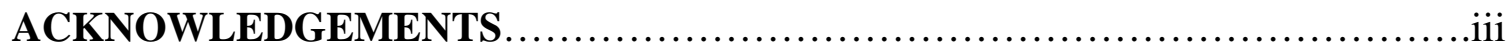

\section{CHAPTERS}

1 INTRODUCTION

1.1 Overview.............................................................

1.2 Specific Aims........................................................

2 REVIEW OF THE LITERATURE

2.1 Epidemiology of Childhood Cancer...................................... 5

2.2 Childhood Cancer........................................................6

2.3 Quality of Life Research...........................................13

2.4 Coping.............................................................

2.5 Measuring Coping: The Kidcope Questionnaire..........................25

3 STUDY DESIGN AND METHODS

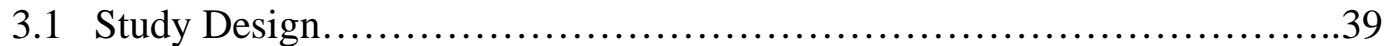

3.2 Study Population..................................................41

3.3 Kidcope Questionnaire Administration...................................43

3.4 Categorization of Stressors........................................ 44

3.5 Factor Analysis.................................................... 45

3.6 Statistical Analysis................................................... 47

3.7 Preliminary Analysis...................................................55

4 EXAMINING CHANGES IN STRESSORS AND COPING LONGITUDINALLY IN CHILDHOOD CANCER SURVIVORS

Abstract...................................................................58

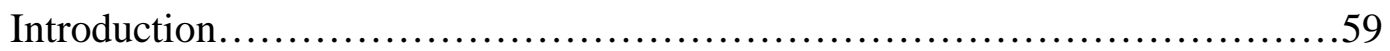

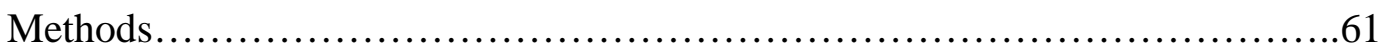

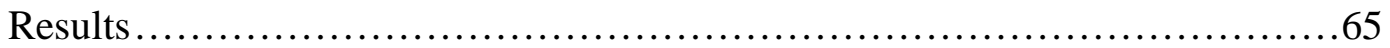

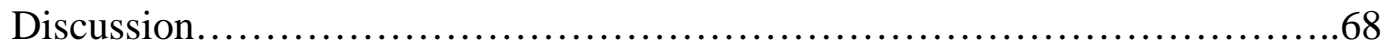

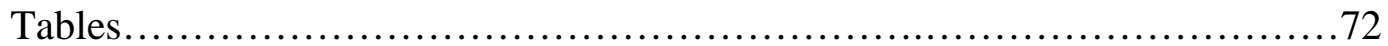

5 DETERMINANTS OF COPING IN CHILDHOOD CANCER SURVIVORS: INFLUENCE OF ILLNESS, TREATMENT, AND DEMOGRAPHIC FACTORS

Abstract...................................................................... 77

Introduction............................................................ 78

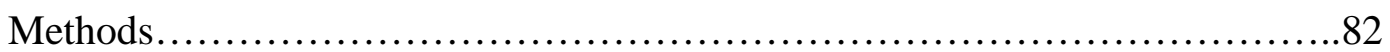

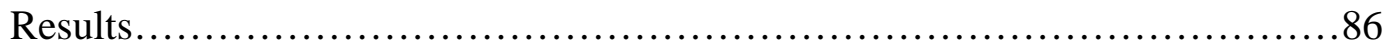

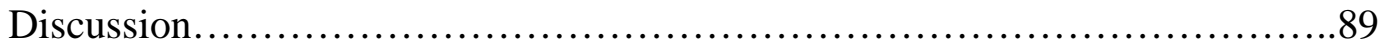

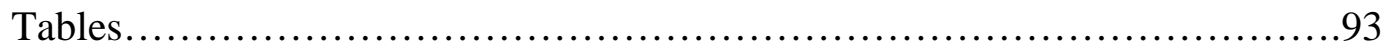


6 DETERMINANTS OF COPING ENDORESEMENT AND EFFICACY IN CHILDHOOD CANCER SURVIVORS: INFLUENCE OF DEMOGRAPHIC AND FAMILY STRUCTURE FACTORS

Abstract............................................................. 100

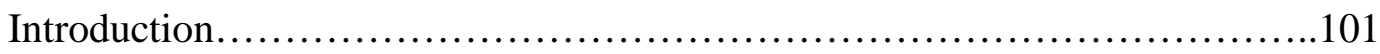

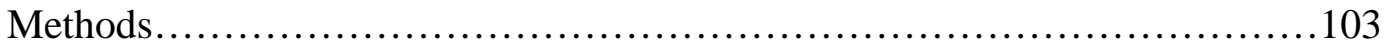

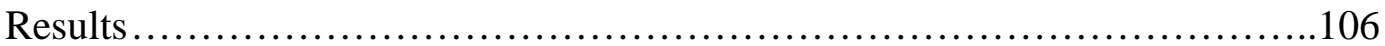

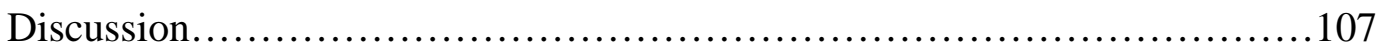

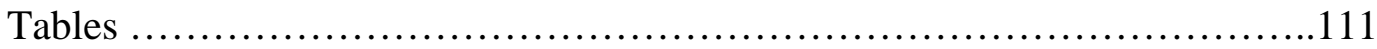

7 STRENGTHS, LIMITATIONS, AND CONCLUSIONS

7.1 Strengths and Limitations.............................................115

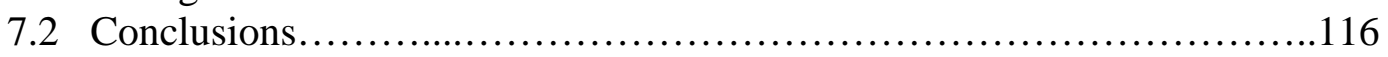

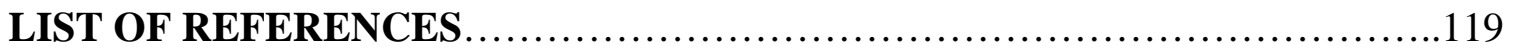

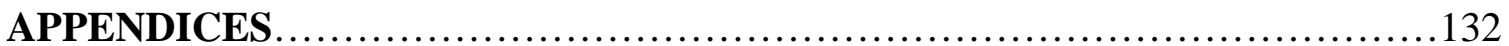

Appendix A: HIPAA Authorization and Consent to Participate Forms

Appendix B: Medical Record Data Collection Form

Appendix C: Kidcope Questionnaires

Appendix D: Stressor Coding 


\section{CHAPTER 1: INTRODUCTION}

\subsection{Overview}

Childhood cancer is the second leading cause of death, second only to accidents, and is the leading cause of death by disease among children ages 0-15 (American Cancer Society, 2012). In the United States in 2013, approximately 11,630 children under the age of 15 will be diagnosed with cancer and about 1,310 children will die from the disease (American Cancer Society, 2012). Over the past 34 years, the incidence of children diagnosed with cancer has increased 33\% from 13.0 cases per 100,000 in 1975 to 17.3 cases per 100,000 in 2009 (Howlander et al., 2012). The increase in incidence is not fully understood but is due in part to better diagnostic techniques as well as an increase in environmental exposures and genetic dispositions that can lead to cancer. Conversely, mortality rates have declined 68\% over the past four decades from 6.5 per 100,000 in 1969 to 2.1 per 100,000 in 2009 (American Cancer Society, 2012), and the 5year survival rate increased from 61.7\% in 1975 to 83.1\% in 2008 (Howlander et al., 2012). These declines in mortality represent treatment-related improvements. Therefore, the increased incidence rate combined with improved rates of survival has resulted in many more childhood cancer survivors. These statistics support the need for research focused on a child's short and long term adjustment to the experience of surviving cancer.

Cancer alters children’s lives in many ways, beginning at diagnosis and continuing well after therapy ends. Some effects are directly related to the physical course of the disease and treatment. In addition, childhood cancer survivors may face psychological problems such as learning disabilities, academic failure, behavioral and 
other adjustment problems, as well as depression (Mulhern et al., 1989). Certain combinations of demographic variables, disease and treatment factors, and residual physical disabilities have been suggested as predictors of more difficult psychological adjustment in childhood cancer survivors (Mulhern et al., 1989). These risk factors influence the child's coping strategies, which, in turn, affect their overall adjustment.

The concept of coping refers to the use of cognitive, emotional, and behavioral strategies in responding to stressful situations (Lazerus et al., 1993). It is important to discern the coping resources, processes, and styles used by children who are faced with cancer, other chronic illnesses and traumatic events because they impact future psychosocial adjustment (Compas et al., 1987, 1993). Existing child-focused research on coping with cancer includes children’s coping during painful medical procedures (Blount et al., 1991), coping with aversive symptoms and physical changes (Bull et al., 1991) and general psychosocial adjustment (Sanger et al., 1991). In pediatric cancer, little attention has been dedicated to the specific demands or coping tasks involved in a given situation and how changing situational or emotional demands affect coping (Patenaude et al., 2005).

The focus of this dissertation is on determinants of coping in survivors of childhood cancer. Specifically, participant’s age, gender and race; family characteristics; and specific disease and treatment regimen were hypothesized to be associated with the survivors' ability to cope. Additionally, given that the data would be both cross sectional and longitudinal, this research had the potential to make inferences about coping over time. Results could be used to inform support strategies for patients and their families to minimize the psychosocial consequences of disease and treatment. Furthermore, the 
results could potentially be clinically relevant by identifying high-risk individuals to be targeted for preventative intervention.

\subsection{Specific Aims}

The goal of this study was to evaluate the stressors identified by survivors of childhood cancer and how the participants coped with those stressors in relation to their cancer diagnosis and treatment (Figure 1). This study also sought to examine the relationship between the type of stressor faced by the survivor, time since completion of treatment, and the effects of contextual factors (household structure, socioeconomic status, and siblings) on the identified coping strategies. Specifically, the aims of the research were to:

\section{Determine the association between time since the completion of cancer} treatment and the type of stressor (cancer-related versus non-cancer-related) identified.

Hypothesis 1a: Stressors related to the medical treatment of the cancer (i.e. needles, chemotherapy, hospital) predominate during and soon after treatment but diminish over time and give way to stressors not related to the cancer (i.e. school, family, friends).

Sub-aim: Determine whether the stressor identified (cancer-related or noncancer-related) and strategies utilized to cope with that stressor change over time for specific individuals.

Hypothesis 1b: Stressors directly related to a participant's cancer and withdrawal coping strategies predominate during and soon after treatment is completed 
but diminish over time and give way to non-cancer-related stressors and approach coping strategies.

2. Determine whether type of cancer and treatment are associated with specific coping strategies.

Hypothesis: Participants with a more severe diagnosis and who require more extensive treatment will exhibit withdrawal coping strategies.

3. Determine if family characteristics (household structure, median household income, and presence of siblings) impact the endorsement and efficacy of coping strategies utilized.

Hypothesis: Participants with siblings, higher median household income, and from two-parent households will use approach coping strategies and will have higher reported coping efficacy.

Figure 1: Conceptual model of the relations among participant and family characteristics, cancer diagnosis and treatment, stressors and coping strategies

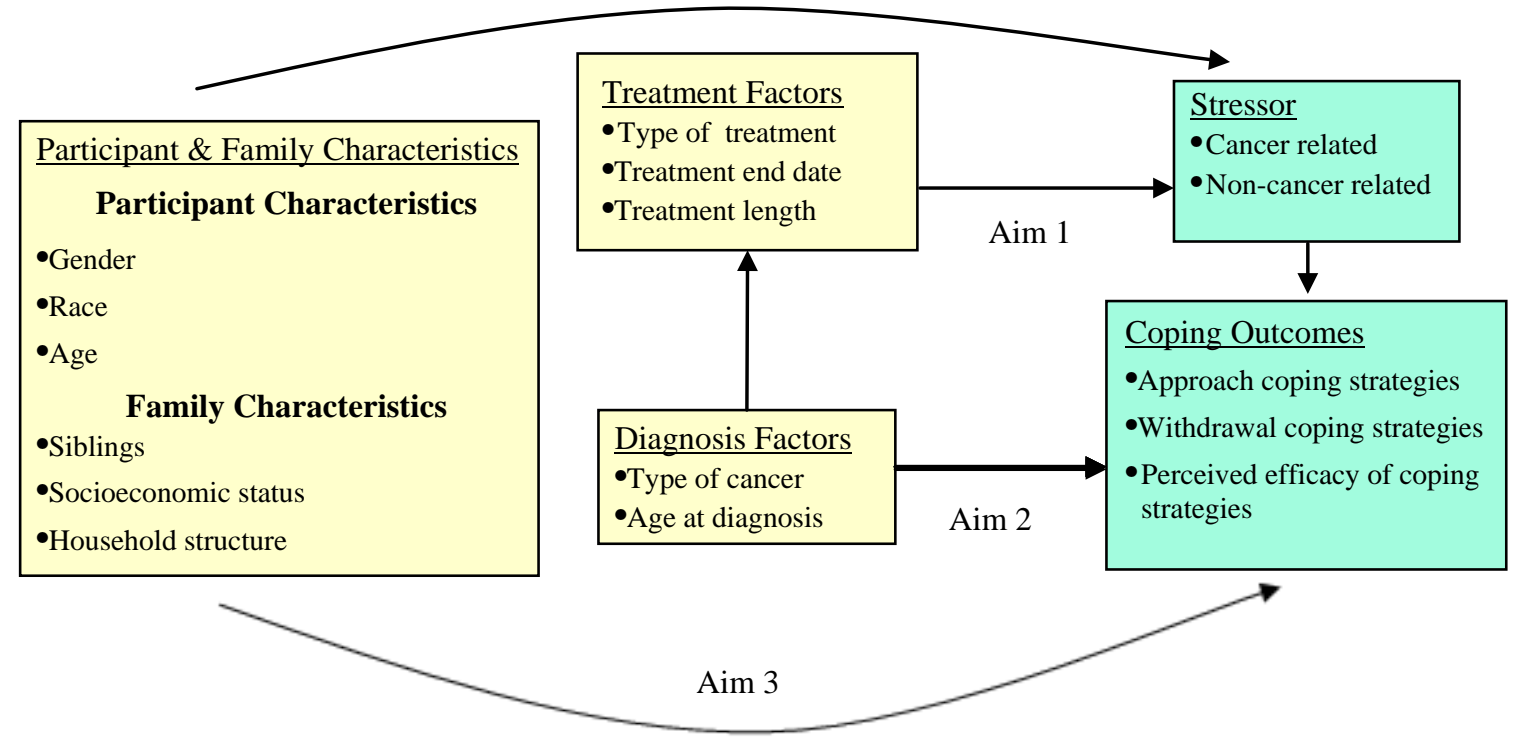




\section{CHAPTER 2: REVIEW OF THE LITERATURE}

\subsection{Epidemiology of Childhood Cancer}

Childhood cancer is the second leading cause of death after accidents and is the leading cause of death by disease among children ages 0-15 (American Cancer Society, 2012). In the United States in 2013, approximately 11,630 children under the age of 15 will be diagnosed with cancer and about 1,310 children will die from the disease (American Cancer Society, 2012). During the past 34 years, the incidence of children diagnosed with cancer has increased 33\% from 13.0 cases per 100,000 in 1975 to 17.3 cases per 100,000 in 2009 (Howlander et al., 2012). The increase in incidence is not fully understood but is due in part to better diagnostic techniques as well as an increase in environmental exposures and genetic dispositions that can lead to cancer. During this same time period, the death rate of those diagnosed declined dramatically which explains an increased rate of survival. The 5-year survival rate increased from 61.7\% in 1975 to 83.1\% in 2008 (Howlander et al., 2012). These declines in mortality represent treatmentrelated improvements and high rates of participation in clinical trials. The increased incidence of cancer necessitates research that determines ways to mitigate the effects of invasive procedures, evaluates children’s coping processes, and identifies psychological or behavioral interventions (Patenaude et al., 2005).

The successful medical treatment of children with cancer has greatly increased their survival rates. Reports have indicated that $75 \%$ of children and adolescents diagnosed with cancer in the United States are likely to achieve a relatively normal life span (Zebrack et al., 2002). This set of circumstances has resulted in more childhood 
cancer survivors and thus a greater need to study the adjustment of children who survived cancer.

\subsection{Childhood Cancer}

\subsubsection{Types of Childhood Cancer}

Types of childhood cancers include leukemias, brain and nervous system cancers, neuroblastoma and other cancers of the nerves, Wilms' tumor, lymphoma, soft tissue sarcomas, kidney cancers, retinoblastoma, and bone cancers. Each type of cancer has unique symptoms, courses of treatment and prognosis. Table 1 summarizes the most common types of childhood cancer in regards to the number of children diagnosed with that cancer, the 5-year survival rate, and the treatment for each type of cancer displayed. The most common types of childhood cancer are described in further detail below.

Each year, 500-3,500 children are newly diagnosed with white blood cell cancers, nervous system cancers, or kidney cancers. Leukemias are the most common childhood cancer as they account for 34\% of all childhood cancers (American Cancer Society, 2012). Brain and nervous system cancers are the second most common cancers in children, accounting for $27 \%$ of childhood cancers (American Cancer Society, 2012). To the contrary, only 5-6\% of all childhood cancers are diagnosed as neuroblastomas or Wilms’ Tumor (American Cancer Society, 2012). The average age of onset for all types of childhood cancer ranges from one to seven years of age with the 5-year survival rate of $90 \%$ or better for low risk types of cancer. The treatment regimen for all types of childhood cancer consists of chemotherapy and/or radiation therapy. In some cancers, surgery is necessary to remove a tumor. 


\subsubsection{Causes of Childhood Cancer}

The causes of childhood cancers are largely unknown. Two factors may determine a child's susceptibility to developing cancer: genetic predisposition to the disease and environmental cues that may either initiate the disease or cause it to progress. A child may inherit mutations in a gene that cause cancer to occur, or a child may suffer sporadic mutations in a gene that cause cancer to occur; specifically, children with Down’s syndrome are at increased risk of developing cancer (American Cancer Society, 2012).

In addition to genetic causes, environmental exposures have long been suspected of increasing the risk of certain childhood cancers. High-level radiation and high doses of certain chemicals are known risk factors for causing certain childhood cancers, but the influence of low-level contaminants is harder to define (American Cancer Society, 2012). The environmental agents linked to causing cancers include pesticides, solvents, paints, electromagnetic fields, metals, oral contraceptives and secondhand tobacco smoke (American Cancer Society, 2012). Researchers continue to examine environmental influences on childhood cancer; however, it remains difficult to identify a child's prior exposures particularly if they occurred many years in the past. The effects of prior exposure are even more difficult to determine because some exposures to environmental influences could have occurred during pregnancy or even prior to the conception of the child (American Cancer Society, 2012). 
Table 1: Prevalence of Childhood Cancers and Associated Risk factors, 5-year Survival Rates, Symptoms, and Treatment.

\begin{tabular}{|c|c|c|c|c|c|c|}
\hline Type of Cancer & $\begin{array}{c}\text { \# Children } \\
\text { Diagnosed/Yr. }\end{array}$ & $\begin{array}{c}\text { Proportion of } \\
\text { Childhood } \\
\text { Cancer } \\
\end{array}$ & $\begin{array}{c}\text { Average Age } \\
\text { of Onset } \\
\text { (yrs.) }\end{array}$ & Risk Factors & $\begin{array}{c}\text { 5-Year } \\
\text { Survival Rate }\end{array}$ & Treatment \\
\hline $\begin{array}{c}\text { Acute Lymphocytic } \\
\text { Leukemia (ALL) \& } \\
\text { Acute Myelogenous } \\
\text { Leukemia (AML) [13] }\end{array}$ & $\begin{array}{c}3,500 \\
75 \%(\text { ALL) } \\
25 \% \text { (AML) }\end{array}$ & $34 \%$ & $2-4$ & $\begin{array}{l}\text { Male, Caucasian, } \\
\text { Hispanic, Down } \\
\text { syndrome, prenatal } \\
\text { exposure to x-rays }\end{array}$ & $\begin{array}{c}91 \% \text { (ALL); } \\
\text { 60\%-70\% } \\
\text { (AML) }\end{array}$ & $\begin{array}{c}\text { S, RT, CT, } \\
\text { BMT, PBSCT. } \\
\text { Blood } \\
\text { transfusions } \\
\end{array}$ \\
\hline $\begin{array}{c}\text { Central Nervous } \\
\text { System Tumors [14] }\end{array}$ & 4,000 & $27 \%$ & 3-7 & $\begin{array}{l}\text { Male, Caucasian, } \\
\text { radiation exposure } \\
\text { to head }\end{array}$ & $75 \%$ & $\begin{array}{l}\text { S, RT, CT, } \\
\text { craniotomy }\end{array}$ \\
\hline Neuroblastoma [15] & 700 & $6 \%$ & $1-2$ & $\begin{array}{l}\text { Male, family } \\
\text { history of } \\
\text { neuroblastoma }\end{array}$ & $\begin{array}{l}\text { 95\% (low } \\
\text { risk); } \\
30 \%-50 \% \\
\text { (high risk) }\end{array}$ & $\begin{array}{l}\text { S, RT, CT, } \\
\text { PBSCT retinoid } \\
\text { therapy }\end{array}$ \\
\hline Wilms' Tumor [16] & 500 & $5 \%$ & 3-4 & $\begin{array}{l}\text { Female, African } \\
\text { American, missing } \\
\text { iris of the eye, } \\
\text { hemihypertrophy, } \\
\text { urinary tract issues }\end{array}$ & $\begin{array}{c}87 \%-99 \% \\
\text { (favorable } \\
\text { histology); } \\
55 \%-83 \% \\
\text { (unfavorable } \\
\text { histology) }\end{array}$ & S, RT, CT \\
\hline $\begin{array}{c}\text { Non-Hodgkins } \\
\text { Lymphoma (NHL) }\end{array}$ & 500 & $4 \%$ & $7-11$ & $\begin{array}{l}\text { Male, Caucasian, } \\
\text { older age, } \\
\text { weakened immune } \\
\text { system, Epstein- } \\
\text { Barr virus infection }\end{array}$ & $\begin{array}{l}60-90 \% \\
\text { depending on } \\
\text { type of NHL }\end{array}$ & S, RT, CT \\
\hline Rhabdomyosarcoma & 350 & $3 \%$ & 7-8 & $\begin{array}{l}\text { Male, younger age, } \\
\text { rare inherited } \\
\text { conditions }\end{array}$ & $\begin{array}{l}90 \% \text { (low } \\
\text { risk); } \\
20 \%-40 \% \\
\text { (high risk) }\end{array}$ & S, RT, CT \\
\hline Osteosarcoma & 400 & $3 \%$ & 15 & $\begin{array}{l}\text { Male, African } \\
\text { American, } \\
\text { teenagers, taller for } \\
\text { age, bone disease, } \\
\text { radiation therapy }\end{array}$ & $\begin{array}{l}90 \% \text { (stage } 1 \text { ); } \\
40 \% \text { (stage } 2) ; \\
30 \% \text { (stage } 3 \text { ) }\end{array}$ & S, RT, CT \\
\hline
\end{tabular}

Note: S=surgery; RT=radiation therapy; CT=chemotherapy; BMT=bone marrow transplant; PBSCT=peripheral blood stem cell transplant 


\subsubsection{Treatment for Childhood Cancer}

Given the diversity of childhood cancers, the type of treatment needed depends on the type and severity of cancer and the child's age. All childhood cancer treatments have been associated with a wide variety of short-term and long-term side effects.

Chemotherapy and radiation therapy are the most commonly used forms of treatment for childhood cancers.

Chemotherapy medication used to kill cancer cells can be administered intravenously or orally. The duration of chemotherapy treatment and type of drugs used depend on the specific diagnosis and response by the patient to the drugs. Short-term side effects of chemotherapy include nausea, vomiting, hair loss, fatigue, anemia, abnormal bleeding, increased risk of infection and kidney damage (American Cancer Society, 2012; Bryant et al., 2003). Some chemotherapy drugs can also cause hearing loss, liver damage and heart or skin problems (American Cancer Society, 2012; Bryant et al., 2003). Some long-term side effects of chemotherapy can include infertility, growth problems, organ damage, or increased risk of other cancers (American Cancer Society, 2012; Bryant et al., 2003).

Radiation therapy can be used in conjunction with chemotherapy or surgery. A child who receives radiation therapy is treated with a stream of high-energy particles or waves that destroy or damage cancer cells and shrink tumors. Side effects of radiation therapy include fatigue, skin damage, hair loss, mouth sores, tooth decay, and gastrointestinal problems (American Cancer Society, 2012; Bryant et al., 2003). Increased risk for future malignancy, infertility, abnormal bone growth, and learning or memory problems are possible long-term side effects of radiation therapy (American 
Cancer Society, 2012; Bryant et al., 2003). Blood and platelet transfusions, tube feeding, and prescription medication are measures used to manage the side effects of cancer treatment (Bryant et al., 2003).

Several studies have examined the risk of secondary malignancies after childhood cancer. According to recent findings from the Childhood Cancer Survivor Study, the two most frequent secondary malignancies diagnosed in childhood cancer survivors are nonmelanoma skin cancer and breast cancer (Friedman et al., 2010). Additionally, the secondary diagnosis that had the highest excess risk compared to the general population was bone cancer (SIR=19.0, 95\% CI=14.2 to 25.5) (Friedman et al., 2010). This study indicated the primary risk factors for secondary malignancies as female sex $(R R=1.5)$, older age at primary childhood cancer diagnosis $(\mathrm{RR}=1.3)$, radiation therapy exposure $(\mathrm{RR}=2.7)$ and primary diagnosis of Hodgkin lymphoma $(\mathrm{RR}=1.5)$ (Friedman et al., 2010).

The possibility of second cancers represents one of the biggest worries for survivors and their parents (Zebrack et al., 2001). In fact, one study found $10 \%$ of childhood cancer survivors reported worry about future cancer compared to $1 \%$ of children with no history of chronic medical or psychological problems (Greenberg et al., 1989). The variety in treatment, prognosis, and possible side effects for each type of cancer introduce complexities in attempting to comprehend what the child experiences and thus their need for coping strategies.

\subsubsection{Late Effects of Cancer Treatment}

Due to advances in treatment, nearly $80 \%$ of children treated for cancer survive five years or more (American Cancer Society, 2012). Due to the increase in long-term 
survival, there has been an escalation in survivors experiencing late effects of treatment. Childhood cancer treatments can cause health problems that may not show up until months or even years after treatment. These problems, referred to as late effects, are primarily caused by chemotherapy or radiation, which causes damage to healthy cells in the body. Specifically, two-thirds of survivors can be expected to experience at least one late effect that may impair their quality of life, while one-quarter experience a severe or life threatening late effect (Meeske et al., 2007). Age at diagnosis, time since diagnosis and type of treatment can all contribute simultaneously to later physical effects for cancer survivors (Zeltzer et al., 2008).

Children who get both intrathecal chemotherapy and radiation to the brain are more at risk for learning disabilities and special education placements and are less likely to finish high school and complete a bachelor's degree (American Cancer Society, 2012; Seo, 2010). The younger the child is at the time of treatment, the greater the risk. Other late effects to the brain depending on the type of treatment used can include seizures and headaches. Certain chemotherapy drugs can also cause vision problems and hearing loss. Chemotherapy treatments can damage cells and interfere with normal growth and development; therefore, decreased growth is another common result of cancer treatment (American Cancer Society, 2012). Radiation also directly affects bone growth in the area treated. For example, children who have received radiation to the chest, experience an increased risk of respiratory problems in the short run and lung cancer in the long run (American Cancer Society, 2012).

Cancer and its treatment can have a significant emotional impact on a child. Previous studies indicated that radiation therapy, chemotherapy, and surgical intervention 
may have long-term effects on the psychosocial well-being of survivors that can adversely affect their quality of life (Zeltzer et al., 2009; Li et al., 2011). Children can feel a range of emotions that include fear, depression, anxiety, and symptoms similar to post-traumatic stress disorder. They may also feel lost or isolated because they lack stability or a sense of control over their lives. Lack of interest and poor self-esteem can last long after the treatment ends. Children may also experience confusion and embarrassment as they try to return to their normal day-to-day routines while dealing with the physical side effects related to their diagnosis and treatment. Overall, survivors of childhood cancer are rated as more socially isolated, and they have fewer friends than do other children (Seo, 2010). Similar results were reported in adult childhood cancer survivors having more difficulty with close friendships and romantic relationships (Zeltzer et al., 2009).

Survivors who report substantial late physical effects also demonstrate less positive psychosocial outcomes. Greenberg et al. (1989) conducted a cross sectional study of long-term cancer survivors compared to healthy controls. The results indicated that children with severe medical late effects had less overall self-esteem, more depressive symptoms, and a greater external locus of control than those with no or mild to moderate late effects (Greenberg et al., 1989). Other, more current studies, reported similar results of survivors reporting lower self-esteem and higher depression and anxiety levels than healthy children (Servitzoglou et al., 2008; Recklitis et al., 2006; Michel et al., 2010; Li et al., 2011). Additionally, a recent finding from the Childhood Cancer Survivor Study indicated that childhood cancer survivors were 1.5 times more likely than their siblings to have symptoms of depression and anxiety (Schultz et al., 2007). Further 
research by Meeske et al. (2007) identified factors that related to poor quality of life in childhood cancer survivors and observed that fatigue and more severe late effects were associated with poorer physical functioning. Fatigued survivors also reported significantly poorer social, school and emotional functioning than non-fatigued survivors (Meeske et al., 2007).

With the extensive list of possible long lasting psychosocial impacts of childhood cancer, it is unlikely that any child remains unchanged by the experience. Late effects of cancer treatment can be associated with poorer physical and psychological functioning and therefore affect a child's quality of life forever. Some quality of life studies have indicated that childhood cancer survivors who were diagnosed at an older age, were older at the time of inquiry, or were treated with high-intensity therapies demonstrate more negative psychosocial outcomes (Zebrack et al., 2002; Kupst et al., 1995). Kazak et al. (1996) reported that survivors of childhood cancer recall disturbing memories of procedures up to 12 years after treatment has ended. Therefore, ensuring healthy psychosocial well-being and enhancing quality of life in childhood cancer survivors should be a prime concern of health care professionals.

\subsection{Quality of Life Research}

Long-term, disease-free survival is clearly the primary goal of modern cancer therapy, but another important goal is to optimize the quality of life of pediatric cancer survivors. Several studies have examined groups of childhood cancer survivors to determine who may be most at risk for psychosocial problems. A child’s cancer diagnosis is an important risk factor for psychosocial and emotional problems later in life. 
A recent study conducted by the Childhood Cancer Survivor Study using measures of quality of life and life satisfaction outcomes identified that survivors of Hodgkin's disease, sarcomas or bone tumors were found to be at an increased risk for cancer-related anxiety (Zeltzer et al., 2009). Additionally, the Childhood Cancer Survivor Study has identified brain tumor survivors as a particularly vulnerable group who report psychological distress, fatigue, cognitive problems, and diminished life satisfaction (Zeltzer et al., 2009). Severe deficits are most noted among brain tumor survivors especially those treated with radiation. These children were more at risk for learning disabilities and were less likely to finish high school (Seo, 2010). Social development issues have also been linked to adolescents with a history of central nervous system malignancies. Studies have reported children who were treated for central nervous system malignancies have identified problems in social competence and communication with peers as well as social isolation (Holmquist et al., 2002). More frequent disease relapse is also a predictor of psychological maladjustment (Boman et al., 2000).

Demographic factors have also been linked to psychosocial and emotional problems in childhood cancer survivors. Results from the Childhood Cancer Survivor Study indicated that symptoms of depression and anxiety were significant issues for childhood cancer survivors, particularly those who are women, are unemployed, have low income levels and were struggling with late or delayed effects of cancer therapy (Zeltzer et al., 2009). Furthermore, higher patient age at follow-up was a predictor of psychological maladjustment in adolescents and young adults (Boman et al., 2000). 
Programs, such as the Follow-Up After Cancer Treatment (FACT) clinic at the Medical University of South Carolina, guided toward the preventative medical and psychosocial care of childhood cancer survivors are important to help alleviate the psychosocial problems that emerge during survivorship. The Children’s Oncology Group has developed exposure-related guidelines for ongoing follow-up of childhood cancer survivors. These guidelines enable the clinician to determine a specific follow-up plan for each survivor tailored to risk of late effects based on therapeutic exposures. In addition, several screening tools have been developed in order to assess psychosocial risk and coping abilities in children/adolescents that can be used with childhood cancer survivors (Kazak et al., 2005; Blount et al., 2008).

Additional studies have shown that children with cancer had a four-fold increase in school-related problems compared to healthy children (Mulhern et al., 1989; Parsons et al., 1998). Children treated for leukemia were reported to have more school absences, poorer concentration, less energy, less willingness to try new things, less emotionality and delay in skill development compared with cancer free children (Parsons et al., 1998). In a study of long-term psychological effects of leukemia, $50 \%$ of the children had learning problems at 5-year follow-up and $61 \%$ displayed poor concentration and short attention (Parsons et al., 1998). Psychological adjustment was strongly related to functional status and days missed from school (Parsons et al., 1998). Clearly, pediatric cancer survivors often bear significant functional morbidities that compromise school performance.

Compared to children from two-parent households, childhood cancer survivors from single-parent households had increased risk of school problems and showing 
fearful, inhibited, or over controlled behavior (Mulhern et al., 1989). Single parents have more difficulty meeting their children's medical and academic needs than do parents with a spouse to rely on, potentially making the child more vulnerable to problems in school and other settings (Mulhern et al., 1989). Reports also indicate that children's quality of life is often correlated strongly with parent's sense of his or her own level of support as well as socioeconomic status, education, and emotional function (Parsons et al., 1998). This suggests family characteristics may have an important impact on a child's ability to cope and the types of coping strategies they use.

The successful treatment of children with cancer has greatly increased survival rates compared to children diagnosed with cancer 30 years ago. However, even after cure, childhood cancer has been described as a "chronic condition" due to the long lasting psychological effects that can impair quality of life (Meeske et al., 2007). Due to the increase in survival rates there is a need to direct attention and resources to the psychosocial consequences of childhood cancer. In order to surmount the late effects of cancer treatment it is necessary for a child to utilize strategies to successfully cope with their disease.

\subsection{Coping}

\subsubsection{Coping Strategies}

The concept of coping has been used to refer to the various ways an individual responds to stressful events in an effort to alleviate the stress (Lazarus et al., 1993). Coping strategies used by the individual may vary across types of stressor and over time. The type of coping strategy can either be behavioral or cognitive as well as positive or negative with the focus of coping behaviors being oneself, the environment, or others 
(Spirito et al., 1996). There is no consensus about a "gold standard" measure to assess coping in pediatric psychology (Spirito et al., 1995). The lack of a "gold standard" is due in part to the fact that there are many different definitions of coping, and the emphasis on the type of coping varies from study to study.

\section{Problem-focused coping vs. Emotion-focused coping}

There are two theoretical perspectives on coping: the ways of coping model (Lazarus \& Folkman, 1984) and the primary-secondary model (Band et al., 1988). The ways of coping model classifies coping approaches as problem-focused coping or emotion-focused coping. Problem-focused coping is often referred to as active or approach coping and is how an individual manages the stressful situation (Lazarus et al., 1993; Spirito et al., 1996; Compas et al., 1988). Specific problem-focused strategies include problem solving, logical analysis and information seeking (Spirito et al., 1996; Compas et al., 1988). Emotion-focused coping is also referred to as passive, avoidant and affect-management coping (Lazarus et al., 1993; Spirito et al., 1996; Compas et al., 1988). Emotion-focused coping strategies include distraction, wishful thinking and social withdrawal (Spirito et al., 1996).

If people think the stressor can be managed, they are more likely to choose problem-focused coping. Emotion-focused coping is used more often with health related stressors (Lazarus \& Folkman, 1984). Folkman et al. (1986) found that individuals used more problem-focused coping in situations that they appraised as changeable and used more emotion-focused coping in situations that they appraised as unchangeable realities that they must accept. 
Primary-secondary coping

The primary-secondary model is a broader approach to coping involving primary control and secondary control. Primary control is coping aimed at influencing objective conditions or events whereas secondary control is aimed at maximizing one’s goodness of fit with conditions as they are (Band \& Weisz, 1988). An example of primary control coping is to use problem solving or active support seeking as a way to cope (Rudolph et al., 1995). Whereas, an individual employing secondary coping strategies would use cognitive distraction or self-talk in order to cope (Rudolph et al., 1995). The style of coping used varies depending on the perceived demands of a particular situation. Band \& Weisz (1988) suggested that primary control coping led to better adjustment when dealing with illness-related stressors than secondary coping.

\subsubsection{Coping Related to Development}

The ways that children cope are highly dependent on their psychosocial and cognitive development (Li et al., 2011). Developmental studies of coping suggest an increase in cognitive strategies and a broader range of methods for controlling distress with increasing age and cognitive maturity (Peterson et al., 1989; Altshuler et al., 1989). Therefore, it is important to consider theories of developmental stages of childhood and adolescence in relation to coping in order to have a more thorough understanding of how children cope with stressful events.

Piaget's concrete operational period applies to children who are between the ages of 7 and 11 years. Children in this period are rapidly acquiring cognitive operations and applying these to situations or events they have experienced (Shafer et al., 1993). 
Children in this stage tend to use emotion focused coping strategies. Previous studies have shown that children at earlier development levels tend to be more likely to view medical procedures as assaultive and less likely to understand the beneficial aspects of the procedures, whereas older children are less likely to view procedures as punishment and more likely to recognize the usefulness of treatment and better able to comprehend the long-term benefits of the procedures (Rudolph et al., 1995).

By age 11 or 12 children are entering the formal operations stage of development. Formal operations are mental actions performed on ideas and propositions, which allow an individual to reason logically about hypothetical processes and events and use scientific approaches to problem solving (Shafer et al., 1993). Erikson described adolescence as the process of acquiring an identity and the struggle for independence (Shafer et al., 1993). Children tend to use denial and self-blame as their primary coping strategies, which evolves into repression in adolescence allowing the adolescent not to consider certain disturbing or painful events (Corner et al., 2001). It is important for health care providers to understand how children and adolescents cope in order to properly address their fears about cancer.

Several childhood cancer survivor studies have documented the existence of worries about disease recurrence, future treatments, late effects, fertility, academic achievement and general health (Gray et al., 1992; Haase et al., 1994; Zebrack et al., 2001). Furthermore, older age at study, longer time since end of treatment, a perception of being "cured" and life events such as follow-up examinations and normal illnesses have been demonstrated to have significant effects on worries about relapse (Haase et al., 1994; Weigers et al., 1998). Age at diagnosis was found to be significantly related to 
self-image suggesting that cancer's life disruption during the teenage years may result in a greater likelihood of survivors worrying, not believing themselves to be cured and subsequent lower self-image (Zebrack et al., 2001). Furthermore, age, gender, time since diagnosis, and level of distress have been shown to influence the type and number of strategies employed to manage medical stressors (Blount et al., 1991; Bull et al., 1991; Smith et al., 1989).

\subsubsection{Coping in Children}

Studies on the process and situational aspects of coping with childhood cancer found children and families utilized a variety of coping strategies, and these were situation-dependent (Bull et al., 1991; Kupst et al., 1988). Although some studies have found support for one strategy over another, no strategy has emerged as the most favorable coping mechanism (Patenaude et al., 2005). Some studies have found that most pediatric cancer survivors reported good psychological adjustment and that rates of depression and anxiety were comparable to norms and control groups (Boman et al., 1995; Eiser et al., 2000; Kazak et al., 1997). However, other studies have identified subsets of pediatric cancer survivors who do not cope or adjust well. These studies consistently identified a small group (estimated to be 25-30\%) of survivors who did not cope well or who had considerable difficulties with personal, family, and social functioning (Patenaude et al., 2005; Kupst et al. ,1995). When compared to other childhood illness groups, cancer survivors had lower life satisfaction and increased maladjustment (Aldridge et al., 2007).

Studies involving coping in children are summarized in table 2. Of the five studies mentioned, all were cross sectional in nature ranging from 30-73 participants per 
study. Four of the studies examined children with cancer or childhood cancer survivors while the remaining study focused on elementary school children and acutely ill/injured children and adolescents. Participants in the studies were close to half female and primarily ranged in age from two to twenty years. A variety of measures were used to examine coping, stress, behavior and general health and functioning. Results examined coping with respect to age, gender, type of cancer or illness and length of remission.

These studies all support the notion that coping is a process that differs somewhat within individuals across situations (Lazerus et al., 1993; Bull et al., 1991). The variability in the patient populations suggests that coping behavior is not confined to groups of children facing unusual amounts of stress. Although a variety of measures were used in these studies, they were similar in that they examined overall coping or coping strategies used. While some studies reported age and gender differences in coping, others found no difference. This could be due in part to the small sample sizes of the studies. Another weakness of these studies is that some of the measures used had a narrow focus and could not fully capture the difficulties experienced by children with cancer.

It is evident that styles of coping change depending on the stressor the child is presented with. Pediatric patients use a wide variety of coping strategies to manage their disease and its side effects. 
Table 2: Previous studies conducted on coping and childhood cancer. The reference, size, and study population are presented as well as the gender and ages of participants, plus the coping measures used and the results found.

\begin{tabular}{|c|c|c|c|c|c|c|}
\hline Study & $\mathbf{n}$ & Study Population & $\begin{array}{c}\% \\
\text { Girls } \\
\end{array}$ & $\begin{array}{l}\text { Age } \\
\text { (yrs.) }\end{array}$ & Measure & Results \\
\hline Bull et al. (1991) & 39 & $\begin{array}{l}\text { Children and } \\
\text { adolescents whose } \\
\text { cancer was in } \\
\text { remission }\end{array}$ & 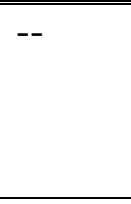 & $7-17$ & $\begin{array}{l}\text { CSI, } \\
\text { Coping } \\
\text { Interview, } \\
\text { PPVT-R }\end{array}$ & $\begin{array}{l}\text { Emotional Management (Adolescents vs. children, } p=.005 \text {; Females vs. } \\
\text { males, } p=.020 \text { ) } \\
\text { Problem Solving (Children vs. adolescents, } p=.006 \text {; Males vs. females, } \\
p=.018 \text { ) }\end{array}$ \\
\hline $\begin{array}{l}\text { Band et al. } \\
\text { (1988) }\end{array}$ & 73 & $\begin{array}{l}\text { Elementary school } \\
\text { children }\end{array}$ & $59 \%$ & $6-12$ & $\begin{array}{l}\text { Structured } \\
\text { interviews }\end{array}$ & $\begin{array}{l}\text { Primary coping ( } 6 \text { yrs. old vs. } 9 \text { and } 12 \text { yrs. old, } \mathrm{p}<.05, \mathrm{p}<.01 \text { ) } \\
\text { Coped better with medical situation (Girls vs. boys (both age } 12 \text { ), } \\
\mathrm{p}<.05 \text { ) } \\
\text { Overall failure to cope }=3.5 \%\end{array}$ \\
\hline $\begin{array}{l}\text { Sawyer et al. } \\
\text { (2000) }\end{array}$ & 88 & $\begin{array}{l}\text { Children treated for } \\
\text { cancer and their } \\
\text { parents; healthy } \\
\text { controls }\end{array}$ & $\begin{array}{l}49 \% \\
51 \%\end{array}$ & $2-12$ & $\begin{array}{l}\text { CBCL, } \\
\text { GHQ, } \\
\text { GFS }\end{array}$ & $\begin{array}{l}\text { Number of psychological problems experienced by children treated for } \\
\text { cancer and their parents did not differ from that of the comparison } \\
\text { group. }\end{array}$ \\
\hline $\begin{array}{l}\text { Boman et al. } \\
(2000)\end{array}$ & 30 & $\begin{array}{l}\text { Childhood cancer } \\
\text { survivors }\end{array}$ & $50 \%$ & $\begin{array}{l}18 \text { and } \\
\text { older }\end{array}$ & $\begin{array}{l}\text { Clinical } \\
\text { interviews }\end{array}$ & $\begin{array}{l}\text { Better coping (Leukemia and Lymphoma vs. Brain and solid tumors, } \\
\mathrm{p}=.05 \text { ) } \\
\text { Better coping (Longer vs. shorter period of remission, } \mathrm{p}=.05 \text { ) } \\
\text { Gender, age at illness onset, parents' occupational level and age at } \\
\text { investigation were not related to patients' coping levels. }\end{array}$ \\
\hline $\begin{array}{l}\text { Campbell et al. } \\
\text { (2008) }\end{array}$ & 30 & $\begin{array}{l}\text { Childhood cancer } \\
\text { survivors of ALL }\end{array}$ & $50 \%$ & $10-20$ & $\begin{array}{l}\text { RSQ, } \\
\text { CBCL }\end{array}$ & $\begin{array}{l}\text { Disengagement coping (avoidance, denial, wishful thinking) associated } \\
\text { with behavior problems, } \mathrm{p}<.01 \text {. }\end{array}$ \\
\hline
\end{tabular}

CSI=Children's Stress Inventory; PPVT-R= Revised Peabody Picture Vocabulary Test; CBCL=Child Behavior Checklist;

GHQ=General Health Questionnaire; GFS=General Functioning Scale of the Family Assessment Device; RSQ=Responses to Stress

Questionnaire 


\subsubsection{Family Impact on Coping in Children}

Characteristics such as low family income, low maternal education and absence of either of their biological parents placed children with health conditions at risk for behavioral problems (Gortmaker et al., 1990; Lavigne et al., 1993). Table 3 depicts family impact on coping in children in one cross sectional and two longitudinal studies. The two longitudinal studies were actually the same study completed at two different time points, six to eight and ten years post cancer diagnosis. All three studies were conducted with families of children with chronic health conditions; specifically, the longitudinal studies were limited to families of children with cancer. Each study population consisted of almost 50\% females and ranged in ages from five to thirty years. There were a variety of measures used to assess symptoms, coping, and adjustment. Parental/family coping and distress were measured directly and child-level coping was indirectly measured through parental reporting. Findings indicated a strong familial impact on coping in children; specifically those using positive coping strategies were from families with higher socioeconomic status, stable parental marital status, and had siblings, indicating family support. 
Table 3: Summary of studies of Family Impact on Coping in Children

\begin{tabular}{|c|c|c|c|c|c|c|}
\hline Study & $\mathbf{n}$ & Study Population & $\begin{array}{c}\% \\
\text { Girls }\end{array}$ & Age (yrs.) & Measure & Results \\
\hline Kupst et al (1988) & $\begin{array}{l}43 \\
\text { families, } \\
28 \\
\text { children }\end{array}$ & $\begin{array}{l}\text { Families of children with } \\
\text { cancer (6-8 years post } \\
\text { diagnosis) }\end{array}$ & $50 \%$ & 12 (mean) & $\begin{array}{l}\text { CARS, } \\
\text { FCS }\end{array}$ & $\begin{array}{l}\text { Good copers (Higher vs. lower fathers occupational } \\
\text { level, } \mathrm{p}<.05 \text { ) } \\
\text { Better family support (Good vs., poor coping families, } \\
\mathrm{p}<.01 \text { ) } \\
\text { Better quality of parents marital relationship(Good vs. } \\
\text { poor coping families, } \mathrm{p}<.01 \text { ) }\end{array}$ \\
\hline Kupst et al (1995) & $\begin{array}{l}28 \\
\text { families, } \\
28 \\
\text { children }\end{array}$ & $\begin{array}{l}\text { Families of children with } \\
\text { cancer ( } 10 \text { years post } \\
\text { diagnosis) }\end{array}$ & $43 \%$ & $14-30$ & $\begin{array}{l}\text { CARS } \\
\text { FCS, BSI }\end{array}$ & $\begin{array}{l}\text { Good copers (High SES vs. low SES, } \mathrm{p}<.005 \text { ) } \\
\text { Perceived Adjustment lower(Children with school } \\
\text { problems vs. children without school problems, } \\
\text { p <.05) }\end{array}$ \\
\hline Silver et al (1999) & $\begin{array}{l}365 \\
\text { Mother- } \\
\text { child pairs }\end{array}$ & $\begin{array}{l}\text { Mothers of children with } \\
\text { chronic health conditions } \\
\text { who received care at } 2 \\
\text { large urban medical } \\
\text { centers. }\end{array}$ & $46 \%$ & $5-8$ & $\begin{array}{l}\text { Interviews, } \\
\text { PSI, ECBI }\end{array}$ & $\begin{array}{l}38.8 \% \text { of children had conduct problems } \\
\text { High maternal distress }(\mathrm{p}=.001) \text {, child having a } \\
\text { learning disability ( } \mathrm{p}=.005) \text {, poorer perceived } \\
\text { prognosis }(\mathrm{p}=.02) \text {, child's age }(\mathrm{p}=.04) \text {, and mother has } \\
\text { husband or live-in partner unrelated to the child } \\
(\mathrm{p}=.03 \text { ) were all significantly related to the presence } \\
\text { of a conduct problem. }\end{array}$ \\
\hline
\end{tabular}

CARS=Current Adjustment Rating Scale; FCS=Family Coping Scale; BSI=Brief Symptom Inventory; PSI=Psychiatric Symptom Index; ECBI=Eyberg Child Behavior Inventory 


\subsection{Measuring coping: The Kidcope Questionnaire}

Children with acute and chronic illnesses are confronted with a number of illnessspecific tasks and stressors to which they must frequently respond. To date, the only assessment tool specifically designed to investigate distress and coping in pediatric patients is the Kidcope questionnaire. The Kidcope questionnaire has become a widely used instrument for measuring coping in various samples of children from different socioeconomic status, age groups, countries, and health conditions. The reliability of this questionnaire has been examined in populations of high school students (Spirito et al., 1988), children with diabetes (Spirito et al., 1988; Edgar et al., 2003) and children with a variety of medical conditions, including cancer (Spirito et al., 1988, 1995) and will be discussed in further detail in the next section. In addition, the Kidcope survey has been used in adolescent girls with a history of an STD (Prinstein et al., 1996), in pediatric oncology patients on active treatment (Tyc et al., 1995; Frank et al., 1997), adolescent suicide attempters (Spirito et al., 1996), chronically and acutely ill children (Spirito et al., 1994; Khairkar et al., 2010), children/adolescents with Sickle Cell disease (Gold et al., 2008), families with hemophilia (Miller et al., 2000), siblings of cancer patients (MadanSwain et al., 1993), children/adolescents with chronic fatigue (Garralda et al., 2004), adolescents with type 1 diabetes (Grylli et al., 2005), children/adolescents affected by natural disasters (Papadatou et al., 2012; Prinstein et al., 1996; Vigna et al., 2010; (Jeney-Gammon et al., 1993), children involved in road traffic accidents (Stallard et al., 2001), adolescents with a cleft lip (Berger et al., 2011), and youth with behaviorally aquired HIV (Salama et al., 2013). The Kidcope survey has been used in males and 
females, a variety of settings as previously mentioned and with participants ranging in age from 5-18 years of age.

\subsubsection{Reliability of the Kidcope Checklist}

Reliability refers to a condition where a measurement process yields consistent scores over repeated measurements. If repeated measurements produce highly consistent results, then the measurement method reflects a high degree of reliability. To the contrary, when great variations among repeated measurements occur, then reliability of the measure is low. This type of reliability is often referred to as test-retest reliability.

The reliability of the Kidcope questionnaire was initially assessed by Spirito et al. (1988) in six different samples. Sample one consisted of 60 high school children from white, lower and middle class families. Participants were administered the Kidcope questionnaire on two separate occasions three days apart using the same stressor both times. Sample two included ninety ninth grade students from white, middle class families. Besides initially completing the Kidcope questionnaire, half of these subjects also completed the Coping Strategies Inventory (CSI) and then one week later, completed another Kidcope questionnaire. The other half of sample two completed the Kidcope survey and the Adolescent-Coping Orientation for Problem Experiences (ACOPE) scale. Sample three consisted of 142 ninth grade students from predominantly white, lower to middle class families. These students were administered the Kidcope survey on two occasions ten weeks apart choosing a different stressor each time. Sample four included seventy-two high school students from white, lower and middle class families. Kidcope questionnaires were completed by this sample twice, two weeks apart, once using their own personal stressor and once using a standard stressor. Sample five included thirty- 
eight pediatric patients with varying medical diagnoses, including cancer. Patients completed the Kidcope survey in response to a specific stressor associated with their disease. Sample six consisted of thirty-four children attending a diabetes camp. Children in this sample completed the Kidcope survey in response to a stressor related to their disease.

Test-retest correlations for these samples resulted in moderate (.41) to fairly high (.83) correlations over short periods of three to seven days (Spirito et al., 1988). Testretest correlations were much lower at two week (.04 to .56) and ten week intervals (.15 to .43) (Spirito et al., 1988). In sample four, the consistency in the use of coping strategies across similar situations was examined by use of the standard stressor (grounding by parents for the weekend for not doing chores or grounding by parents for the weekend for violating curfew). The results indicated moderate correlations for most of the coping strategies (.13 to .56) (Spirito et al., 1988). The low test-retest correlations for two and ten week intervals can be explained by the fact that coping is a process that changes over time and according to individual and situational variables at the time of measurement (Lazerus et al., 1993). According to Lazarus et al. (1993) coping is an active and dynamic process involving continually changing behavioral and cognitive efforts. Prinstein et al. (1996) distinguish coping behavior, which is a specific effort or response, from coping style, which is a "generalized strategy or habitualized preference for approaching problems irrespective of their source of nature”. Coping as a "state" refers to the coping styles an individual may utilize to deal with a stressor.

Internal consistency reliability assesses item interrelatedness or homogeneity of the items within a scale. A scale is internally consistent to the extent that its items are 
highly correlated. High inter-item correlations suggest that the items are all measuring the same thing. Cronbach's alpha is the most widely used internal consistency reliability coefficient. Gold et al. (2008) reported the Cronbach's alpha estimate of internal consistency of the Kidcope survey for a study population of children with Sickle Cell disease and their healthy siblings was .76 for the entire coping scale. Vernberg et al. (1996) conducted a principal components factor analysis with varimax rotation for all 15 items of the Kidcope survey indicated four factors with eigenvalues greater than 1.0. Two items cross loaded on two or more factors and were deleted from further analysis. A second principal components analysis with the remaining 13 items indicated that each loaded cleanly on one of four factors: positive coping, blame/anger, wishful thinking, and social withdrawal. The internal consistency (Cronbach's alpha) for the scales formed by these four factors were .77 for positive coping, .53 for blame/anger, .67 for wishful thinking and .43 for social withdrawal (Vernberg et al., 1996). Although Cronbach’s alpha for the blame/anger and social withdrawal scales are lower than desirable, the factor loadings for the items comprising these two scales are high (mean loading=.73). Each of the 13 items had a factor loading of .57 or higher on one of the four factors. None had a factor loading greater than .36 on another factor. The four factors together accounted for $56 \%$ of the variance in the Kidcope questionnaire. Spirito et al. (1988) reported moderate internal consistency was demonstrated for problem solving, social support and distraction $(\mathrm{r}=.67, .63, .62)$. Lower correlations were found for denial/avoidance, blame and passive acceptance/wishful thinking (r=.22, .31, .42) (Spirito et al., 1988). 
The moderate to low reliability coefficients could be due in part to the brevity of the Kidcope survey in that it only allows for one or two items to tap into each coping strategy, which significantly reduces the range of responses. Moreover, children may have trouble differentiating between coping behaviors using the Kidcope questionnaire because several of the items include more than one behavior. For example, a single item assessing problem solving includes a number of behaviors from thinking about solutions to talking to others for more information.

As previously mentioned, the reliability of the Kidcope questionnaire has been tested with childhood cancer patients on treatment. To date, the Kidcope questionnaire has not been used with childhood cancer survivors. Childhood cancer patients on treatment and childhood cancer survivors experience similar stressors in relation to their illness so the reliability of Kidcope survey completed by childhood cancer patients could extend to its use in childhood cancer survivors. However, childhood cancer survivors are more likely to report more situational variability in regards to the stressor identified than children still on active cancer treatment. One main limitation of using the Kidcope survey in childhood cancer survivors is the heterogeneous nature of the sample. Factors such as diagnosis, treatment, age and time since treatment will vary greatly. Another limitation is that the data obtained on coping could be retrospective if the participant is reporting a stressor related to his or her disease. Therefore, the data may not accurately reflect the strategies employed to cope at the time the stressor occurred.

\subsubsection{Validity of the Kidcope Checklist}

Criterion validity is the degree to which a measure covaries with a previously validated "gold standard" measure of the same construct. This type of validity is not 
concerned with understanding a process, but merely predicting it, so it is often referred to as predictive validity. The strength of the relationship between two empirical events is the most important aspect of this type of validity.

In order to assess criterion validity the authors of the Kidcope questionnaire needed to theorize that their measure of coping should be able to predict coping strategies. As evidence of criterion validity, Spirito et al. (1988) analyzed correlations between eight of the frequency items and eight scales on the Coping Strategies Inventory (CSI). Five of these correlations were significant $\left(\mathrm{p}^{<.05}\right)$ and when compared to Adolescent-Coping Orientation for Problem Experiences (ACOPE) scale, seven out of ten correlations were significant (Spirito et al., 1988). The CSI and ACOPE scales were used as criteria to assess validity. These statistically significant correlations demonstrated criterion validity.

\subsubsection{Kidcope Questionnaire}

The primary purpose for the development of the Kidcope questionnaire was to provide a brief, clinically useful checklist to screen coping in children and adolescents. A brief scale enables examination of changes in coping over time and across situations because it is feasible to administer such a scale on several different occasions. The Kidcope questionnaire requires children to report a personal problem (the stressor) within a specific situation (the setting) and then to describe their efforts at coping with that problem (coping strategies) (Pretzlik et al., 1999). The Kidcope survey is composed of four parts: the stressor within a setting, the distress felt by the child in relation to the stressor, the child's way of coping with the stressor, and the helpfulness of that coping strategy (Spirito et al., 1988). 
The Kidcope questionnaire consists of ten items, each of which draws on a particular cognitive and behavioral coping strategy such as distraction ("I thought about something else; tried to forget it; and/or watch TV or play a game to get it off my mind”), cognitive restructuring ("I would try to see the good side of things"), problem solving ("I thought of ways to solve the problem"), emotional regulation ("I would try to calm myself by talking to myself, talking a walk, praying, or just trying to relax”), and resignation (“I would just accept the problem because I knew I couldn’t do anything about it”). Additional coping strategies covered in the Kidcope survey are distraction, social support, social withdrawal, self-criticism, blaming others, and wishful thinking (Spirito et al., 1988).

A version of the scale for adolescents is composed of ten items, one item per coping category, and the version for younger children is composed of 15 items, with one to two items per coping category that are collapsed to the same ten coping categories as the older version (Table 4). If the participant uses either item in a category, then the participant is rated as having used that coping category. If two items in a category are chosen, the highest efficacy rating selected by the participant should be scored. The Kidcope survey for younger children has been used with children as young as five years of age (Pretzlik et al., 1999). For each coping strategy, the child or adolescent rates how often they use the strategy (i.e. frequency) and how much it helps (i.e. efficacy). For the adolescent version, the frequency scale is completed by using a four-point Likert-type rating scale ranging from "not at all” to "almost all the time.” For the younger child version, it is answered "yes" or "no." The efficacy scale is scored on either a three or five-point Likert-type scale for children and adolescents. 
Table 4: Kidcope questionnaire coping categories and corresponding question number

\begin{tabular}{lr}
\hline Coping Category & Corresponding Question* \\
\hline \hline Distraction & 1,2 \\
Social Withdrawal & 3,4 \\
Cognitive Restructuring & 5 \\
Self-Criticism & 6 \\
Blaming Others & 7 \\
Problem Solving & 8,9 \\
Emotional Regulation & 10,11 \\
Wishful Thinking & 12,13 \\
Social Support & 14 \\
Resignation & 15 \\
\hline
\end{tabular}

*Refer to Kidcope questionnaires in Appendix C

\subsubsection{Studies involving Kidcope}

The Kidcope questionnaire has been used with a variety of populations as is evident in table 5. All studies using the Kidcope survey have been cross sectional in nature and have ranged from 25-676 participants. The Kidcope survey was used with children as young as five and as old as eighteen years of age with $20-100 \%$ of the population being female. Coping strategies were assessed with relation to gender, age, type of problem and setting. Blaming others was the most common coping strategy reported across the studies.

These studies demonstrated that the Kidcope questionnaire is a useful tool to screen children for coping abilities at an early age as well as demonstrating that children from different social and economic backgrounds differed in the stressors reported and in the coping strategies used. Some of these studies had a large number of participants and were able to examine differences in coping strategies by gender, age, and stressor reported. Numerous studies have shown that age, gender, time since diagnosis, and level of distress influenced the type and number of strategies employed to manage medical 
stressors (Blount et al., 1991; Bull et al., 1991; Smith et al., 1989; Tyc et al., 1995). Most previous research completed using the Kidcope survey had a control group; however, none were longitudinal in nature. Therefore, the relationship between changes in stressors and coping strategies over time could not be determined.

Another limitation of these studies was the hypothetical nature of the inquiry. The research methodology consisted of describing a stressful situation (stressor) to the study children. Coping was measured based on the child's report of how he/she would respond to that situation. However, based on this research Tyc et al. (1995) suggested that the controllability of a given stressor may influence the selection of a particular coping strategy. In children undergoing aversive medical procedures, primary control coping strategies (attempts to modify environmental events or other people’s behavior) have been found to be generally adaptive for controllable stressors; while secondary control coping strategies (attempts to modify oneself to conditions) have been more adaptively useful for uncontrollable stressors (Compas et al., 1988). 
Table 5: Summary of studies involving use of the Kidcope questionnaire

\begin{tabular}{|c|c|c|c|c|c|}
\hline Study & $\mathbf{n}$ & Study Population & $\begin{array}{l}\text { \% } \\
\text { Girls }\end{array}$ & $\begin{array}{c}\text { Age } \\
\text { (yrs.) }\end{array}$ & Coping Strategies \\
\hline $\begin{array}{l}\text { Baker et al. } \\
\text { (2001) }\end{array}$ & 67 & " Adolescent girls with an STD history & $100 \%$ & $12-15$ & $\begin{array}{l}\text { Self-Criticism (STD acquisition vs. interpersonal stressor, } \mathrm{p}<.01 \text { ) } \\
\text { Problem Solving (Interpersonal stressor vs. STD acquisition, } \mathrm{p}=.03 \text { ) }\end{array}$ \\
\hline $\begin{array}{l}\text { Edgar et al. } \\
(2003)\end{array}$ & 70 & Adolescents with diabetes & $43 \%$ & $11-18$ & $\begin{array}{l}\text { Self-Criticism (Higher socioeconomic status (SES) vs. lower SES, } \mathrm{p}<.005 \text { ) } \\
\text { Problem Solving (Girls vs. boys, } \mathrm{p}<.05 \text { ) }\end{array}$ \\
\hline $\begin{array}{l}\text { Garralda et al. } \\
\text { (2004) }\end{array}$ & 85 & $\begin{array}{l}\text { Children/adolescents with chronic fatigue } \\
\text { syndrome (CFS) matched with children } \\
\text { with Juvenile Idiopathic Arthritis (JIA) and } \\
\text { children with emotional disorders (ED) }\end{array}$ & $72 \%$ & $10-18$ & $\begin{array}{l}\text { Emotional Regulation (CFS vs. JIA, } \mathrm{p}<.01 \text { ) } \\
\text { Resignation (CFS vs. ED, } \mathrm{p}<.01 \text { ) } \\
\text { Social Withdrawal (ED vs. CFS, }<<.01 \text { ) } \\
\text { Self-Criticism (ED vs. CFS, } \mathrm{p}<.01 \text { ) }\end{array}$ \\
\hline $\begin{array}{l}\text { Madan-Swain et } \\
\text { al. (1993) }\end{array}$ & 61 & $\begin{array}{l}\text { Siblings of patients diagnosed with } \\
\text { childhood cancer; childhood cancer } \\
\text { patients; nonclinical controls }\end{array}$ & $52 \%$ & $5-17$ & $\begin{array}{l}\text { Wishful Thinking (Siblings of brain tumor pts. vs. siblings of ALL pts., } \mathrm{p}<.009 \text { ) } \\
\text { Blaming Others (Sibling older age vs. sibling younger age, } \mathrm{p}<.005 \text { ) } \\
\text { Problem Solving (Sibling older age vs. sibling younger age, } \mathrm{p}<.004 \text { ) }\end{array}$ \\
\hline $\begin{array}{l}\text { Miller et al } \\
\text { (2000) }\end{array}$ & 25 & $\begin{array}{l}\text { Children from families where one family } \\
\text { member had hemophilia }\end{array}$ & $20 \%$ & $6-15$ & $\begin{array}{l}\text { Wishful Thinking: } 88 \% \text { used } \\
\text { Emotional Regulation and Problem Solving: } 72 \% \text { used }\end{array}$ \\
\hline $\begin{array}{l}\text { Pereda et al. } \\
\text { (2009) }\end{array}$ & 168 & $\begin{array}{l}\text { Children in primary school and an after- } \\
\text { school care center }\end{array}$ & $49 \%$ & $7-12$ & $\begin{array}{l}\text { Emotional Regulation (Boys vs. girls, } \mathrm{p}=0.03 \text { ) } \\
\text { Blaming others (After school care vs. school setting, } \mathrm{p}=0.001 \text { ) and cognitive } \\
\text { restructuring (After school care vs. school setting, } \mathrm{p}=0.02 \text { ) }\end{array}$ \\
\hline $\begin{array}{l}\text { Spirito et al. } \\
\text { (1996) }\end{array}$ & 258 & $\begin{array}{l}\text { Suicide attempters/ideators*; nonsuicidal } \\
\text { psychiatric patients; high school students }\end{array}$ & $64 \%$ & $11-17$ & $\begin{array}{l}\text { Social withdrawal (Mental health problems vs. none, } \mathrm{p}<001 \text { ) } \\
\text { Blaming Others (Boys vs. girls, } \mathrm{p}<.05 \text { ) }\end{array}$ \\
\hline $\begin{array}{l}\text { Spirito et al. } \\
(1995)\end{array}$ & 177 & Children with chronic illnesses & $47 \%$ & $7-18$ & $\begin{array}{l}\text { Blaming others (Pain problem vs. diagnosis problem, } \mathrm{p}<.05 \text { ) } \\
\text { Resignation (Pain problem vs. diagnosis problem, } \mathrm{p}<.05 \text { ) }\end{array}$ \\
\hline $\begin{array}{l}\text { Spirito et al. } \\
\text { (1994) }\end{array}$ & 54 & $\begin{array}{l}\text { Chronically ill and acutely ill/injured } \\
\text { children and adolescents }\end{array}$ & $41 \%$ & $7-17$ & $\begin{array}{l}\text { Social Withdrawal (acutely ill/injury children vs. chronic illness children and } \\
\text { acutely ill/injury adol., } \mathrm{p}<.05 \text { ) } \\
\text { Self-criticism (acutely ill/injury adol. vs. chronic illness adol., } \mathrm{p}<.05 \text { ) } \\
\text { Wishful Thinking (chronic illness children vs. acute illness/injury adol. and chronic } \\
\text { illness adol., } \mathrm{p}<.05 \text { ) } \\
\text { More coping strategies used (Younger children vs. older children, } \mathrm{p}<.05 \text { ) }\end{array}$ \\
\hline $\begin{array}{l}\text { Spirito et al. } \\
\text { (1991) }\end{array}$ & 676 & $\begin{array}{l}4^{\text {th }}-8^{\text {th }} \text { grade children from middle to upper } \\
\text { middle socioeconomic classes }\end{array}$ & -- & $9-14$ & $\begin{array}{l}\text { Blaming Others (Boys vs. girls, } \mathrm{p}<.04 \text { ) } \\
\text { Self-Criticism (School problem vs. sibling problem, } \mathrm{p}<.001 \text { ) } \\
\text { Emotional Regulation (Sibling problem vs. school problem, } \mathrm{p}<.01 \text { ) }\end{array}$ \\
\hline Tyc et al. (1995) & 57 & $\begin{array}{l}\text { Pediatric oncology patients currently } \\
\text { receiving treatment }\end{array}$ & $42 \%$ & $6-18$ & $\begin{array}{l}\text { Overall: 25\% successful copers } \\
\text { Social Withdrawal (Boys vs. girls OR=5.6; 95\% CI: 1.6-19.4) } \\
\text { Resignation (Teen vs. child OR=16.6; 95\% CI: 3.3, 83.1) }\end{array}$ \\
\hline $\begin{array}{l}\text { Stallard et al. } \\
\text { (2001) }\end{array}$ & 97 & $\begin{array}{l}\text { Children and adolescents who involved in a } \\
\text { road traffic accident }\end{array}$ & $46 \%$ & $7-18$ & $\begin{array}{l}\text { Social Withdrawal (PTSD vs. no PTSD, } \mathrm{p}=.001 \text { ) } \\
\text { Distraction (PTSD vs. no PTSD, } \mathrm{p}=.02 \text { ) } \\
\text { Emotional Regulation (PTSD vs. no PTSD, } \mathrm{p}=.01 \text { ) } \\
\text { Blaming Others (PTSD vs. no PTSD, } \mathrm{p}=.03 \text { ) }\end{array}$ \\
\hline
\end{tabular}




\begin{tabular}{|c|c|c|c|c|c|}
\hline Study & $\mathbf{n}$ & Study Population & $\begin{array}{c}\% \\
\text { Girls }\end{array}$ & $\begin{array}{c}\text { Age } \\
\text { (yrs.) }\end{array}$ & Coping Strategies \\
\hline $\begin{array}{l}\text { Salama et al. } \\
(2013)\end{array}$ & 59 & Y Youth with behaviorally acquired HIV & $60 \%$ & $14-23$ & $\begin{array}{l}\text { Positive/Approach Coping (Boys vs. girls, } \mathrm{p}<.05 \text { ) } \\
\text { More coping strategies used (Younger children vs. older children, } \mathrm{p}<.05 \text { ) }\end{array}$ \\
\hline $\begin{array}{l}\text { Khairkar et al. } \\
(2010)\end{array}$ & 100 & Children with $\beta$-thalassemia & $25 \%$ & $6-14$ & $\begin{array}{l}\text { Emotional regulation: } 98 \% \text { used; Wishful thinking: } 86 \% \text { used; } \\
\text { Problem solving: } 80 \% \text { used }\end{array}$ \\
\hline $\begin{array}{l}\text { Grylli et al. } \\
\text { (2005) }\end{array}$ & 199 & $\begin{array}{l}\text { Adolescents with Type } 1 \text { diabetes, with and } \\
\text { without eating disorders }\end{array}$ & $48 \%$ & $11-17$ & $\begin{array}{l}\text { Self-Criticism (Eating disorder vs. no eating disorder, } \mathrm{p}<.05 \text { ) } \\
\text { Blaming Others (Eating disorder vs. no eating disorder, } \mathrm{p}<.05 \text { ) } \\
\text { Wishful Thinking (Eating disorder vs. no eating disorder, } \mathrm{p}<.05 \text { ) }\end{array}$ \\
\hline $\begin{array}{l}\text { Papadatou et al. } \\
\text { (2012) }\end{array}$ & 1468 & Adolescents involved in a wildfire disaster & -- & $12-17$ & $\begin{array}{l}\text { Escape/Avoidant Coping (PTSD vs. no PTSD, } \mathrm{p}<.001 \text { ) } \\
\text { Escape/Avoidant Coping (Depression vs. no depression, } \mathrm{p}<.001 \text { ) } \\
\text { Control/Approach Coping (PTSD vs. no PTSD, } \mathrm{p}<.001 \text { ) }\end{array}$ \\
\hline $\begin{array}{l}\text { Jeney-Gammon } \\
\text { et al. (1993) }\end{array}$ & 257 & $\begin{array}{l}3^{\text {rd }}-5^{\text {th }} \text { grade children } 5 \text { months after } \\
\text { Hurricane Hugo }\end{array}$ & $51 \%$ & 8-11 & $\begin{array}{l}\text { Wishful Thinking: 94\% used; Cognitive Restructuring: 89\% used; Distraction: 88\% } \\
\text { used }\end{array}$ \\
\hline
\end{tabular}




\section{Rationale}

Cancer alters children’s lives in many ways, beginning at diagnosis and continuing well after therapy ends. Some effects are directly related to the physical course of the disease and treatment. In addition, a child may face psychological problems such as learning disabilities, academic failure, behavioral and other adjustment problems, as well as depression (Mulhern et al., 1989). Certain combinations of demographic variables, disease and treatment factors, and residual physical disabilities have been suggested as predictors of more difficult psychological adjustment in childhood cancer survivors (Mulhern et al., 1989). These risk factors influence the child’s coping strategies which in turn could affect his/her overall adjustment. Poor coping in childhood cancer survivors can lead issues with anxiety, depression, and overall lower life satisfaction (Zeltzer et al., 2008). Developing a predictive model for coping could have value for both research and practice.

The identification of perceived stressors and coping responses has important implications for the long-term mental health of childhood cancer survivors. The American Cancer Society (2012) reports that follow-up care has not implemented the regular use of questionnaires for survivors or parents to assess the late effects of cancer on coping as a mediator that can impact adjustment outcomes. The use of questionnaires at long term follow-up clinics allows repeated standardized measures collected from the same individuals across time, providing critical longitudinal data for assessment of the late effects of cancer treatment. Longitudinal data have been collected on $52 \%$ of the study population, allowing for changes in stressors and coping to be examined over time. Examining stressors and coping over time will allow health care professionals to assess if 
survivors need therapeutic intervention. Moreover, these data may provide knowledge of how chronological age influences childhood cancer survivors' emotional responses to late treatment related effects.

Employing the Kidcope questionnaire as a screening tool would enable identification of those patients with limited coping strategies at their disposal or who rate their coping strategies as ineffective. When clinicians are able to recognize ineffective coping strategies, they may be able to assist the patient in replacing them with more effective strategies, improving long-term psychosocial outcomes. To date, the Kidcope survey has not been reported as being utilized in clinical practice.

Further, this research could serve to identify characteristics associated with stressors and maladaptive coping that could be used to identify childhood cancer survivors at risk of poor outcomes. Risk factors could include gender, age at time of survey, age at diagnosis, race, diagnosis, treatment factors, duration of disease, and household structure. Demographic and familial factors may have a substantial impact on the stressors children experience and the coping strategies they use to manage those stressors. Previous studies have not examined familial and treatment factors in relation to coping.

Prior studies using the Kidcope survey were hypothetical in nature. In that, a situation (stressor) was presented to the children and they were asked how they would respond to that situation and coping was assessed from their responses. This study will assess real stressors chosen by the children related to events that actually happened to them. It is likely that a coping response initiated by real events differs from those reported as response to a fictional scenario. Relatively few studies have focused directly 
on cancer-related stressors for children and adolescents who have completed cancer treatment (e.g., Kazak et al., 1996; 2001).

Finally, a recent review of the literature found no studies that had used the Kidcope questionnaire to evaluate childhood cancer survivors. Additionally, currently, there are no studies that evaluate changes in stressors and coping strategy use over time. Therefore, this study presents novel findings on the perceived stressors of childhood cancer survivors as well as the endorsement and efficacy of coping strategies utilized to cope with the stressor. 


\section{CHAPTER 3: STUDY DESIGN AND METHODS}

\subsection{Study Design}

This was a cross sectional study of childhood cancer survivors with a longitudinal component in which data for this study were obtained from a sample of childhood cancer survivors who were diagnosed and treated between 1987 and 2004. This study took advantage of data that were previously collected as part of routine clinic visit but had not previously been evaluated. Figure 2 demonstrates the sequence of sampling and reasons for exclusions in the childhood cancer survivors' cohort. Of the 274 patients in the eligible population, 139 participants completed a Kidcope survey during the Follow-up After Cancer Treatment (FACT) clinic; twenty-one patients were excluded from the overall sample because they were still receiving active treatment at the time of survey. Additionally, four patients completed surveys while they were on treatment as well as off treatment due to relapse of their disease. Surveys completed from these four patients while they are on treatment were eliminated from the analysis. 
Figure 2: Invited vs. non-invited participants and inclusion criteria

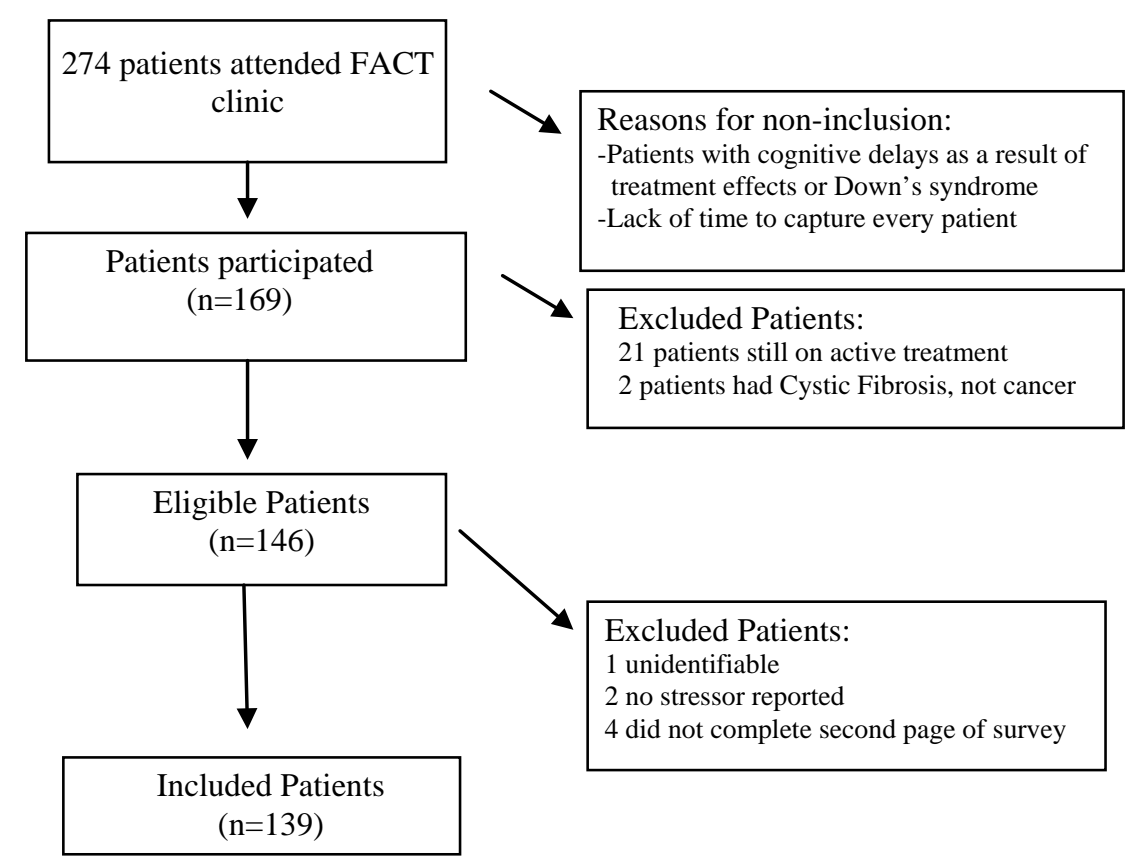

Outcomes examined were coping endorsement (use of approach or withdrawal coping strategies), coping efficacy, and type of stressor (cancer-related or non-cancerrelated) reported. The longitudinal dataset was constructed from multiple Kidcope surveys completed by the same participant. Fifty-two percent completed more than one survey. Of the participants in the study, 34 participants completed two surveys, 19 completed three surveys, 16 completed four surveys, and three completed five surveys. The timing of survey administration also varied. Some participants completed the Kidcope survey at their initial visit to the FACT clinic and then again at subsequent visits while others, for example, did not complete a Kidcope survey for the first time until their third visit to the FACT clinic. 


\subsection{Study Population}

Participants were recruited from the FACT clinic between 1996 and 2011. The inclusion criterion for the study population was all childhood cancer survivors who completed a Kidcope survey at the FACT clinic. Complete data was not available for all patients who sought services from the FACT clinic. The Kidcope survey was time consuming to complete and involved a therapeutic component from the Child Life Specialist. Given that the Kidcope survey took about an hour to complete and patients were scheduled every fifteen minutes, it was not possible to capture data on every patient at every visit to the FACT clinic. Additionally, participants were excluded from the study if there was an extensive amount of missing information on the Kidcope survey. Kidcope surveys were completed by participants when they were receiving active treatment and then completed again by the same participants when they were off treatment. Therefore, surveys were excluded if the participants were still on active cancer treatment when the Kidcope questionnaire was completed ( $\mathrm{n}=25)$.

\subsubsection{FACT Clinic}

The FACT clinic was developed as a comprehensive clinic at the Medical University of South Carolina to focus on survivors of childhood cancer and the late effects of therapy. The FACT clinic meets once a month and is for survivors who have been disease free and off all treatment for cancer for at least five years. Childhood cancer survivors are seen on an annual basis until they reach thirty years of age. During their visit to the FACT clinic each survivor meets with a nurse, oncologist, social worker and child life specialist. The FACT clinic serves to provide early detection and treatment of any problem related to being a cancer survivor. The clinic also provides psychosocial 
screening/assistance and emotional support as needed to survivors and family members. During their visit, survivors received health education related to their diagnosis and treatment as well as potential risks and preventative behaviors. Collaboration with team members resulted in the development of protocols to monitor for toxicities as well as communication of follow-up needs to the survivor's primary care physician.

\subsubsection{Integration of Medical Record Data with FACT Clinic Data}

For this project, data were collected from the Kidcope survey during FACT clinic,

the participant's medical records, and participant and family characteristics as reported by the child life specialist. Table 6 depicts the data collected and the sources. To assess family impact on reported stressors and coping, information on siblings, socioeconomic status (SES), and household structure were collected. Siblings was a binary variable (yes/no) that indicated whether or not the study participant had siblings at the time of survey. Household structure described with whom the participant was living during his/her cancer treatment. As an indicator of socioeconomic status, zip codes obtained from the child's medical record were used to acquire estimates of median household income (Variable: B19013; Median Household Income in the Past 12 months (In 2011 inflation-adjusted dollars) from the American Community Survey (U.S. Census Bureau, 2011). 


\section{Table 6: Sources of Data Collection}

\begin{tabular}{lll}
\hline \multirow{1}{*}{ Medical Record } & \multicolumn{2}{c}{ FACT Clinic } \\
\cline { 2 - 3 } & Child Life Specialist & \multicolumn{1}{c}{ Kidcope Survey } \\
\hline \hline Date of birth & Siblings & Date surveyed \\
Gender & Household structure & Date of birth \\
Race & & Child's name \\
Diagnosis & & Grade in school \\
Diagnosis date & Age at survey \\
Treatment & Stressor \\
Treatment end date & Distress scores \\
Age at diagnosis & Coping strategies \\
Zip code (SES-census acquired) & & Coping efficacy \\
\hline
\end{tabular}

\subsection{Kidcope Questionnaire Administration}

During administration of the Kidcope questionnaire the participant was asked to describe a stressor he/she had recently encountered or a stressor he/she remembered related to the illness. The stressor was documented. The participant then completed the set of questions during a one-on-one interview with the child life specialist based on the stressor he or she identified.

After the participant described his/her stressor to the child life specialist, he/she then responded to four additional questions about anxiety ("Did/does this situation make you nervous?”), sadness (“Did/does this situation make you sad?”), anger (Did/does this situation make you angry or mad?”), and fear (“Did/does this situation make you afraid?'). One final question was asked prior to completing the Kidcope survey; "Compared to all other problems that you've had, how much does this one bother you?" If the participant did not consider the current stressor his/her worst problem, the child life specialist asked the participant what he/she considered his/her worst problem. Responses to these questions were assigned to a five-point Likert-type scale ranging from "not at all” (0) to "very much” (4). Participants were then asked to complete the Kidcope survey 
and rate each of the items according to the frequency with which he/she used a particular coping strategy to deal with their stressor and the efficacy of coping strategies endorsed.

On the younger version of the Kidcope survey, only a "yes/no" response was required for frequency and a three point Likert-type scale ranging from "not at all” to "a lot” was employed for efficacy. On the adolescent version of the Kidcope survey, a four point Likert-type scale "not at all" to "almost all the time" was used to assess frequency and a five point scale ranging from "not at all" to "very much" was employed to examine efficacy. Responses on the frequency scale were recoded into "not used" versus "used", such that frequency indicated a selection of a coping strategy at least some of the time. Responses on the efficacy scale were recoded into "not effective" and "a little effective" versus "a lot effective.” These conversions were completed to make the younger version consistent with the adolescent version of the Kidcope questionnaire for analytical purposes as has been done in previous studies using the Kidcope survey (Spirito et al., 1994; Tyc et al., 1995).

The Kidcope questionnaire was individually administered by a licensed child life specialist during the FACT clinic. All surveys were administered by the same child life specialist each time. The project was approved by the Medical University of South Carolina Institutional Review Board. Consent forms and HIPAA authorizations were signed by either the participant or the participant's parent, depending on the age of the participant, prior to the completion of the Kidcope survey.

\subsection{Categorization of Stressors}

Categories for the stressors were derived by reviewing the individual participant responses on the Kidcope questionnaire and then arranging them into two distinct groups: 
cancer-related stressors and not cancer-related stressors. The stressors were then further sub-categorized within each group (Appendix D). Twenty-three separate categories were constructed to account for every response on the Kidcope surveys.

\subsection{Factor Analysis}

Previous studies have attempted to analyze Kidcope data using higher order factor structures, but the number of resulting factors was inconsistent among studies. Factor structures found have included single factor structures (Spirito et al., 1996), two-factor control/escape oriented structures (Chen \& Chan, 2003), three factor structure (problem focused coping, problem avoidant coping, negative coping) (Spirito et al., 1994), three factor structure (problem-avoidant coping, internalized negative coping, externalized negative coping) (Vigna et al., 2010), and four factor structures (positive coping, blame and anger, wishful thinking, social withdrawal) (Vernberg et al., 1996). The varying factor structure could be due to the various study populations and stressors reported in studies involving the Kidcope survey.

\subsubsection{Confirmatory Factor Analysis}

A confirmatory factor analysis was used to assess the adequacy of model fit using the factor structures determined in previous research. Criteria for an adequate fit included a non-significant chi-square statistic. However, given that the chi-square statistic is sensitive to sample size, other fit indices were examined, including the root mean square error of approximation (RMSEA) value, comparative fit index (CFI), and Tucker-Lewis index (TLI) (StataCorp, 2011). Values of 0.9 or higher for the CFI and TLI were considered indicators of good fit between the model and the data, with values 
closer to 1.0 considered better. Values for RMSEA between .05 and .08 indicate acceptable fit, with values below .05 indicating good fit (StataCorp, 2011).

Using previous factor structures, three models were tested: A two-factor model including emotional and behavioral coping (Lazerus and Folkman, 1993), a two-factor model including escape- and control-oriented coping (Cheng \& Chan, 2003), and a three-factor model including avoidant, negative, and acitve coping (Spirito et al., 1994). The results indicated that Lazerus and Folkman's (1993) two-factor model yielded a poor fit , CFI $=.708$, TLI=.613, RMSEA $=.07, \mathrm{X}^{2}(34)=83.36, \mathrm{p}<.001$. Cheng and Chang's (2003) two-factor model also yielded a generally poor fit, CFI=.71, TLI=.64, RMSEA $=.08, X^{2}(43)=123.72, p<.001$. Lastly, Spirito et al.'s (1994) three-factor model approximated an adequate fit, $\mathrm{CFI}=.84, \mathrm{TLI}=.767, \mathrm{RMSEA}=.06$. Although, marginally acceptable, these indices did not indicate a good fit, and $X^{2}(19)=36.94$ was significant, $\mathrm{p}<.01$. Spirito et al.'s three-factor model of the Kidcope approximated a better fit for the current sample than Cheng and Chan's and Lazerus and Folkman's two-factor models. However, neither model truly produced a good fit.

\subsubsection{Exploratory Factor Analysis}

Because no model proposed by previous literature yielded a good fit to the current data, exploratory factor analyses (EFAs) were conducted. Exploratory factor analysis is used to explore the dimensionality of a measurement instrument by finding the smallest number of interpretable factors needed to explain the correlations among a set of variables (Netemeyer et al., 2003). Criteria for determining factor solutions of the Kidcope survey included factor loadings greater than or equal to .35 and eigenvalues greater than or equal to 1.0 (Vernberg et al., 1996; Vigna et al., 2010). 
Analyses were conducted forcing two and three factors, as indicated by previous literature. Initial results produced a three-factor structure; however, two coping strategies cross loaded on two or more factors (self-criticism and blaming others) and were deleted from further analysis as suggested by Vernberg et al. (1996). A second EFA was conducted with the remaining eight coping strategies resulting in a two-factor structure with a correlation of .10 between the factors.

The first factor accounted for $21.8 \%$ of the variance and included four items (cognitive restructuring=.67, problem solving=.59, emotional regulation=.41, social support $=.72$ ). This factor was labeled as positive/approach coping, because all of the items involved efforts to maintain or regain a positive emotional or cognitive state. The second factor accounted for $17 \%$ of the variance and contained four items (distraction $=.50$, social withdrawal=.67, wishful thinking $=.53$, resignation $=.53$ ). This factor was labeled withdrawal coping. Confirmatory factors analyses showed that this

two-factor model fit the data (CFI=.96, TLI=.92, RMSEA $=.03, \mathrm{X}^{2}(13)=16.76, \mathrm{p}=.211$. Internal consistency was assessed using Cronbach's alpha, including only the items that loaded saliently on each factor. The Cronbach's alpha for all factors were below the accepted standard of .7, ranging from .38 to .51 , indicating that the two-factor model might not provide sufficent internal consistency.

\subsection{Statistical Analysis}

Analyses and data cleaning were completed using StataSE 12 (StataCorp, 2011). To determine the coding for the outcome variables of interest, a confirmatory factor analysis and an exploratory factor analysis were conducted. Given the nature of the data, which consists of both cross sectional and longitudinal observations, Hierarchical Linear 
Modeling (HLM) were used. Hierarchical Linear Modeling is a complex form of ordinary least squares regression that is used to analyze variance in outcome variables when the predictor variables are at different hierarchical levels. In longitudinal research, data collected at different times and under different conditions are treated as being nested within each study participant. Ordinary least squares regression assumes independence of observations, but nested data violate this assumption, leading to inappropriately small standard errors and a corresponding increase in Type 1 error and potentially incorrect rejection of a true null hypothesis. Moreover, effects of the predictor variables may be misinterpreted, not only in magnitude but in direction as well.

The number of Kidcope surveys per participant varied. The majority of participants (48.2\%) had completed one survey, 25.2\% completed two surveys and 26.7\% completed three or more surveys. The timing of survey administration varied among the participants as well. For example, one participant could have completed a survey at his/her first visit to the FACT clinic and one at the second visit, while another participant may have completed surveys at his/her first and fourth visits to the FACT clinic. The average time between a participant's first and second surveys was 2.13 years, $S \mathrm{D}=1.79$. The variation in time intervals between surveys required use of HLM, since unbalanced and unequally spaced data can be handled adequately using this technique. Additionally, HLM can assess cross-level data relationships and accurately disentangle the effects of between-group and within-group variance (Woltman et al., 2012).

For two-level models, Maas and Hox's (2005) suggested that samples with thirty Level 2 units should provide reasonably unbiased estimates of regression coefficients, standard errors of regression coefficients, and variance components. However, standard 
errors of the Level 2 variance components were biased among samples with as many as fifty Level 2 units, so large samples at Level 2 are truly ideal (Maas \& Hox, 2005). The level 2 units used in analyses of aim 1 and 1 a were 123 and 72 subjects respectively.

\section{Statistical Analysis of Specific Aims}

\subsubsection{Specific aim one analysis}

The first specific aim was to determine the association between time since completion of treatment to time of survey and the type of stressor (cancer-related versus non-cancer-related) identified. For all data, a time variable was calculated to represent the date difference from the date of survey to their off treatment date (Mean=7.06 years, $\mathrm{SD}=3.42)$. The stressors reported were coded into two groups: cancer-related and noncancer-related stressors and were evaluated in relation to the time since completion of treatment.

In order to obtain statistical justification for using HLM, an interclass correlation (ICC) was calculated using a null model. The ICC can be defined both as the proportion of stressor score variation that occurs across participants and as the expected correlation between the stressor scores from surveys from the same participant. There is no consensus on a cut-off point, however if the ICC is very low, the HLM analyses may not yield different results from a traditional analysis. As the ICC increased, the proportion of stressor score variation that occurred across participants increased, resulting in violations of the independence assumption.

The null model for aim 1 exhibited the following form: 
Level 1: $Y t i=\beta o i+r t i$, where $Y t i=$ the outcome variable of type of stressor identified for participant i at time $\mathrm{t}(Y t i=1$ or $Y t i=0)$. The subscript $\mathrm{t}$ refers to repeated response variable observations (level-1 units) collected from i participants (level-2 units). $\beta$ oi $=$ intercept represents each participant's reported stressor, and $r t i=$ time specific residual term that reflected differences in reported stressors.

Level 2: $\beta o i=\gamma o o+u o i$, where $\beta o i$ is modeled as a function of a grand mean stressor score for all participants (yoo) plus a term (uoi) that reflected deviations in a participant's reported stressor mean around the grand mean. The combined equation for the null model is: $Y t i=$ yoo $+u o i+r t i$. The ICC was expected to be significant to explain that there were differences among participants.

The results of the null model were chibar ${ }^{2}(01)=13.12, \mathrm{p}<.0001$ with an interclass correlation of 0.416 suggesting that $42 \%$ of the variance in stressor reported is at the group level indicating the groups were not independent and justified hierarchical multiple regression analyses. Therefore, the next step to evaluate the relationship between the stressor identified and time since off treatment employed an HLM model to examine the relative contribution of the demographic variables of gender, age, and race, time since completion of treatment and treatment length to stressor. The main predictor variable represented time since off treatment to assessment and was group centered to yield more accurate estimates of the intercepts.

The HLM model for aim 1 exhibited the following general form: 
$\operatorname{logit}\left(p_{i j}\right)=\beta_{o}+b_{i}+\beta_{1 \Delta t i j}$ where $p_{i j}=P\left(Y_{i j}=1\right)$ and $p_{i j}=$ the probability that $Y_{i j}=1 . Y_{i j}$ represented the outcome variable of type of stressor identified in the $\mathrm{i}^{\text {th }}$ participant at the $\mathrm{j}^{\text {th }}$ visit. $Y_{i j}=1$ if a non-cancer stressor was identified by participant i at visit j. $Y_{i j}=0$ if a cancer related stressor was identified by

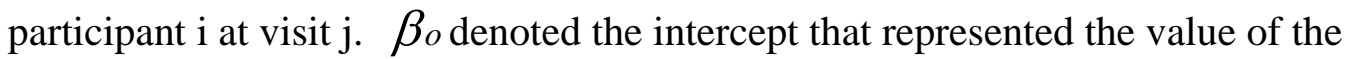
dependent measure at time $0 . \beta_{1}$ was the log odds ratio of the probability that $Y_{i j}=1$ as the change in time increased. $b_{i}$ represented participant i's random intercept. $b i$ denoted the deviation of the $\mathrm{i}^{\text {th }}$ individual's intercept from the population's intercept $\beta_{o}$. The participant was considered the random effect in this model since the number of measurements and timing of measurements varied across participants. $b i$ assumed that each participant had different baseline levels of coping. $\Delta t i j$ represented the amount of time from end of cancer treatment to survey in participant $\mathrm{i}$ at visit $\mathrm{j}$.

\section{Subaim:}

To determine whether coping strategies and stressors change over time in childhood cancer survivors, the longitudinal data were analyzed using HLM. A time variable (survey wave) was created to represent the order and timing in which the surveys were completed for each participant (range: 1-5). There were longitudinal data on 72 participants with a total of 203 Kidcope surveys. The results of the null model were $\operatorname{chibar}^{2}(01)=12.21, \mathrm{p}<.0002$ with an interclass correlation of 0.406 suggesting that $41 \%$ of the variance in stressor 
reported was at the group level indicating that groups were not independent and thus justification for hierarchical multiple regression analyses.

Level 1 of the HLM is considered the within-subject variation and explains the variance among the repeated Kidcope measures for given individuals. Level 2 represents the between-subjects variation, with the observation unit (the participant) being a grouping variable for the Kidcope measures.

\subsubsection{Specific aim two analysis}

Aim two tested the hypothesis that participants with a more severe diagnosis and who require more extensive treatment will exhibit withdrawal coping strategies. The initial plan for this aim was to use HLM with cancer diagnosis being the grouping variable instead of participant, which was used in aim one. For random effect models, the null and alternative hypotheses were: $\mathrm{H}_{0}: \sigma_{\beta}^{2}=0 ; H_{1}: \sigma_{\beta}^{2}>0$. The results of the null model $\left(\sigma^{2}=1.10^{\mathrm{e}-12}\right)$ indicated that the groups were independent and therefore we failed to reject the null hypothesis. Furthermore, a multilevel model with the independent (diagnosis, treatment, and demographics) and dependent variables (approach/withdrawal coping) and diagnosis as the grouping variable was not significant. This could be due in part to the small sample size of the level 2 variable $(n=8)$. Overall, it was determined that a multilevel model was not appropriate to analyze this aim.

Therefore, a backwards stepwise logistic regression was used to identify factors associated with coping. The overall goal was to build a parsimonious model with good predictivity to compare participants who used approach coping and those who favored withdrawal coping. Data from the first survey for each participant were included to 
obtain a cross sectional snapshot of the data. The eight coping strategies were dichotomized into approach or withdrawal coping based on the results of the exploratory factor analysis. Several variables were dummy coded to allow for easier interpretation of effects. The backwards stepwise logistic regression analyses tested the following covariates: age at assessment (7-12 years versus 13-25 years), age at diagnosis (years), gender (male versus female), race (white versus black), length of treatment ( $<12$ months versus $\geq 12$ months), treatment type (chemotherapy versus chemotherapy and radiation), and diagnosis (leukemia versus all other cancers). Additionally, interaction variables of treatment type*treatment length, diagnosis*treatment type, and diagnosis*treatment length were included in the models as well.

Prior to analyses variables were assessed for normality using histograms and box and whisker plots. Variables with skewed distributions (age at diagnosis) were transformed using a log transformation in order to obtain a normal distribution. A simpler model was preferred to a complex model to reduce the possibility of over fitting a model to the data. The strategy for this model building or pairing down began with a full model including the exposure of interest, potential confounders, and three interaction terms. A stepwise backward elimination procedure evaluated each model. Covariates with a p-value of $<0.2$ were retained until the best predictive model was developed. Hosmer-Lemeshow and global chi-square tests were used to assess goodness-of-fit.

\subsubsection{Specific aim three analysis}

Aim 3 sought to test the hypothesis that participants with siblings, higher median household income, and from two-parent households used approach coping strategies and had higher reported coping efficacy. In this aim, demographic variables as well as three 
family related variables were examined with respect to the coping strategies outcome: household structure, siblings, and socioeconomic status. Household structure referred to with who the participant lives (i.e. both parents, mother, father, grandparent(s)). Siblings were also considered in this aim as their supportive role can contribute to a stronger family structure. Socioeconomic status was determined using zip codes to gather information on median household income.

Initially, this aim assessed the association between demographic and family variables and coping strategy endorsement and efficacy using multilevel modeling. Based on the results of the null model, the interclass correlation coefficient for coping strategy endorsement $\left(\sigma^{2}=.416\right)$ and coping efficacy $\left(\sigma^{2}=.307\right)$ were significant, providing evidence for use of HLM. We expected this result to be significant since the grouping variable was the participant. However, despite the significant results of the null model we were unable to obtain a significant full model.

Subsequently, multiple linear regression was used to examine the relationship between demographic and family characteristics of interest with coping efficacy. Coping efficacy referred to the "How much did it help?" section on the Kidcope survey (Appendix C). The outcome variable of coping efficacy was determined using the mean scores for this section, which ranged from 0-2 for all ten questions.

In addition to the linear model, logistic regression was used to identify factors associated with coping. The overall goal was to build a parsimonious model with good predictivity to compare those who used approach coping and those who favored withdrawal coping strategies. Data from the first survey observation for each participant were included to obtain a cross sectional snapshot of the data. The eight coping strategies 
were dichotomized into approach or withdrawal coping based on the results of the exploratory factor analysis. Several variables were dummy coded to allow for easier interpretation of their effects. Backwards stepwise logistic regression analyses tested the following covariates: age at assessment (7-12 years versus 13-25 years), gender (male versus female), race (white versus black), household structure (both parents versus other), median household income ( $<\$ 50,000$ versus $\geq \$ 50,000)$, and siblings (yes versus none). Interaction variables of household*race and household*income were also included in the models.

Prior to analyses variables were assessed for normality using histograms and box and whisker plots. Variables with skewed distributions were transformed using log or quadratic transformations to obtain a normal distribution. A simpler model was preferred to a complex model to reduce the possibility of over fitting a model to the data. The strategy for this model building or pairing down began with a full model including the exposure of interest, potential confounders, and three interaction terms. A stepwise backward elimination procedure evaluated each of the models. Covariates with a p-value of $<0.2$ were retained until the best predictive model was developed. Hosmer-Lemeshow and global chi-square tests assessed goodness-of-fit.

\subsection{Preliminary Results}

Results of the stressors reported on the Kidcope questionnaire indicated that chemotherapy, needles/shots, hair loss, hospital and having cancer in general were the five most common stressor categories reported in the cancer related stressors group. For non-cancer-related stressors school, peers and family were the most common stressor categories reported. Table 7 displays the prevalence of all stressors reported. Overall, of 
the 270 surveys, $65.9 \%$ reported a cancer-related stressor and 34.1\% reported a noncancer-related stressor. Table 8 provides further detail on stressor reporting stratified by age group. Differences in stressor reporting by age group were measured using Fisher's exact test, in order to account for cell sizes with $\mathrm{n}<5$. Statistically significant differences between age of participant and the stressor category were seen for three categories: needles/shots, not being able to participate in activities, and friends/family deaths.

Table 7: Cancer-related and non-cancer-related stressors reported by participants on the Kidcope survey

\begin{tabular}{lrr}
\hline Cancer-Related Stressors & n & \% \\
\hline \hline Needles/shots & 44 & 24.7 \\
Having cancer in general & 24 & 13.5 \\
Hair loss & 15 & 8.4 \\
Hospital & 15 & 8.4 \\
Chemotherapy & 13 & 7.3 \\
Surgery & 12 & 6.7 \\
Not being able to participate in activities & 11 & 6.2 \\
IV/blood draw & 9 & 5.1 \\
Port & 8 & 4.5 \\
Medicine & 6 & 3.4 \\
Fear of cancer recurrence & 6 & 3.4 \\
Radiation & 5 & 2.8 \\
Thoughts of death & 4 & 2.2 \\
Pain & 3 & 1.7 \\
Painful procedures & 3 & 1.7 \\
\hline Non-Cancer-Related Stressors & $\mathbf{n}$ & $\mathbf{\%}$ \\
\hline School & 26 & 28.3 \\
Family & 20 & 21.7 \\
Peers & 16 & 17.4 \\
Friends/family deaths & 13 & 14.1 \\
Friends & 7 & 7.6 \\
Not having any friends & 4 & 4.4 \\
Other & 4 & 4.4 \\
Pet died & 2 & 2.1 \\
\hline
\end{tabular}


Table 8: Cancer-related and non-cancer-related stressors reported on the Kidcope survey stratified by age.

\begin{tabular}{|c|c|c|c|c|c|c|c|}
\hline \multirow[t]{2}{*}{ Cancer-Related Stressors } & \multicolumn{2}{|c|}{$\begin{array}{l}\text { Children } \\
\text { 7-12 years }\end{array}$} & \multicolumn{2}{|c|}{$\begin{array}{l}\text { Adolescents } \\
\text { 13-17 years }\end{array}$} & \multicolumn{2}{|c|}{$\begin{array}{c}\text { Adults } \\
\text { 18-28 years }\end{array}$} & \multirow[t]{2}{*}{ p-value } \\
\hline & $\mathbf{n}$ & $\%$ & $\mathbf{n}$ & $\%$ & $\mathbf{n}$ & $\%$ & \\
\hline Chemotherapy & 5 & 4.1 & 4 & 3.4 & 4 & 12.1 & 0.118 \\
\hline Surgery & 6 & 5.0 & 4 & 3.4 & 2 & 6.1 & 0.707 \\
\hline Needles/shots & 28 & 23.1 & 16 & 13.8 & - & -- & $<0.001$ \\
\hline Hair loss & 5 & 4.1 & 6 & 5.2 & 4 & 12.1 & 0.197 \\
\hline Port & 4 & 3.3 & 2 & 1.7 & 2 & 6.1 & 0.329 \\
\hline IV/blood draw & 5 & 4.1 & 4 & 3.4 & - & -- & 0.717 \\
\hline Hospital & 5 & 4.1 & 7 & 6.0 & 3 & 9.1 & 0.487 \\
\hline Painful procedures & 1 & 0.8 & 2 & 1.7 & - & -- & 0.740 \\
\hline Medicine & 3 & 2.5 & 1 & 0.9 & 2 & 6.1 & 0.145 \\
\hline Radiation & 1 & 0.8 & 3 & 2.6 & 1 & 3.0 & 0.439 \\
\hline Pain & 2 & 1.7 & 1 & 0.9 & - & -- & 0.999 \\
\hline Fear of cancer recurrence & 1 & 0.8 & 5 & 4.3 & - & -- & 0.183 \\
\hline $\begin{array}{l}\text { Not being able to participate in } \\
\text { activities }\end{array}$ & 2 & 1.7 & 3 & 2.6 & 6 & 18.2 & $<0.001$ \\
\hline Thoughts of death & 1 & 0.8 & 3 & 2.6 & - & -- & 0.622 \\
\hline Having cancer in general & 7 & 5.8 & 11 & 9.5 & 6 & 18.2 & 0.077 \\
\hline \multirow[t]{2}{*}{ Non-Cancer-Related Stressors } & \multicolumn{2}{|c|}{$\begin{array}{l}\text { Children } \\
\text { 7-12 years }\end{array}$} & \multicolumn{2}{|c|}{$\begin{array}{l}\text { Adolescents } \\
\text { 13-17 years }\end{array}$} & \multicolumn{2}{|c|}{$\begin{array}{c}\text { Adults } \\
\text { 18-28 years }\end{array}$} & p-value \\
\hline & $\mathbf{n}$ & $\%$ & $\mathbf{n}$ & $\%$ & $\mathbf{n}$ & $\%$ & \\
\hline School & 10 & 8.2 & 16 & 13.8 & - & -- & 0.037 \\
\hline Peers & 7 & 5.8 & 8 & 6.9 & 1 & 3.0 & 0.821 \\
\hline Family & 12 & 9.9 & 7 & 6.0 & 1 & 3.0 & 0.366 \\
\hline Friends/family deaths & 2 & 1.7 & 11 & 9.5 & - & -- & 0.011 \\
\hline Pet died & 2 & 1.7 & - & -- & - & -- & 0.613 \\
\hline Friends & 6 & 5.0 & 1 & 0.9 & - & -- & 0.111 \\
\hline Not having any friends & 4 & 3.3 & - & -- & - & -- & 0.185 \\
\hline Other & 2 & 1.7 & 1 & 0.9 & 1 & 3.0 & 0.480 \\
\hline
\end{tabular}




\title{
CHAPTER 4
}

\section{Paper 1: Examining Changes in Stressors and Coping Longitudinally in Childhood Cancer Survivors}

\begin{abstract}
Objectives: The purpose of this research was to determine the association between time elapsed since completion of treatment to time of survey and the type of stressor (cancerrelated versus non-cancer-related) identified. Additionally, this study sought to determine whether the stressor identified (cancer-related or non-cancer-related) and strategies utilized to cope with that stressor change over time for childhood cancer survivors.
\end{abstract}

Background: As increasing numbers of children survive childhood cancer there is a need to understand the cancer-related and non-cancer-related stressors survivors face as well as the coping strategies they utilize to manage these stressors. Such information would be helpful in designing psychosocial interventions to enhance the coping efforts of childhood cancer survivors.

Methods: One hundred thirty-nine childhood cancer survivors were examined using both cross-sectional and longitudinal data collected at the Follow-up After Cancer Treatment (FACT) clinic at the Medical University of South Carolina. Hierarchical regression modeling examined the participant's treatment length, time since completion of treatment to assessment, and demographic variables as a predictor of type of stressor reported. Change in stressor reporting and coping strategy usage over time were also evaluated.

Results: Hierarchical regression analyses revealed age at assessment and time since completion of treatment to assessment significantly predicted type of stressor reported (Wald $\chi^{2}(5)=13.07, \mathrm{p}<.05$ ). A greater lapse in time from treatment to assessment was associated with non-cancer-related stressor reporting $(\mathrm{p}<.05)$. Stressor reporting and coping strategy use changed over time, when controlling for age, race, and gender $(\mathrm{p}<.05)$.

Conclusions: Overall, this research demonstrated that stressors and coping strategy use in childhood cancer survivors changed over time to give way to non-cancer-related stressors and adaptive coping strategies. This research provided evidence for the beneficial use of questionnaires, such as the Kidcope, in follow-up care. Employing the Kidcope survey in this fashion would enable identification of those patients with limited coping strategies at their disposal or adolescents who rate their coping strategies as ineffective. 


\section{$\underline{\text { INTRODUCTION }}$}

In the United States in 2013, approximately 11,630 children under the age of 15 will be diagnosed with cancer and about 1,310 children will die from the disease (American Cancer Society, 2012). Over the past 34 years, the incidence of children diagnosed with cancer has increased 33\% from 13.0 cases per 100,000 in 1975 to 17.3 cases per 100,000 in 2009 (Howlander et al., 2012). Conversely, mortality rates have declined 68\% over the past four decades from 6.5 per 100,000 in 1969 to 2.1 per 100,000 in 2009 (American Cancer Society, 2012), and the 5-year survival rate increased from 61.7\% in 1975 to 83.1\% in 2008 (Howlander et al., 2012). The successful medical treatment of children with cancer has greatly increased survival rates. Reports have indicated that $75 \%$ of children and adolescents diagnosed with cancer in the United States are likely to achieve a relatively normal life span (Zebrack et al., 2002). This set of circumstances has resulted in more childhood cancer survivors and thus a greater need to study the adjustment of children who survived cancer.

Childhood cancer survivors often must deal simultaneously with cancer-related stressors as well as non-cancer-related stressors (e.g. school, peers, and family). All survivors experience at least occasional problems in social adjustment and continue to be concerned about their medical and social futures. There is evidence that survivors of childhood cancer recall disturbing memories of procedures up to 12 years after treatment has ended (Kazak et al., 1996). The exposure to multiple stressors places extraordinary demands on childhood cancer survivors and may necessitate special coping strategies and these coping strategies may change depending on the type of stressor the person is faced 
with (Bull \& Drotar, 1991). Pediatric patients use a wide variety of coping strategies to attempt to manage their disease and its side effects.

Some studies have found that most pediatric cancer survivors reported good psychological adjustment and that rates of depression and anxiety were comparable to norms and control groups (Boman et al., 1995; Eiser et al., 2000; Kazak et al., 1997). However, other studies have identified subsets of pediatric cancer survivors who do not cope or adjust well. These studies consistently identified a small group (estimated to be 25-30\%) of survivors who did not cope well or who have considerable difficulties with personal, family, and social functioning (Patenaude et al., 2005; Kupst et al.,1995). When compared to other childhood illness groups, cancer survivors had lower life satisfaction and increased maladjustment (Aldridge \& Roesch, 2007).

Relatively few studies have focused directly on cancer-related stressors for children and adolescents who are off treatment (e.g., Kazak et al., 1996; 2001). Currently, no study has evaluated changes in stressors and coping strategy usage over time. To address this gap in the literature, this study aimed to determine the association between time since completion of treatment to time of survey and the type of stressor (cancer-related versus non-cancer-related) identified.

Additionally, this study sought to determine whether the stressor identified (cancer-related or non-cancer-related) and strategies utilized to cope with that stressor change over time for childhood cancer survivors. Coping is a gradual, dynamic process that prospective longitudinal assessment of coping is necessary to detect temporal effects. The current literature does not reflect studies of childhood cancer survivors who were evaluated with the Kidcope questionnaire. Therefore, this study could present novel 
findings on the perceived stressors of childhood cancer survivors as well as the endorsement of coping strategies utilized to cope with the stressor.

\section{METHODS}

\section{Subjects}

One hundred thirty-nine participants were recruited from the Follow-up After Cancer Treatment (FACT) clinic between 1996 and 2011. The FACT clinic was developed as a comprehensive clinic at the Medical University of South Carolina to focus on survivors of childhood cancer and the late effects of cancer treatment. The FACT clinic is for patients who have been disease free and off treatment for at least five years. Typically survivors attend the FACT clinic once per year and may complete a Kidcope survey each time they attend the clinic. Therefore, multiple Kidcope surveys were completed by 52\% of the study population for a total of 270 complete surveys for the 139 participants; specifically, 34 participants completed two surveys, 19 completed three surveys, 16 completed four surveys, and three completed five surveys.

The participant’s age at diagnosis was 0.2-16.8 years (mean, 4.8 years). The mean age at participation was 13.49 years (range, 7-28 years). Further characteristics of the study population are displayed in Table 1 . The majority of participants (72\%) were white and there was an approximately equal distribution between males (45\%) and females (55\%).

Procedure

Survivors and their parents who attended the FACT clinic were approached by a child life specialist about participating in the Kidcope survey. Informed consent and 
HIPAA authorization were obtained from interested participants and their parents if the participant was a minor. Participants met individually with the child life specialist to complete the Kidcope survey. During the Kidcope questionnaire, participants were asked to describe a stressor they recently encountered or a stressor related to their cancer experience. Then, participants were instructed to rate each coping strategy according to the frequency with which they used a particular coping strategy and the perceived efficacy of each strategy endorsed. The study was approved by the Medical University of South Carolina Institutional Review Board.

\section{Measures}

The Kidcope survey is a self-report measure designed to assess cognitive and behavioral coping strategies employed by children and adolescents (Spirito et al., 1988). The Kidcope questionnaire assesses the use of ten specific coping strategies including distraction, social withdrawal, cognitive restructuring, self-criticism, blaming others, problem solving, emotional regulation, wishful thinking, social support, and resignation.

There are two versions of the Kidcope survey, a 15-item younger version is appropriate for children ages 7-12, while the 10-item version is for adolescents ages 1318. On the younger version of the Kidcope survey, only a "yes/no" response is required for frequency and a three-point Likert-type scale ranging from "not at all” to "a lot” is employed for efficacy. On the adolescent version, a four-point Likert-type scale ranging from "not at all" to "almost all the time" is used to assess frequency and a five-point scale ranging from "not at all” to "very much" is employed to examine efficacy. In order to make the two versions of the Kidcope questionnaire compatible for statistical analysis, responses on the frequency scale were recoded into "not used" versus "used," such that 
frequency indicates selection of a coping strategy at least some of the time (Spirito et al, 1994; Tyc et al. 1995). Additionally, responses on the efficacy scale were recoded into “not effective,” "little effective,” and “a lot effective” (Spirito et al, 1994; Tyc et al. 1995).

Moderate test-retest correlation coefficients have been reported for the Kidcope survey for periods up to two weeks. Criterion validity was assessed using the Coping Strategies Inventory (CSI) and the Adolescent-Coping Orientation for Problem Experiences ACOPE) scale (Spirito et al., 1988). Correlations between items on the Kidcope survey and on the CSI and ACOPE were statistically significant and therefore provided evidence for criterion validity.

\section{Stressor Categorization}

Categories for the stressors were derived by reviewing the individual participant responses on the Kidcope questionnaire and then arranging them into two distinct groups: cancer-related stressors and not cancer-related stressors. The stressors were then further sub-categorized within each group. Twenty-three separate categories were constructed in order to account for every response on the Kidcope surveys. Chemotherapy, needles/shots, hair loss, hospital and having cancer in general were the five most common stressor categories reported in the cancer related stressors group. For noncancer-related stressors school, peers and family were the most common stressor categories reported. Table 2 displays the prevalence of all stressors reported. Overall, of the 270 surveys, $65.9 \%$ reported a cancer-related stressor and 34.1\% reported a noncancer-related stressor. 


\section{Statistical Analysis}

Analyses were performed using StataSE 12 (StataCorp, 2011). Given the nature of the data, which consists of both cross sectional and longitudinal observations, Hierarchical Linear Modeling (HLM) was used. Hierarchical Linear Modeling is a complex form of ordinary least squares regression that is used to analyze variance in the outcome variables when the predictor variables are varying at hierarchical levels. In longitudinal research, data collected at different times and under different conditions are nested within each study participant. Ordinary least squares regression assumes independence of observations, but nested data violate this assumption, leading to inappropriately small standard errors and a corresponding increase in Type 1 error. Type 1 error is the incorrect rejection of a true null hypothesis. Therefore, HLM is a necessity to avoid excessive Type 1 errors and biased parameter estimates.

The number of measurements per participant varied. Forty-eight percent of the participants had completed one survey, 25\% had completed two surveys and 27\% had completed three or more surveys. The timing of survey administration varied among the participants as well. For example, one participant may have completed one survey at his/her first visit to the FACT clinic and one at the second, while another participant may have completed surveys at his/her first and fourth visits to the FACT clinic. The average time between a participant's first and second surveys was 2.13 years, $\mathrm{SD}=1.79$. The variation in time intervals between surveys was further justification for the use of a hierarchical model since unbalanced and unequally spaced data can be handled under HLM. Moreover, HLM can assess cross-level data relationships and accurately 
disentangle the effects of between-group and within-group variance (Woltman et al., 2012).

For all data, a time variable was calculated to represent the date difference from the date of survey to the off treatment date. The stressors reported were coded into two groups: cancer-related and non-cancer-related stressors and were evaluated in relation to the time since completion of treatment. Additionally, a survey wave variable was created to represent the order and timing in which the surveys were completed for each participant (range: 1-5). The analysis of the data was two-fold. First, all surveys $(n=270)$ were evaluated to determine the association between time since completion of cancer treatment to assessment and the stressor identified. The second part of the analyses included only the longitudinal data $(n=203)$ to evaluate change in coping strategy usage and stressor reporting over time. Gender and race were controlled for but were not estimated since these factors do not change over time.

Maas and Hox's (2005) research suggested for two level models, samples with 30 level 2 units should provide reasonably unbiased estimates of regression coefficients, standard errors of regression coefficients, and variance components. The first phase of the analysis had 123 level 2 units and the second phase had 72. Model fit was examined using the Akaike Information Criterion (AIC) and deviance to compare the different models. The best fit model was chosen based on the lowest values for AIC and deviance.

\section{$\underline{\text { RESULTS }}$}

Descriptive Statistics

Overall, emotional regulation (94\%) and distraction (90\%) were the most used coping strategies. The least used strategy was self-criticism (25\%). The complete 
frequencies of coping strategy endorsement by stressor type listed in table 3 indicated that there were statistically significant differences between the two stressor groups in four coping strategies (social withdrawal, self-criticism, blaming others, and resignation). The mean number of coping strategies used for all surveys was $7.5(\mathrm{SD}=2.12)$.

\section{Null Model}

In order to obtain statistical justification for using HLM, an interclass correlation (ICC) was calculated using a null model. The ICC can be defined both as the proportion of stressor score variation that occurs across participants and as the expected correlation between the stressor scores from surveys from the same participants. The null model exhibited the following form:

Level 1: $Y t i=\beta o i+r t i$

where $Y t i=$ the outcome variable of type of stressor identified for participant $i$ at time $\mathrm{t}$ (Yti=1 or $Y t i=0$ ). The subscript $t$ refers to repeated response variable observations (level-1 units) collected from $i$ participant (level-2 units) over time. $\beta$ Bo $i=$ intercept representing each participant's reported stressor, and $r t i=$ time specific residual term that reflects differences in reported stressors.

Level 2: $\beta o i=$ yoo + uoi

where $\beta o i$ is modeled as a function of a grand mean stressor score for all participants ( $\mathrm{yoo}$ ) plus a term (uoi) that reflects deviations in a participant's reported stressor mean around the grand mean. The combined equation for the null model was:

$Y t i=\gamma o o+u o i+r t i$. The results of the null model were $\operatorname{chibar}^{2}(01)=13.12, \mathrm{p}<.0001$ with an interclass correlation of 0.416 suggesting that $42 \%$ of the variance in stressor 
reported was at the group level indicating the groups were not independent and thus justification for hierarchical multiple regression analyses.

\section{Hierarchical Regression Analyses}

The next step to evaluate the relationship between the stressor identified and time since off treatment was to employ a HLM model to examine the relative contribution of the demographic variables of gender, age, and race, time since completion of treatment and treatment length to cancer-related or non-cancer-related stressor reported. The main predictor variable represented time since off treatment to assessment and was a grand mean centered variable in order to yield more accurate estimates of the intercepts. The HLM model exhibited the following general form: $\operatorname{logit}\left(p_{i j}\right)=\beta_{o}+b_{i}+\beta_{1} \Delta t_{i j}$; where $p_{i j}=P\left(Y_{i j}=1\right)$ and $p i j=$ the probability that $Y i j=1$.

Before the hierarchical regression analyses were performed, the independent variables were examined for collinearity. Results of the variance inflation factor (all less than 2.0) and the collinearity tolerance (all greater than .79) suggested that the estimated $\beta$ 's were well established in the following regression model. Various models were tested including models that contained both random slope and random intercepts. Using a likelihood ratio test to compare the models, there was no statistically significant difference between the two models and therefore the random intercept model provided a better fit for the data. The unstandardized regression coefficients (B) and standard errors for the full model are reported in table 4. The best fitting model for predicting type of stressor reported (Wald $\left.\chi^{2}(5)=13.07, \mathrm{p}<.05\right)$ contained two significant variables, age at assessment and time since completion of treatment to assessment. Addition of gender, race and treatment length did not significantly improve the prediction. Participants who 
were ages 18 and older at the time of assessment were more likely to report a cancerrelated stressor $(\mathrm{p}<.05)$. Childhood cancer survivors with a longer lapse in time between end of treatment and assessment had a greater likelihood of reporting a non-cancerrelated stressor (OR=3.18; 95\% CI: 1.10, 9.20)

The analysis of only the longitudinal data revealed that participants were more likely to use approach coping strategies $(\mathrm{p}<.05)$ to manage their stressors during subsequent follow-up visits to the FACT clinic compared to use of withdrawal coping strategies at initial visits, while controlling for stressor, age, race, and gender. Moreover, stressor reporting changed over time from cancer-related stressors to non-cancer-related stressors $(\mathrm{p}<.05)$. Age was a significant predictor $(\mathrm{p}<.05)$ of change in stressor reporting while controlling for race and gender. As the participant in the study aged, the odds of reporting a non-cancer-related stressor were multiplied by .76.

\section{DISCUSSION}

The purpose of this study was to compare the types of stressors and coping strategies described by childhood cancer survivors. Subjects were not asked to select their most difficult or most frequently occurring problem. Rather, they were asked to select a situation that bothered them in order to have the participants select the most salient problem to maximize accuracy in their identification and description of coping strategies.

Previous studies using the Kidcope survey were hypothetical in nature. In that, a situation (stressor) was presented to participants and they were asked how they would respond to that situation and coping was measured based on their responses. This method 
could be problematic since it does not take into account contextual factors related to the stressor that may affect how participants cope (Tyc et al., 1995; Compas et al., 2001).

Among all surveys, 69.8\% reported a cancer-related stressor and 30.2\% reported a non-cancer-related stressor. Despite having been off treatment for at least five years, issues such as needles/shots, being in the hospital, and having cancer in general remained significant concerns for childhood cancer survivors. Further, age appeared to be associated with the type of problem selected. Adolescents more often reported a cancer related stressor associated with their overall illness or a non-cancer-related stressor. Whereas children more frequently reported a cancer-related stressor specifically in regards to pain related problems. This finding suggests that adolescents are more often able to focus directly on the implications of their disease, whereas younger children more often focus on the symptoms as a manifestation of their concerns (Spirito et al., 1994). This may be understood developmentally as well, since, younger children have not yet achieved the cognitive maturity needed for a full understanding of the stressors encountered (Li et al., 2011) (Shafer et al., 1993).

Results of this study indicated that participants aged 18 and older were more likely to report a cancer-related stressor than a non-cancer-related stressor. This is contrary to findings of previous studies. Age at diagnosis may account for this difference. Seventy-two percent of adult participants were diagnosed with cancer at six years of age or older. A further breakdown of age at diagnosis revealed that $34 \%$ of the adults were diagnosed at age 11 or older compared to only $4 \%$ of adolescents. Some quality of life studies have found that childhood cancer survivors diagnosed at an older age who were older at the time of inquiry or treated with high-intensity therapies 
demonstrate more negative psychosocial outcomes (Zebrack et al., 2002; Kupst et al., 1995). Occurrence of cancer later in life for a large percentage of the sample may have contributed to more frequent reports of cancer-related stressors in older participants.

Some of the cancer-related stressors described by adults were "fear of cancer recurrence" and "not being able to participate in activities." Given that a large percentage of the adult participants were diagnosed during adolescence they spent much of this crucial time period of psychosocial development in the hospital and removed from the normal everyday activities in which most adolescents build relationships. Zebrack \& Chelser (2001) reported the things that childhood cancer survivors worry about may shape their self-images and life outlooks, and subsequently may affect their ability to achieve economically and socially productive lives.

Length of time between completion of cancer treatment and survey administration were associated with reporting of cancer-related stressors. Specifically, increased time from completion of treatment to assessment resulted in a greater likelihood of reporting a non-cancer-related stressor. Age at assessment was also related to stressor reporting with older participants less likely to report a cancer-related stressor. The younger the participant was at diagnosis, the less likely they are to remember events of their illness or treatment and therefore, report non-cancer-related stressors (Kadan-Lottick et al., 2002). Additionally, participants who attended the FACT clinic multiple times tended to report a cancer-related stressor on the initial Kidcope questionnaire and non-cancer-related stressors during subsequent visits.

Coping strategy changed over time as well. Participants reported using withdrawal coping strategies (i.e. distraction, social withdrawal, wishful thinking, or 
resignation) during their first or early visits to the FACT clinic and over time adopted the use of approach coping strategies (i.e. problem solving, social support, cognitive restructuring, or emotional regulation). However, participants who completed multiple Kidcope surveys over the years received additional psychosocial support from the child life specialist. This may have contributed to the observed changes in coping strategy.

Although cancer-related stressors appear to diminish over time a substantial number of survivors reported fear of recurrence, treatment, and potential disability five years after treatment. Age at diagnosis, particularly diagnosis during adolescence appears to be a risk factor for long-term negative psychosocial outcomes. Age at report was associated with type of stressor. Young children reported stressors related to pain associated with treatment while adolescents reported overall disease focused and psychosocial stressors. These characteristics could be used to identify survivors most at risk for continued cancer-related stress and maladaptive responses and to develop ageappropriate support modalities to improve psychosocial outcomes. 
Table 1: Characteristics of study population

\begin{tabular}{lrr}
\hline \multicolumn{1}{c}{ Variable } & \multicolumn{1}{c}{ Mean (SD) } & Range \\
\hline Age at diagnosis & $4.85(3.61)$ & $0-16$ \\
Duration of treatment (months) & $18.71(12.33)$ & $1-47$ \\
Time since diagnosis to initial assessment & $7.09(2.48)$ & $3-22$ \\
Time since treatment to initial assessment & $5.56(2.59)$ & $2-22$ \\
Age at initial assessment & $12.39(3.67)$ & $7-25$ \\
Age at assessment (all surveys) & $13.49(3.88)$ & $7-28$ \\
\hline
\end{tabular}

*All results are in years unless otherwise noted.

Table 2: Cancer-related and non-cancer related stressors reported by participants on the Kidcope survey

\begin{tabular}{lrr}
\hline Cancer-Related Stressors & n & \% \\
\hline \hline Needles/shots & 44 & 24.7 \\
Having cancer in general & 24 & 13.5 \\
Hair loss & 15 & 8.4 \\
Hospital & 15 & 8.4 \\
Chemotherapy & 13 & 7.3 \\
Surgery & 12 & 6.7 \\
Not being able to participate in activities & 11 & 6.2 \\
IV/blood draw & 9 & 5.1 \\
Port & 8 & 4.5 \\
Medicine & 6 & 3.4 \\
Fear of cancer recurrence & 6 & 3.4 \\
Radiation & 5 & 2.8 \\
Thoughts of death & 4 & 2.2 \\
Pain & 3 & 1.7 \\
Painful procedures & 3 & 1.7 \\
\hline \hline Non-Cancer-Related Stressors & $\mathbf{n}$ & $\mathbf{\%}$ \\
\hline \hline School & 26 & 28.3 \\
Family & 20 & 21.7 \\
Peers & 16 & 17.4 \\
Friends/family deaths & 13 & 14.1 \\
Friends & 7 & 7.6 \\
Not having any friends & 4 & 4.4 \\
Other & 4 & 4.4 \\
Pet died & 2 & 2.1 \\
\hline
\end{tabular}


Table 3: Percentages of children and adolescents reporting on the endorsement and efficacy of Kidcope strategies utilized for cancer related and non-cancer related stressors.

\begin{tabular}{|c|c|c|c|c|c|c|c|}
\hline \multirow{2}{*}{$\begin{array}{l}\text { Kidcope Coping } \\
\text { Strategy }\end{array}$} & \multicolumn{2}{|c|}{$\begin{array}{c}\text { All Surveys } \\
(n=270)\end{array}$} & \multicolumn{2}{|c|}{$\begin{array}{c}\text { Cancer Stressor } \\
(\mathrm{n}=178)\end{array}$} & \multicolumn{2}{|c|}{$\begin{array}{c}\text { Non-Cancer Stressor } \\
(\mathrm{n}=92)\end{array}$} & \multirow{2}{*}{$\begin{array}{c}\text { Chi- } \\
\text { Squared } \\
\text { p-value }\end{array}$} \\
\hline & Frequency & Efficacy & Frequency & Efficacy & Frequency & Efficacy & \\
\hline Emotional Regulation & 94.1 & 75.2 & 93.3 & 73.6 & 95.7 & 78.3 & 0.430 \\
\hline Distraction & 90.4 & 71.5 & 91.1 & 72.0 & 89.1 & 71.7 & 0.246 \\
\hline Social Support & 89.3 & 73.7 & 90.5 & 74.2 & 87.0 & 72.8 & 0.381 \\
\hline Cognitive Restructuring & 86.7 & 67.4 & 86.5 & 69.1 & 87.0 & 64.1 & 0.920 \\
\hline Resignation & 78.9 & 58.2 & 84.8 & 84.8 & 67.4 & 67.4 & $<0.001$ \\
\hline Problem Solving & 76.7 & 55.2 & 74.7 & 52.8 & 80.4 & 59.8 & 0.293 \\
\hline Wishful Thinking & 71.9 & 41.5 & 70.2 & 41.6 & 75.0 & 41.3 & 0.408 \\
\hline Social Withdrawal & 55.6 & 31.1 & 51.1 & 25.8 & 64.1 & 41.3 & 0.041 \\
\hline Blaming Others & 31.9 & 18.9 & 24.2 & 12.9 & 46.7 & 30.4 & $<0.001$ \\
\hline Self-Criticism & 24.8 & 9.3 & 19.7 & 6.7 & 34.8 & 14.1 & 0.006 \\
\hline
\end{tabular}

Table 4: Association Between Covariates and Stressor Final Model

\begin{tabular}{lrrrr}
\hline \multicolumn{1}{c}{ Variables } & Estimate & \multicolumn{1}{c}{ SE } & \multicolumn{1}{c}{ OR } & 95\% CI \\
\hline \hline Intercept & -5.97 & 2.42 & & \\
Time since off treatment to assessment & 1.16 & .54 & 3.18 & $(1.10,9.20)$ \\
Gender & -.33 & .46 & .72 & $(.29,1.76)$ \\
Race & -.06 & .54 & .94 & $(.33,2.69)$ \\
Age at assessment & -3.01 & .88 & .05 & $(.01, .27)$ \\
Treatment length & .64 & .49 & 1.89 & $(.73,4.91)$ \\
\hline
\end{tabular}




\section{REFERENCES}

Aldridge, A., \& Roesch, S. (2007). Coping and Adjustment in Children with Cancer: A Meta-Analytic Study. Journal of Behavioral Medicine, 30(2), 115-29.

American Cancer Society. (2012). Cancer Facts and Figures 2012. Atlanta: American Cancer Society.

Boman, K., \& Bodegard, G. (1995). Psychological Long-Term Coping with Experience of Disease and Treatment in Childhood Cancer Survivors. Acta Pardiatr, 12, 1395-402.

Bull, B., \& Drotar, D. (1991). Coping with Cancer in Remission: Stressors and Strategies Reported by Children and Adolescents. Journal of Pediatric Psychology, 16(6), 767-82.

Compas, B., Connor-Smith, J., Saltzman, H., Thomsen, A., \& Wadsworth, M. (2001). Coping with Stress During Childhood and Adolescence: Problems, Progress, and Potential in Theory and Research. Psychological Bulletin, 127, 87-127.

Eiser, C., HIll, J., \& Vance, Y. (2000). Examining the Psychological Consequences of Surviving Childhood Cancer: Systematic Review as a Research Methos in Pediatric Psychology. Journal of Pediatric Psychology, 25(6), 449-60.

Howlander, N., Noone, A., \& Krapcho, M. (2012). SEER Cancer Statistics Review, 19752009. Bethesda, MD: National Cancer Institute.

Kadan-Lottick, N. S., Robinson, L. L., Gurney, J. G., \& Neglia, J. P. (2002). Childhood Cancer Survivors' Knowledge About Their Past Diagnosis and Treatment. Journal of the Americal Medical Association, 287(14), 1832-1839. 
Kazak, A. (2005). Evidence-Based Interventions For Survivors of Childhood Cancer and Their Families. Journal of Pediatric Psychology, 30(1), 29-39.

Kazak, AE., Barakat, LP., Meeske, K., Gallagher, P., Cnaan, A., Stuber, M. (2001). Posttraumatic stress in survivors of childhood cancer and their mothers: development and validation of the Impact of Traumatic Stressors Interview Schedule (ITSIS). Journal of Clinical Psychology Medicine, 8, 307-323.

Kazak, A., Meeske, K., \& Barakat, L. (1997). Posttraumatic Stress, Family Functioning, and Social Support in Survivors of Childhood Leukemia and Their Mothers and Fathers. Journal of Consulting and Clinical Psychology, 65(1), 120-9.

Kazak, AE., Penati, B., Boyer, BA., Himelstein, B., Brophy, P., Johnson, K. (1996). A randomized controlled perspective outcome study of a psychological and pharmacological intervention protocol for procedural distress in pediatric leukemia. Journal of Pediatric Psychology, 21, 615-631.

Kupst, M., \& Richardson, C. (1995). Family Coping with Pediatric Leukemia: Ten Years After Treatment. Journal of Pediatric Psychology, 20(5), 601-17.

Li, H., Chung, O. K., \& Ho, K. Y. (2011). Coping Strategies Used by Children Hospitalized with Cancer: An Exploratory Study. Psycho-Oncology, 20(9), 969976.

Maas, C., \& Hox, J. (2005). Sufficent sample sizes for multilevel modeling. Methodology: European Journal of Research Methods for the Behavioral and Social Sciences, 85-92.

Patenaude, A., \& Kupst, M. (2005). Psychosocial Functioning in Pediatric Cancer. Journal of Pediatric Psychology, 30(1), 9-27. 
Shafer, D. (1993). Developmental Psychology: Childhood and Adolescence. Belmont: Brooks Cole Publishing.

Spirito, A., Stark, L., \& Tyc, V. (1994). Stressors and Coping Strategies Described During Hospitalization by Chronically Ill Children. Journal of Clinical Child Psychology, 23(3), 314-22.

Spirito, A., Stark, L., \& Williams, C. (1988). Development of a Brief Coping Checklist for Use with Pediatric Populations. Journal of Pediatric Psychology, 13(4), 55574.

StataCorp. (2011). Stata Statistical Software. College Station, TX: StataCorp LP.

Tyc, V., \& Mulhern, R. (1995). Chemotherapy-Induced Nausea and Emesis in Pediatric Cancer Patients: An Analysis of Coping Strategies. Journal of Pain and Symptom Management, 10(5), 338-47.

Woltman, H., Feldstain, A., MacKay, C., \& Rocchi, M. (2012). An Introduction to Hierarchical Linear Modeling. Tutorials in Quantitative Methods for Psychology, 8(1), 52-69.

Zebrack, B., \& Chesler, M. (2002). Quality of Life in Childhood Cancer Survivors. Psycho-Oncology, 11, 132-41.

Zebrack, B. \& Chesler, M. (2001). Health-Related Worries, Self-Image, and Life Outlooks of Long-Term Survivors of Childhood Cancer. Health and Social Work, 26(4), 245-256. 


\title{
CHAPTER 5
}

\section{Paper 2: Determinants of Coping in Childhood Cancer Survivors: Influence of Illness, Treatment, and Demographic Factors}

\begin{abstract}
Objectives: The purpose of this research was to determine whether type of cancer and treatment are associated with specific coping strategies.

Background: Cancer alters children's lives in many ways, beginning at diagnosis and continuing well after therapy ends. Certain combinations of demographic variables, cancer diagnosis, and treatment factors have been suggested as predictors of more difficult psychological adjustment in childhood cancer survivors. These risk factors can influence the child's coping strategies, which, in turn, can affect their overall adjustment.

Methods: One hundred and twenty-one childhood cancer survivors were examined using cross-sectional data collected at the Follow-up After Cancer Treatment (FACT) clinic at the Medical University of South Carolina. Data were obtained through administration of the Kidcope questionnaire. The outcome was defined as use of approach (0) or withdrawal coping strategies (1). Logistic regression analyses were performed to examine the child's medical diagnosis, treatment, and demographic characteristics as predictors of coping strategy.
\end{abstract}

Results: The model containing gender, diagnosis, and the two interaction terms significantly $(\mathrm{p}<.05)$ predicted withdrawal coping. Female participants had a significant increased odds of using approach coping (OR=2.27; 95\% CI: 1.04, 4.93) and participants with a diagnosis of leukemia had a greater likelihood using withdrawal coping $(\mathrm{OR}=2.91$; 95\% CI: 1.07, 7.87) controlling for treatment and treatment length. Race, age at assessment, and age at diagnosis were not observed to be significant predictors of coping.

Conclusions: The predictive model indicated that those patients who are male with a previous leukemia diagnosis and with increased duration of chemotherapy and radiation treatment are at risk for using maladaptive coping strategies. Health care professionals should seek to intervene with childhood cancer survivors at follow-up clinics who meet the criteria for being at risk for poor coping. 


\section{$\underline{\text { INTRODUCTION }}$}

Childhood cancer is the second leading cause of death, second only to accidents and is the leading cause of death by disease among children ages 0-15 (American Cancer Society, 2012). In the United States in 2013, approximately 11,630 children under the age of 15 will be diagnosed with cancer and about 1,310 children will die from the disease (American Cancer Society, 2012). Over the past 34 years, the incidence of children diagnosed with cancer has increased 33\% from 13.0 cases per 100,000 in 1975 to 17.3 cases per 100,000 in 2009 (Howlander et al., 2012). The increase in incidence is not fully understood but is due in part to better diagnostic techniques as well as an increase in environmental exposures and genetic dispositions that can lead to cancer. Conversely, mortality rates have declined 68\% over the past four decades from 6.5 per 100,000 in 1969 to 2.1 per 100,000 in 2009 (American Cancer Society, 2012), and the 5year survival rate increased from 61.7\% in 1975 to 83.1\% in 2008 (Howlander et al., 2012). These declines in mortality represent treatment related improvements. Therefore, the increased incidence rate combined with improved rates of survival has resulted in many more childhood cancer survivors. These statistics support the need for research focused on a child's short and long term adjustment to the experience of surviving cancer.

\section{Treatment for Childhood Cancer}

Given the diversity of childhood cancers, the type of treatment needed depends on the type and severity of cancer and the child's age. All childhood cancer treatments have been associated with a wide variety of short-term and long-term side effects. 
Chemotherapy and radiation therapy are the most commonly used forms of treatment for childhood cancers.

Chemotherapy medication used to kill cancer cells, can be administered intravenously or orally. The duration of chemotherapy treatment and type of drugs used depend on the patient's specific diagnosis and their response to the drugs. Radiation therapy can be used in conjunction with chemotherapy or surgery. A child who receives radiation therapy is treated with a stream of high-energy particles or waves that destroy or damage cancer cells and shrink tumors.

The possibility of second cancers represents one of the biggest worries for survivors and their parents (Zebrack et al., 2001). In fact, one study found 10\% of childhood cancer survivors reported worry about future cancer compared to $1 \%$ of children with no history of chronic medical or psychological problems (Greenberg et al., 1989). The variety in treatment, prognosis, and possible side effects for each type of cancer introduce complexities in attempting to comprehend what the child experiences and thus their need for coping strategies.

Due to advances in treatment, nearly $80 \%$ of children treated for cancer survive five years or more (American Cancer Society, 2012). Due to the increase in long-term survival, there has been an escalation in survivors experiencing late effects of treatment. Childhood cancer treatments can cause health problems that may not show up until months or even years after treatment. Specifically, two-thirds of survivors can be expected to experience at least one late effect that may impair their quality of life, while one-quarter experience a severe or life threatening late effect (Meeske et al., 2007). Age 
at diagnosis, time since diagnosis and type of treatment can all contribute simultaneously to later physical effects for cancer survivors (Zeltzer et al., 2008).

Cancer and its treatment can have a significant emotional impact on a child. Previous studies indicate that radiation therapy, chemotherapy, and surgical intervention may have long-term effects on the psychosocial well-being of survivors that can adversely affect their quality of life (Zeltzer et al., 2009; Li et al., 2011). Children can feel a range of emotions that include fear, depression, anxiety, and symptoms similar to post-traumatic stress disorder. Recent studies have indicated that childhood cancer survivors have reported lower self-esteem and higher depression and anxiety levels than healthy children (Servitzoglou et al., 2008; Recklitis et al., 2006; Michel et al., 2010; Li et al., 2011). Moreover, a recent finding from the Childhood Cancer Survivor Study indicated that childhood cancer survivors were 1.5 times more likely than their siblings to have symptoms of depression and anxiety (Schultz et al., 2007).

With the extensive list of possible long lasting psychosocial impacts of childhood cancer, it is unlikely that any child remains unchanged by the experience. Some quality of life studies have indicated that childhood cancer survivors who were diagnosed at an older age, were older at the time of inquiry, or were treated with high-intensity therapies demonstrate more negative psychosocial outcomes (Zebrack et al., 2002; Kupst et al., 1995). Therefore, ensuring healthy psychosocial well-being and enhancing quality of life in childhood cancer survivors should be a prime concern of health care professionals.

Coping

Cancer alters children's lives in many ways, beginning at diagnosis and continuing well after therapy ends. Certain combinations of demographic variables, 
disease and treatment factors, and residual physical disabilities have been suggested as predictors of more difficult psychological adjustment in childhood cancer survivors (Mulhern et al., 1989). These risk factors can influence the child's coping strategies which in turn can affect their overall adjustment. Additional studies have indicated that radiation therapy, chemotherapy, and surgical intervention may have long-term effects on the psychosocial well-being of survivors that can adversely affect their quality of life (Zeltzer et al., 2009; Li et al., 2011). The concept of coping refers to the use of cognitive, emotional, and behavioral strategies in responding to stressful situations (Lazerus et al., 1993).

The ways that children and adolescents cope are highly dependent on their psychosocial and cognitive development (Li et al., 2011). Developmental studies of coping suggest an increase in cognitive strategies and a broader range of methods for controlling distress with increasing age and cognitive maturity (Peterson et al., 1989; Altshuler et al., 1989). Age, gender, time since diagnosis, and level of distress have been shown to influence the type and number of strategies employed to manage medical stressors (Blount et al., 1991; Bull et al., 1991; Smith et al., 1989).

Although studies of coping in childhood cancer survivors have been assessed, no studies have evaluated coping in childhood cancer survivors using the Kidcope survey. Additionally, an exploratory factor analysis revealed a different factor structure for coping than previous studies have reported.

This study had three objectives. The first was to examine systematically the type of coping strategies used by children and adolescents in response to a cancer-related stressor or non-cancer-related stressor. The second objective was to determine the factor 
structure of the survey data. The final objective was to determine whether cancer diagnosis and severity of treatment influenced which coping strategies childhood cancer survivors relied on to cope with their stressor.

\section{$\underline{\text { METHODS }}$}

Subjects

One hundred thirty-nine participants were recruited from the Follow-up After Cancer Treatment (FACT) clinic between 1996 and 2011. The FACT clinic was developed as a comprehensive clinic at the Medical University of South Carolina to focus on survivors of childhood cancer and the late effects of cancer treatment. The FACT clinic is for survivors who have been disease free and off treatment for at least five years. Complete data were available for 121 participants.

The majority of participants (43.8\%) were diagnosed with acute lymphocytic leukemia (ALL); the remaining participants were diagnosed with lymphomas, solid tumors and other malignant neoplasms. The participant's age at diagnosis was 0.2-16.8 years (mean, 4.8 years). The mean age at participation was 12.39 years (range, 7-25 years). The majority of participants (72\%) were white. There was an approximately equal distribution between males (45\%) and females (55\%). Due to the varying diagnoses, participants had differing chemotherapy, radiation therapy and surgery histories.

Procedure

Childhood cancer survivors and their parents who attended the FACT clinic were approached by a child life specialist about participating in the Kidcope survey. Informed 
consent and HIPAA authorization were obtained from interested participants and their parents if the participant was a minor. Participants met individually with the child life specialist to complete the Kidcope survey. During the Kidcope survey, participants were asked to describe a stressor they recently encountered or a stressor related to their cancer experience. Then, participants were instructed to rate each coping strategy according to the frequency with which they used a particular coping strategy and the perceived efficacy of each strategy endorsed. The study was approved by the Medical University of South Carolina Institutional Review Board.

\section{Measures}

The Kidcope questionnaire is a self-report measure designed to assess cognitive and behavioral coping strategies employed by children and adolescents (Spirito et al., 1988). The Kidcope survey assesses the use of ten specific coping strategies including: distraction, social withdrawal, cognitive restructuring, self-criticism, blaming others, problem solving, emotional regulation, wishful thinking, social support, and resignation.

There are two versions of the Kidcope survey, a 15-item younger version is appropriate for children ages 7-12, while the 10-item version is for adolescents ages 1318. On the younger version of the Kidcope survey, only a "yes/no” response is required for frequency and a three-point Likert-type scale ranging from "not at all” to "a lot” is employed for efficacy. On the adolescent version, a four-point Likert-type scale ranging from "not at all” to "almost all the time” is used to assess frequency and a five-point scale ranging from "not at all” to "very much" is employed to examine efficacy. In order to make the two versions of the Kidcope survey compatible for statistical analysis, responses on the frequency scale were recoded into "not used” versus "used", such that 
frequency indicates selection of a coping strategy at least some of the time (Spirito et al, 1994; Tyc et al. 1995). Additionally, responses on the efficacy scale were recoded into “not effective”, "little effective”, and “a lot effective” (Spirito et al, 1994; Tyc et al. 1995).

Moderate test-retest correlation coefficients have been reported for the Kidcope survey for periods up to two weeks. Criterion validity was assessed using the Coping Strategies Inventory (CSI) and the Adolescent-Coping Orientation for Problem Experiences ACOPE) scale (Spirito et al., 1988). Correlations between items on the Kidcope survey and on the CSI and ACOPE were statistically significant and therefore providing evidence for criterion validity.

\section{Statistical Analysis}

Analyses were performed using StataSE 12 (StataCorp, 2011). The first phase of the data analysis was descriptive. A chi square analysis was undertaken to compare the type of stressor reported (cancer-related or non-cancer-related) and the coping strategies utilized to manage those stressors. Correlational analyses were also conducted to determine which, if any, of the covariates of interest were associated with coping.

The objective of the second phase was to determine the factor structure of the current data sample. When viewing coping as a reflective concept and the Kidcope questionnaire as a reflective measure, the most common approach analyze the items is to identify the factor structure of a measure (Holen et al., 2012). Factor analysis allows determination of the number of constructs or latent variables underlie a set of items (Netermeyer et al., 2003). The factor structure of Kidcope survey was analyzed, using two different approaches. Confirmatory factor analysis was used to assess the adequacy 
of model fit using the factor structures determined in previous research. Assuming that no previous proposed model yielded a good fit to the data, exploratory factor analyses would be performed to establish the number of factors and the structure that fitted the sample best. Exploratory factor analysis is used to explore the dimensionality of a measurement instrument by finding the smallest number of interpretable factors needed to explain the correlations among a set of variables (Netermeyer et al, 2003). To validate the proposed factor structure, a simultaneous confirmatory factor analysis was conducted. The goodness of fit of the models was assessed using the comparative fit index (CFI), Tucker Lewis index (TLI), and the root mean square error of approximation (RMSEA). The chi square values were also reported. Yu (2002) proposed the following cutoff values as indicative of good fit when using binary outcomes: CFI $\geq .96, T L I \geq 95$, and RMSEA $\leq .05$.

The final phase of the analysis was to identify factors associated with coping. The eight coping strategies were dichotomized into approach (0) or withdrawal (1) coping based on the results of the exploratory factor analysis. Backwards stepwise logistic regression analyses tested the following covariates: age at assessment (7-12 years versus 13-25 years), age at diagnosis (years), gender (male versus female), race (white versus black), length of treatment ( $<12$ months versus $\geq 12$ months), treatment type (chemotherapy versus chemotherapy and radiation), and diagnosis (leukemia versus all other cancers). Variables with a p-value of $<0.2$ were retained until the best predictive model was developed. Results are reported as odds ratios, where odds ratios greater than 1.0 reflect an increased likelihood of more frequent use of either approach or withdrawal coping strategies. 


\section{$\underline{\text { RESULTS }}$}

\section{Kidcope Factor Analysis}

First, confirmatory factor analyses were performed to assess the adequacy of factor structures from previous studies. Model development was based on either traditional or well-documented models of coping proposed from studies with children or actual factor structures based on previous studies using the Kidcope survey. Four models were tested (see Table 1): A two-factor model including emotion-focused and problemfocused coping (Lazerus \& Folkman, 1984), a two-factor model including escape and control-oriented coping (Cheng \& Chan, 2003), a three-factor model that included avoidant, negative, and active coping (Spirito et al., 1994), and a two-factor model including avoidant and approach coping (Spirito et al,. 1996). The fit for all models was poor (CFI range $=.71-.84$ and TLI range $=.61-.77)$.

Since no model proposed by the previous literature yielded a good fit to the data, exploratory factor analyses were conducted to establish the most suitable number of factors. The exploratory factor analysis and confirmatory factor analysis were performed simultaneously on the entire sample due to the limited sample size. Criteria for determining factor solutions of the Kidcope included factor loadings $\geq .35$ and eigenvalues $\geq 1.0$ (Vernberg et al., 1996; Vigna et al., 2010).

Analyses were conducted forcing two and three factors, as indicated by previous literature. Initial results produced a three-factor structure; however, two items cross loaded on two or more factors (self-criticism and blaming others) and were deleted from further analyses as suggested by Vernberg et al. (1996). A second exploratory factor 
analysis was conducted with the remaining eight items resulting in a two-factor structure with a correlation of .10 between the factors. The first factor accounted for $21.8 \%$ of the variance and included four items (cognitive restructuring=.67, problem solving=.59, emotional regulation=.41, social support=.72). This factor was labeled as approach coping, because all of the items involved efforts to maintain or regain a positive emotional or cognitive state. The second factor accounted for $17 \%$ of the variance and contained four items (distraction=.50, social withdrawal=.67, wishful thinking=.53, resignation=.53). This factor was labeled withdrawal coping. Confirmatory factor analyses showed that this two-factor model fit the data (CFI=.96, TLI=.92, RMSEA=.03, $\left.\chi^{2}(13)=16.76, p=.211\right)$. Overall approach and withdrawal coping scores were calculated by summing the scores for each of the four specific strategies that comprise approach and withdrawal coping (Spirito et al., 1988).

\section{Stressor}

Overall, emotional regulation (94\%) and distraction (91\%) were the most used coping strategies. The least used strategy was social withdrawal (50\%). The complete frequencies of coping strategy endorsement by stressor type listed in table 2 indicate that there were no statistically significant differences between the two stressor groups. Furthermore, using the outcome of interest obtained from the exploratory factor analysis, $39 \%$ of all participants reported using withdrawal strategies and $61 \%$ used approach strategies to cope. In relation to stressor reported, $35 \%$ of those who reported a cancerrelated stressor (i.e. needles, hair loss, or hospital) used withdrawal coping strategies and $65 \%$ used approach coping strategies to manage their stressor. For those participants who reported a non-cancer-related stressor (i.e. family, school, or peers), 48\% used 
withdrawal strategies and 52\% used approach strategies to cope. The difference between the groups was not statistically significant. The mean number of coping strategies used by participants was $6.36(\mathrm{SD}=1.15)$.

\section{Correlations}

Correlational analyses were conducted for the predictor and outcome variables of interest. Analyses indicated that none of the associations between the predictor variables and coping outcome were significant, indicating that coping and potential moderators were independent of one another. There were, however, positive correlations between diagnosis and treatment length $(r=0.45, \mathrm{p}<.001)$ and between diagnosis and treatment type $(r=0.68, \mathrm{p}<.001)$.

\section{Logistic regression}

A logistic regression analysis was conducted to predict coping strategy use for 121 childhood cancer survivors using treatment length, treatment type, diagnosis, gender, age, age at diagnosis, and race as predictors. Dummy variables were created for age, race, and diagnosis. Based on the findings from the correlational analysis, two interaction terms (diagnosis*treatment length; diagnosis*treatment type) were also added to the model. A test of the full model against a constant only model was statistically significant, indicating that the predictors as a set reliably distinguished between use of withdrawal and approach coping $\left(\chi^{2}(4)=9.57, \mathrm{p}<.05\right)$. The Wald criterion demonstrated that gender, diagnosis, and the two interaction terms made a significant contribution to prediction. Race and age were not significant predictors. An analysis of the contribution of each covariate to outcome revealed that four had a significant independent 
relationships, namely gender, diagnosis, diagnosis*treatment type, and diagnosis*treatment length. Results of the Hosmer-Lemeshow test suggested good fit of the model $\left(\chi^{2}(8)=2.27, \mathrm{p}=.972\right)$.

Collinearity diagnostics were performed to determine if multicollinearity was present in the model. The tolerance values were .97 for gender, .73 for the interaction variable of diagnosis and treatment length, .35 for diagnosis, and .35 for the interaction variable of diagnosis and treatment. Additionally, the mean variance inflation factor was 1.89. Thus, according to Menard et al. (1995), multicollinearity was not a problem.

Odds ratios were calculated to examine the influence of covariates on approach/withdrawal coping. Female participants had a greater likelihood of belonging to the approach coping group (OR=2.27; 95\% CI: 1.04, 4.93) and participants with a diagnosis of leukemia had a greater likelihood of belonging to the withdrawal coping group (OR=2.91; 95\% CI: 1.07,7.87).

\section{DISCUSSION}

The purpose of this study was to explore cancer diagnosis and treatment variables in relation to coping strategies employed by children and adolescents in order to obtain a predictive model of coping. These relationships were studied using brief survey completed by childhood cancer survivors attending a follow-up clinic.

Confirmatory factor analysis of several factor structures from previous research revealed that none of these structures provided a good fit for the data. Exploratory factor analyses were conducted to explore alternative factor structures for the Kidcope questionnaire. This analysis indicated that the structure of two coping factors corresponded moderately with the current data. Ideally, an exploratory factor analysis 
would have been conducted using half the sample and confirmatory factor analysis on the remaining half. However, the sample was too small to apply this methodology. Furthermore, the Kidcope survey was not originally developed to meet the requirements of factor analysis. In particular, its small number of items (i.e., 10 on adolescent version; 15 on child version), which are not necessarily highly correlated, makes factor analysis a challenge, and therefore the results tend to not be consistent over samples and time. Moreover, Edgar \& Skinner (2003) argue that dichotomizing coping strategies may neglect to account for the fact that people may use both avoidant and approach strategies in managing a single situation.

There are several studies which examined the relationship between use of approach and avoidant coping strategies and adjustment in children and adolescents. Reid et al. (1995) reported higher levels of approach coping strategy use and lower levels of avoidant strategy use were related to positive adjustment. Additionally, studies of sick children adjusting to their own chronic illness found avoidance coping strategies were associated with negative adjustment, and approach coping strategies were associated with positive adjustment (Aldridge \& Roesch, 2007). Since adjustment was not directly measured, only assumptions can be made regarding adjustment based on coping strategy use.

Overall, the results indicated that preference for a particular coping strategy depends, in part, on the participant's medical diagnosis as well as the type of treatment, treatment length, and gender of the participant. Having leukemia, being treated with both chemotherapy and radiation therapy and a longer duration of treatment are all predictors of negative, withdrawal coping. There have been conflicting accounts in the literature 
regarding the relationship between diagnosis and adjustment/coping. Bomen et al. (2000) stated patients with leukemia were better copers than those patients with solid tumors. Whereas, Koocher \& O’Malley (1981) reported that survivors of acute lymphocytic leukemia had a higher incidence of adjustment problems.

In this sample leukemia survivors tended to use withdrawal coping strategies more than approach coping. However, this may be related to length of treatment. Participants with leukemia had an average treatment length of 26.4 months compared to 10.8 months for those participants diagnosed with a different type of cancer. Previous literature has also suggested that patients tend to adopt positive coping strategies with increased experience (Tyc et al., 1995). For many of the participants in the sample, the data obtained for this study was during their first visit to the FACT clinic, therefore, their knowledge and use of coping strategies could be limited.

Significant gender differences were found in coping strategy. Female participants were more likely to use approach coping. This is inconsistent with previous research. Bull \& Drotar (1991) noted that girls demonstrated more emotion-focused management (similar to withdrawal coping) when dealing with cancer-related stressors, whereas boys engaged in more problem-solving (similar to approach coping). The gender differences in coping could be related to cancer type. Eighty-three percent of males were diagnosed with Non-Hodgkins Lymphoma (NHL) compared to $17 \%$ of females $\left(\chi^{2}(1)=7.70\right.$, $\mathrm{p}<.01$ ). Patients diagnosed with NHL tend to be diagnosed at an older age compared to the age of diagnosis for other types of childhood cancer (American Cancer Society, 2012). Seventy-three percent of participants with NHL were diagnosed at five years of age or older and, therefore, the time from diagnosis to assessment was shorter. Previous 
studies have reported that a younger age at diagnosis and a longer time lapse between diagnosis and investigation were related to better coping (Bomen et al., 2000; Koocher \& O’Malley, 1981).

Cancer type, type of treatment and treatment length appear to influence how survivors cope with the illness experience and could have practical clinical implications. Avoidance, or withdrawal coping, has been predictive of depression and anxiety in children and adolescents in remission (Frank et al., 1997). Identification of patients using negative coping strategies and intervening to improve coping could improve long-term outcomes. 
Table 1: Overview of coping factors and corresponding coping strategies as described by different authors

\begin{tabular}{lll}
\hline \multicolumn{1}{c}{ Authors } & \multicolumn{1}{c}{ Coping Factors } & \multicolumn{1}{c}{ Coping Strategies } \\
\hline \hline Lazerus \& Folkman (1984) & Emotion-focused coping & $\begin{array}{l}\text { Distraction, social withdrawal, self-criticism, blaming } \\
\text { others, wishful thinking, resignation, wishful thinking } \\
\text { Problem solving, social support, emotional regulation, } \\
\text { cognitive restructuring }\end{array}$ \\
\hline Cheng \& Chan (2003) & Eroblem-focused coping & $\begin{array}{l}\text { Distraction, social withdrawal, self-criticism, blaming } \\
\text { others, wishful thinking, resignation, emotional outburst } \\
\text { Cognitive restructuring, problem solving, social support, } \\
\text { relaxation }\end{array}$ \\
\hline Spirito et al. (1994) & Avoidant coping & $\begin{array}{l}\text { Distraction, social withdrawal, wishful thinking, } \\
\text { resignation } \\
\end{array}$ \\
& Negative coping & $\begin{array}{l}\text { Self-criticism, blaming others } \\
\text { Problem solving, emotional expression cognitive } \\
\text { restructuring, social support }\end{array}$ \\
& Active coping & $\begin{array}{l}\text { Distraction, wishful thinking, blaming others, } \\
\text { resignation } \\
\text { Problem solving, social support, cognitive restructuring, } \\
\text { emotional regulation }\end{array}$ \\
\hline Spirito et al. (1996) & Avoidant coping & \\
& Approach coping &
\end{tabular}

Table 2: Demographic, Diagnosis, and Treatment Characteristics of Interest

\begin{tabular}{|c|c|c|}
\hline Variables & $\mathbf{n}$ & $\%$ \\
\hline \multicolumn{3}{|l|}{ Gender } \\
\hline Male & 61 & 43.9 \\
\hline Female & 78 & 56.1 \\
\hline \multicolumn{3}{|l|}{ Race } \\
\hline Caucasian & 92 & 71.3 \\
\hline African American & 32 & 24.8 \\
\hline Other & 5 & 3.9 \\
\hline \multicolumn{3}{|l|}{ Age at initial assessment } \\
\hline $7-12$ & 87 & 62.6 \\
\hline $13-17$ & 37 & 26.6 \\
\hline $18+$ & 15 & 10.8 \\
\hline \multicolumn{3}{|l|}{ Diagnosis } \\
\hline AML \& ALL & 68 & 49.6 \\
\hline Lymphomas & 16 & 11.7 \\
\hline Neuroblastoma & 10 & 7.3 \\
\hline Sarcomas & 17 & 12.4 \\
\hline Wilm’s Tumor & 17 & 12.4 \\
\hline Other & 9 & 6.6 \\
\hline \multicolumn{3}{|l|}{ Treatment } \\
\hline Chemotherapy alone & 135 & 98.5 \\
\hline Chemotherapy and radiation & 55 & 39.6 \\
\hline Chemotherapy and Surgery & 67 & 48.2 \\
\hline Chemotherapy, Radiation and Surgery & 38 & 27.3 \\
\hline \multicolumn{3}{|l|}{ Treatment Length } \\
\hline$<12$ months & 51 & 38.3 \\
\hline 12 months + & 82 & 61.7 \\
\hline
\end{tabular}


Table 3: Percentages of children and adolescents reporting on the endorsement of Kidcope strategies utilized for cancer related and non-cancer related stressors.

\begin{tabular}{lrrrr}
\hline \multicolumn{1}{c}{ Kidcope Coping Strategy } & $\begin{array}{c}\text { All Surveys } \\
(\mathbf{n = 1 3 9 )}\end{array}$ & $\begin{array}{c}\text { Cancer } \\
\text { Stressor } \\
(\mathbf{n}=\mathbf{9 7})\end{array}$ & $\begin{array}{c}\text { Non-Cancer } \\
\text { Stressor } \\
(\mathbf{n = 4 2 )}\end{array}$ & $\begin{array}{c}\text { Chi- } \\
\text { Squared } \\
\text { p-value }\end{array}$ \\
\cline { 2 - 4 } & \multicolumn{1}{c}{ Frequency } & Frequency & \multicolumn{1}{c}{ Frequency } & \\
\hline \hline Emotional Regulation & 94.2 & 91.8 & 100.0 & .055 \\
Distraction & 91.4 & 92.8 & 88.1 & .366 \\
Social Support & 87.8 & 89.7 & 83.3 & .293 \\
Cognitive Restructuring & 84.9 & 84.5 & 85.7 & .859 \\
Wishful Thinking & 77.0 & 75.3 & 81.0 & .464 \\
Problem Solving & 75.5 & 72.2 & 83.3 & .160 \\
Resignation & 74.8 & 78.4 & 66.7 & .145 \\
Social Withdrawal & 50.4 & 45.4 & 61.9 & .073 \\
\hline
\end{tabular}

*Percentages refer to children reporting they used a strategy ("yes" or "no") and adolescents who used the strategy, "sometimes", "a lot of the time", or "almost all of the time" (Frequency); and those children who rated it as helpful "a lot of the time" and adolescents who rated it "pretty much" and "very much" helpful (Efficacy).

Table 4: Association Between Covariates and Coping Final Model

\begin{tabular}{lrrrr}
\hline Variables & Estimate & \multicolumn{1}{c}{ SE } & OR & 95\% CI \\
\hline Intercept & -1.54 & .78 & & \\
Gender & -.82 & .40 & 2.27 & $(1.04,4.93)$ \\
Diagnosis & 1.07 & .72 & 2.91 & $(1.07,7.87)$ \\
Diagnosis*Treatment Type & .07 & .04 & 1.07 & $(.99,1.17)$ \\
Diagnosis*Treatment Length & .01 & .01 & 1.01 & $(.99,1.02)$ \\
\hline
\end{tabular}




\section{REFERENCES}

Altshuler, J., \& Ruble, D. (1989). Developmental Changes in Children's Awareness of Strategies for Coping with Uncontrollable Stress. Child Development, 60, 13371349.

American Cancer Society. (2012). Cancer Facts and Figures 2012. Atlanta: American Cancer Society.

Blount, R., Landolf-Fritsche, B., \& Powers, S. (1991). Differences Between High and Low Coping Children and Between Parent and Staff Behaviors During Painful Medical Procedures. Journal of Pediatric Psychology, 16(6), 795-810.

Boman, K. (2000). Long-Term Coping in Childhood Cancer Survivors: Influence of Illness, Treatment, and Demographic Background Factors. Acta Paediatr, 89, 105-111.

Bull, B., \& Drotar, D. (1991). Coping with Cancer in Remission: Stressors and Strategies Reported by Children and Adolescents. Journal of Pediatric Psychology, 16(6), 767-82.

Cheng, S.-T., \& Chan, A. M. (2003). Factorial Structure of the Kidcope in Hong Kong Adolescents. The Journal of Genetic Psychology, 164(3), 261-266.

Frank, N.C., Blount, R.L., Brown, R.T. (1997). Attributions, coping, and adjustment in children with cancer. Journal of Pediatric Psychology,16, 643-663.

Greenberg, H., Kazak, A., \& Meadows, A. (1989). Psychologic Functioning in 8-to-16year-old Cancer Survivors and Their Parents. J Pediatr, 114, 488-93. 
Holen, S., Lervag, A., Waaktaar, T., \& Ystgaard, M. (2012). Exploring the Associations Between Coping Patterns for Everyday Stressors and Mental Health in Young Schoolchildren. Journal of School Psychology, 167-193.

Howlander, N., Noone, A., \& Krapcho, M. (2012). SEER Cancer Statistics Review, 19752009. Bethesda, MD: National Cancer Institute.

Koocher, G., O'Malley, J., \& Gogan, J. (1979). Psychological Adjustment Among Pediatric Cancer Survivors. J Child Psychol Psychiat, 21, 163-73.

Koocher, GP., O'Malley, JE. (1981). The Damocles Syndrome: Psychosocial Consequences of Surviving Childhood Cancer. New York: McGraw-Hill

Kupst, M., \& Richardson, C. (1995). Family Coping with Pediatric Leukemia: Ten Years After Treatment. Journal of Pediatric Psychology, 20(5), 601-17.

Lazarus, R. (1993). Coping Theory and Research: Past, Present and Future. Psychosomatic Medicine, 55, 234-47.

Lazarus, R.S. \& Folkman, S. (1984). Stress, Appraisal and Coping. New York: Springer. Li, H., Chung, O. K., \& Ho, K. Y. (2011). Coping Strategies Used by Children Hospitalized with Cancer: An Exploratory Study. Psycho-Oncology, 20(9), 969976.

Meeske, K., Patel, S., \& Palmer, S. (2007). Factors Associated with Health-Related Quality of Life in Pediatric Cancer Survivors. Pediatr Blood Cancer, 49, 298-305. Michel, G., Rebholz, C., \& al., e. (2010). Psychological Distress in Adult Survivors of Childhood Cancer: The Swiss Childhood Cancer Survivor Study. J Clin Oncol, 28(10), 1740-1748. 
Mulhern, R. A. (1989). Social Competence and Behavioral Adjustment of Children Who Are Long-Term Survivors of Cancer. Pediatrics, 83(1), 18-25.

Netemeyer, R. G., Bearden, W. O., \& Sharma, S. (2003). Scaling Procedures: Issues and Applications. Thousand Oaks: Sage Publications.

Peterson, L. (1989). Coping by Children Undergoing Stressful Medical Procedures: Some Conceptual, Methodological, and Therapeutic Issues. Journal of Counsulting and Clinical Psychology, 57(3), 380-387.

Recklitis, C., Diller, L., \& Najita, J. (2006). Suicide Ideation in Adult Survivors of Childhood Cancer: A Report from the Childhood Cancer Survivor Study. J Clin Oncol, 24(24), 3852-3857.

Reid, G.J., Dubow, E.F. \& Carey, T.C. (1995). Differential and situational differences in coping among children and adolescents with diabetes. Journal of Applied Developmental Psychology, 16, 529-554.

Schultz, K., Ness, K., \& Whitton, J. (2007). Behavioural and Social Outcomes in Adolescent Survivors of Childhood Cancer: A Report from the Childhood Cancer Survivor Study. J Clin Oncol, 25(24), 3649-3656.

Servitzoglou, M., Papadatou, D., \& Tsiantis, I. (2008). Psychosocial Functioning of Young Adolescent and Adult Survivors of Childhood Cancer. Support Care Cancer, 16, 29-36.

Smith, K., Ackerson, J., \& Blotcky, A. (1989). Reducing Distress During Invasive Medical Procedures: Relating Behavioral Interventions to Preferred Coping Style in Pediatric Cancer Patients. Journal of Pediatric Psychology, 14, 405-19. 
Spirito, A., Francis, G., \& Overholser, J. (1996). Coping, Depression, and Adolescent Suicide Attempts. Journal of Clinical Child Psychology, 25(2), 147-55.

Spirito, A., Stark, L., \& Tyc, V. (1994). Stressors and Coping Strategies Described During Hospitalization by Chronically Ill Children. Journal of Clinical Child Psychology, 23(3), 314-22.

Spirito, A., Stark, L., \& Williams, C. (1988). Development of a Brief Coping Checklist for Use with Pediatric Populations. Journal of Pediatric Psychology, 13(4), 55574.

StataCorp. (2011). Stata Statistical Software. College Station, TX: StataCorp LP.

Tyc, V., \& Mulhern, R. (1995). Chemotherapy-Induced Nausea and Emesis in Pediatric Cancer Patients: An Analysis of Coping Strategies. Journal of Pain and Symptom Management, 10(5), 338-47.

Yu, C. (Evaluating cutoff criteria of model fit indices for latent variable models with binary and continuous outcomes). 2002. Univeristy of California, Los Angelos: Doctoral dissertation.

Zebrack, B. (2001). Health-Related Worries, Self-Image, and Life Outlooks of LongTerm Survivors of Childhood Cancer. Health and Social Work, 26(4), 245-256.

Zebrack, B., \& Chesler, M. (2002). Quality of Life in Childhood Cancer Survivors. Psycho-Oncology, 11, 132-41.

Zeltzer, L. (2009). Psychological Status in Childhood Cancer Survivors: A Report From the Childhood Cancer Survivor Study. Journal of Clinical Oncology, 27(14), 2396-2404. 
Zeltzer, L., Qian, L., \& Leisenring, W. (2008). Psychosocial Outcomes and HealthRelated Quality of Life In Adult Childhood Cancer Survivors: A Report from the Childhood Cancer Survivor Study. Cancer Epidemiol Biomarkers Prev, 17, 435446. 


\title{
CHAPTER 6
}

\section{Paper 3: Determinants of Coping Endorsement and Efficacy in Childhood Cancer Survivors: Influences of Demographic and Family Structure Factors}

\begin{abstract}
Objectives: The purpose of this research was to examine the impact of family characteristics (household structure, median household income, and siblings) on the endorsement and efficacy of coping strategies utilized to cope with a stressor.

Background: Coping is a process that can enhance or hinder adjustment and quality of life in children with cancer. Previous studies have indicated that children and adolescents who cope well had higher socioeconomic status, stable parental marital status, high family support, and open family communication.

Methods: One hundred and twenty-two childhood cancer survivors were examined using cross-sectional data collected at the Follow-up After Cancer Treatment (FACT) clinic at the Medical University of South Carolina. Data were obtained through the administration of the Kidcope questionnaire. Linear and logistic regression analyses were performed to examine the two outcomes of interest: mean coping efficacy and use of withdrawal (0) or approach (1) coping strategies. Predictor variables of interest were household structure, median household income, and presence of siblings. Additional variables of gender, race, and age were controlled for in analyses. The following interactions were tested: household structure $\mathrm{x}$ race, household structure $\mathrm{x}$ income, and income $\mathrm{x}$ race.

Results: Results of the logistic regression revealed that the model containing gender, median household income and the interaction term of household $\mathrm{x}$ race significantly $(\mathrm{p}<.05)$ predicted approach coping. Female participants (OR=2.64; 95\% CI: 1.17, 5.97), participants from a two parent household (OR=2.13; 95\% CI: 1.06, 7.19), and those participants who had a median household income of $\geq \$ 50,000$ (OR=1.88; 95\% CI: 1.06, 2.65) had a greater likelihood of using approach coping. Results of the linear regression revealed that the model containing median household income, age at assessment, household structure, and siblings significantly $(\mathrm{p}<.05)$ predicated mean coping efficacy.

Conclusions: There was a direct association between family and household variables and coping outcomes indicating that a stronger family structure was associated with positive coping. Specifically, female Caucasian participants who were older at the time of assessment and from two parent households with higher socioeconomic status reported approach-based coping.
\end{abstract}




\section{$\underline{\text { INTRODUCTION }}$}

In the United States in 2013, approximately 11,630 children under the age of 15 will be diagnosed with cancer and about 1,310 children will die from the disease (American Cancer Society, 2012). During the past 34 years, the incidence of children diagnosed with cancer has increased 33\% from 13.0 cases per 100,000 in 1975 to 17.3 cases per 100,000 in 2009 (Howlander et al., 2012). During this same time period, the death rate of those diagnosed declined dramatically which explains an increased rate of survival. The 5-year survival rate increased from $61.7 \%$ in 1975 to $83.1 \%$ in 2008 (Howlander et al., 2012). The increased incidence of cancer necessitates research that determines ways to mitigate the effects of invasive procedures, evaluates children's coping processes, and identifies psychological or behavioral interventions (Patenaude et al., 2005).

The successful medical treatment of children with cancer has greatly increased their survival rates. Reports have indicated that $75 \%$ of children and adolescents diagnosed with cancer in the United States are likely to achieve a relatively normal life span (Zebrack et al., 2002). This set of circumstances has resulted in more childhood cancer survivors and thus a greater need to study the adjustment of children who survived cancer.

Compared to children from two-parent households, childhood cancer survivors from single-parent households had increased risk of school problems and showing fearful, inhibited, or over controlled behavior (Mulhern et al., 1989). Single parents have more difficulty meeting their children's medical and academic needs than do parents with a spouse to rely on, potentially making the child more vulnerable to problems in school 
and other settings (Mulhern et al., 1989). Reports also indicate that children's quality of life is often correlated strongly with parent's sense of their own levels of support as well as their own socioeconomic status, education, and emotional function (Parsons et al., 1998). Furthermore, characteristics such as low family income, low maternal education and absence of either their biological parent placed children with health conditions at risk for behavioral problems (Gortmaker et al., 1990; Lavigne et al., 1993). This suggests family characteristics may have an important impact on a child's ability to cope and the types of coping strategies they use.

Additional studies have indicated family variables have been found to correlate with adjustment or coping in long-term cancer survivors (Kupst et al., 1988; Kupst et al., 1995; Silver et al., 1999). The longitudinal studies by Kupst et al. (1988; 1995) followed children who all had the same diagnosis and were treated at the same time thus variables such as severity, medical status and type of treatment were all held constant giving these studies increased strength in their findings. The results of these two studies were consistent indicating childhood cancer survivors demonstrating positive coping were from families with higher socioeconomic status, stable parental marital status, high family support, and open family communication.

Evidenced by previous studies, coping is a process influenced by family variables, which can enhance or hinder adjustment and quality of life in childhood cancer survivors. This study of childhood cancer survivors examined coping in relation to demographic factors, household, and family characteristics. 


\section{$\underline{\text { METHODS }}$}

\section{Subjects}

One hundred thirty-nine participants were recruited from the Follow-up After Cancer Treatment (FACT) clinic between 1996 and 2011. The FACT clinic was developed as a comprehensive clinic at the Medical University of South Carolina to focus on survivors of childhood cancer and the late effects of cancer treatment. The FACT clinic is for survivors who have been disease free and off treatment for at least five years. Complete data were available for 122 participants.

The participant's age at diagnosis was 0.2-16.8 years (mean, 4.8 years). The mean age at participation was 12.39 years (range, 7-25 years). The majority of participants (72\%) were white. There was an approximately equal distribution between males (45\%) and females (55\%). Further demographic, family, and household variables are displayed in table 1.

\section{Procedure}

Childhood cancer survivors and their parents who attended the FACT clinic were approached by a child life specialist about participating in the Kidcope survey. Informed consent and HIPAA authorization were obtained from interested participants and their parents if the participant was a minor. Participants met individually with the child life specialist to complete the Kidcope survey. During the Kidcope survey, participants were asked to describe a stressor they recently encountered or a stressor related to their cancer experience. Then, participants were instructed to rate each coping strategy according to the frequency with which they used a particular coping strategy and the perceived 
efficacy of each strategy endorsed. The study was approved by the Medical University of South Carolina Institutional Review Board.

\section{Measures}

The Kidcope questionnaire is a self-report measure designed to assess cognitive and behavioral coping strategies employed by children and adolescents (Spirito et al., 1988). The Kidcope survey assesses the use of ten specific coping strategies including: distraction, social withdrawal, cognitive restructuring, self-criticism, blaming others, problem solving, emotional regulation, wishful thinking, social support, and resignation.

There are two versions of the Kidcope questionnaire, a 15-item younger version is appropriate for children ages 7-12, while the 10-item version is for adolescents ages 1318. On the younger version of the Kidcope survey, only a "yes/no" response is required for frequency and a three-point Likert-type scale ranging from "not at all” to "a lot” is employed for efficacy. On the adolescent version, a four-point Likert-type scale ranging from "not at all" to "almost all the time" is used to assess frequency and a five-point scale ranging from "not at all” to "very much" is employed to examine efficacy. In order to make the two versions of the Kidcope survey compatible for statistical analysis, responses on the frequency scale were recoded into "not used" versus "used", such that frequency indicates selection of a coping strategy at least some of the time (Spirito et al, 1994; Tyc et al. 1995). Additionally, responses on the efficacy scale were recoded into "not effective”, "little effective”, and “a lot effective” (Spirito et al, 1994; Tyc et al. 1995). Coping efficacy was determined from the answers to the questions on the Kidcope section: "How much did it help," referring to whether coping strategy endorsement was beneficial or not. 
Moderate test-retest correlation coefficients have been reported for the Kidcope questionnaire for periods up to two weeks. Criterion validity was assessed using the Coping Strategies Inventory (CSI) and the Adolescent-Coping Orientation for Problem Experiences ACOPE) scale (Spirito et al., 1988). Correlations between items on the Kidcope survey and on the CSI and ACOPE were statistically significant and therefore providing evidence for criterion validity.

\section{Statistical Analysis}

Analyses were performed using StataSE 12 (StataCorp, 2011). The first phase of the data analysis was descriptive. Correlational analyses were also conducted to determine which, if any, of the covariates of interest were associated with coping strategy endorsement and coping efficacy.

The second phase of the analysis was to identify factors associated with coping. The eight coping strategies were dichotomized into approach (1) or withdrawal (0) coping based on the results of the exploratory factor analysis from a previous study. Backwards stepwise logistic regression analyses tested the following covariates: age at assessment, gender (male versus female), race (white versus black), median household income ( $<\$ 50,000$ versus $\geq \$ 50,000$ ), household structure (who the participant lives with) and siblings. Variables with a p-value of $<0.2$ were retained until the best predictive model was developed. Results are reported as odds ratios, where odds ratios greater than 1.0 reflect an increased likelihood of more frequent use of approach coping strategies.

The final phase of the analysis was to identify factors associated with coping efficacy. Coping efficacy was calculated by taking the mean efficacy for the ten coping strategies. Multiple linear regression analyses tested the following covariates: age at 
assessment, gender (male versus female), race (white versus black), socioeconomic status, presence of siblings, and household structure referring to who the participant lived with. As an indicator of socioeconomic status, zip codes obtained from the participant's medical record were used to acquire estimates of median household income from the American Community Survey (U.S. Census Bureau, 2011).

\section{$\underline{\text { RESULTS }}$}

Correlational analyses were conducted for the predictor and outcome variables of interest. There were positive correlations between race and household structure $(r=0.22$, $\mathrm{p}<.005)$ and between gender and siblings $(r=0.20, \mathrm{p}<.05)$. A negative correlation was found between race and income $(r=-0.22, \mathrm{p}<.01)$. Furthermore, income was negatively correlated with use of withdrawal coping $(r=-0.31, \mathrm{p}<.001)$ and household structure was negatively correlated with coping efficacy $(r=-0.19, \mathrm{p}<.05)$.

\section{Coping strategy endorsement}

A logistic regression analysis was conducted to predict coping for 122 childhood cancer survivors using age at assessment, gender, race, median household income, household structure, and siblings as predictors. Dummy variables were created for age, race, household structure, and median household income. Based on the findings from the correlational analysis, two interaction terms (median household income x race; household structure $\mathrm{x}$ race) were also added to the model. A test of the full model against a constant only model was statistically significant, indicating that the predictors as a set reliably distinguished between withdrawal and approach coping $\left(\chi^{2}(3)=9.56, \mathrm{p}<.05\right)$. The Wald criterion demonstrated that three independent variables made a significant contribution to 
prediction, namely gender, median household income, and household structure x race (Table 2). Age, household income, and siblings were not significant predictors. Results of the Hosmer-Lemeshow test suggested good fit of the model $\left(\chi^{2}(6)=6.21, \mathrm{p}=.40\right)$.

Collinearity diagnostics were performed to determine if multicollinearity was present in the model. The tolerance values were .97 for the interaction variable of household structure and race, .93 for gender, and .93 for median household income. Additionally, the mean variance inflation factor was 1.05. Thus, according to Menard et al. (1995), multicollinearity was not a problem.

Odds ratios were calculated to examine the influence of covariates on approach/withdrawal coping. Female participants (OR=2.64; 95\% CI: 1.17, 5.97), participants from a two parent household (OR=2.13; 95\% CI: 1.06, 7.19), and those participants who had a median household income of $\geq \$ 50,000$ (OR=1.88; 95\% CI: 1.06 , 2.65) had a greater likelihood of using approach coping.

\section{Coping efficacy}

Linear regression analyses were conducted to predict coping efficacy. Demographic and family variables significantly predicted coping efficacy $\left(\mathrm{R}^{2}=.10\right.$, $F(4,117)=3.33, p<0.05$, table 3$)$. Household structure and age were the only significant predictors of coping efficacy. Neither, gender, race, siblings, and median household income nor any interaction terms attained statistical significance in this model.

\section{DISCUSSION}

The purpose of this study was to explore family and household variables in relation to coping strategies employed by children and adolescents in order to obtain a 
predictive model of coping. Significant associations among family and household variables and coping outcomes indicated that a stronger family structure was associated with positive coping. A strong family structure refers to two-parent households, higher socioeconomic status, and the presence of siblings.

Overall, female Caucasian participants from two parent households with a median household income of $\geq \$ 50,000$ were more likely to use approach coping strategies than withdrawal strategies. Similar results were found in regards to coping efficacy. Participants from two parent households reported higher coping efficacy than those from single parent households. These results are consistent with previous studies that found a supportive family environment was correlated with positive adjustment (Sarason et al., 1983; Silver et al., 1999). The question on the Kidcope survey of "I turned to my family, friends, and other adults to help me feel better," refers to the coping strategy of social support, which is categorized as approach coping. Social support may be more accessible in a two parent household compared to a single parent household. Mulhern et al. (1989) reported that single parents have more difficulty meeting their children's medical needs than to parents with a spouse to rely on, making the children more vulnerable to problems.

Additional associations of interest were observed among descriptive, predictive and outcome variables. Female participants were more likely to use approach coping strategies. Spirito et al. (1995) suggested that males and females exposed to disease related stressors adopt different strategies to deal with stress and that females are more likely to resort to emotional regulation and social support as a means to cope, which are both categorized as approach coping strategies. There was an association between race 
and withdrawal coping; however, this result was only significant when there was an interaction with household structure. Race alone as a predictor was not significant. Race and household structure were correlated indicating that African American participants tended to live with their mother, father, or grandparent rather than with both parents.

As the age of participants increased, individuals reported higher mean coping efficacy. Adolescents may be more selective about choosing coping strategies as they age, with experience allowing them to identify the most effective strategies. The developmental literature shows that coping styles may progress as children age indicating that adolescents use a wider range of coping responses and vary their coping across situations (Compas et al., 1988; Tyc et al., 1995; Donaldson et al., 2000). JeneyGammon et al. (1993) reported children endorsing fewer depressive symptoms showed higher coping efficacy scores, and were also more likely to make use of cognitive coping strategies and social support.

Participants from households with greater income reported a higher mean coping efficacy. Zebrack et al. (2002) reported that having low socioeconomic status is a risk factor for reporting psychological symptoms in childhood cancer survivors.

Study limitations included derivation of income data and lack of information on parental marital status, parental education, or parental employment. Income data were derived from parental reports even though $11 \%$ of the sample was more than 18 years old. For adult childhood cancer survivors, future analyses of the interrelationship of socioeconomic status and coping should be evaluated using the income attainment of individual survivors to obtain a more reliable estimate of the relationship between coping and socioeconomic status. Parental marital status, parental education, and parental 
employment were unavailable. These socio-economic characteristics can impact family functioning and support and should be included in future research.

Although, most childhood cancer survivors appear to adjust well, a minority continue to have problems coping. Research indicates that continued difficulties coping can lead to depression, lowered quality of life, poor school achievement, and social adjustment problems (Patenaude et al., 2005, Zeltzer et al., 2008; 2009). Therapy or other supports to address stressors and maladaptive coping strategies may be effective in preventing poor long-term outcomes in survivors. The Kidcope questionnaire could be an effective tool to screen and monitor childhood cancer survivors to identify and track those at risk of poor outcomes. 
Table 1: Participant and Family Characteristics of Interest

\begin{tabular}{|c|c|c|}
\hline Variables & $\mathbf{n}$ & $\%$ \\
\hline \multicolumn{3}{|l|}{ Gender } \\
\hline Male & 61 & 43.9 \\
\hline Female & 78 & 56.1 \\
\hline \multicolumn{3}{|l|}{ Race } \\
\hline Caucasian & 92 & 71.3 \\
\hline African American & 32 & 24.8 \\
\hline Other & 5 & 3.9 \\
\hline \multicolumn{3}{|l|}{ Age at Assessment } \\
\hline $7-12$ & 87 & 62.6 \\
\hline $13-17$ & 37 & 26.6 \\
\hline $18+$ & 15 & 10.8 \\
\hline \multicolumn{3}{|l|}{ Household Structure } \\
\hline Both parents & 86 & 67.2 \\
\hline Mother & 23 & 17.9 \\
\hline Father & 7 & 5.5 \\
\hline Grandparent & 12 & 9.4 \\
\hline \multicolumn{3}{|l|}{ Siblings } \\
\hline Yes & 119 & 92.2 \\
\hline No & 10 & 7.8 \\
\hline \multicolumn{3}{|l|}{ Median Household Income } \\
\hline$<\$ 25,000$ & 1 & 0.8 \\
\hline$\$ 25,000-\$ 49,999$ & 79 & 63.2 \\
\hline$\$ 50,000-\$ 74,999$ & 40 & 32.0 \\
\hline$\$ 75,000+$ & 5 & 4.0 \\
\hline
\end{tabular}

Table 2: Association Between Covariates and Coping Final Model

\begin{tabular}{lrrrr}
\hline Variables & Estimate & \multicolumn{1}{l}{ SE } & OR & 95\% CI \\
\hline Intercept & 0.21 & .39 & & \\
Gender & 0.97 & .42 & 2.64 & $(1.17,5.97)$ \\
Income & 0.63 & .43 & 1.88 & $(1.06,2.65)$ \\
Household structure*race & 0.23 & .11 & .80 & $(.64,1.0)$ \\
\hline
\end{tabular}

Table 3: Results of regression using demographic and family variables to predict coping efficacy

\begin{tabular}{lrrrr}
\hline & Regression & & & \\
\hline \hline Variable & B & SE B & \multicolumn{1}{c}{$\boldsymbol{\beta}$} \\
Median household income & .16 & .11 & .13 \\
Age at assessment & 2.09 & .77 & $.24^{*}$ \\
Household structure & .13 & .06 & $.18^{*}$ \\
Siblings & .13 & .11 & .11 \\
\hline${ }^{*} \mathrm{p}<.05$ & & & &
\end{tabular}




\section{REFERENCES}

American Cancer Society. (2012). Cancer Facts and Figures 2012. Atlanta: American Cancer Society.

Compas, B., \& Malcarne, V. F. (1988). Coping with stressful events in older children and young adolescents. Journal of Consulting and Clinical Psychology, 56(3), 405411.

Donaldson, D., Prinstein, M., Danovsky, M., \& Spirito, A. (2000). Patterns of Children's Coping With Life Stress: Implications for Clinicians. American Journal of Orthopsychiatry, 70(3), 351-359.

Gortmaker, S., \& Walker, D. W. (1990). Chronic Conditions, Socioeconomic Risks, and Behavioral Problems in Children and Adolescents. Pediatrics, 85(3), 267-76.

Howlander, N., Noone, A., \& Krapcho, M. (2012). SEER Cancer Statistics Review, 19752009. Bethesda, MD: National Cancer Institute.

Jeney-Gammon, P., Daugherty, T., Finch, A., Belter, R., \& Foster, K. (1993). Children's Coping Styles and Report of Depressive Symptoms Following A Natural Disaster. The Journal of Genetic Psychology, 154(2), 259-267.

Koocher, G., O'Malley, J., \& Gogan, J. (1979). Psychological Adjustment Among Pediatric Cancer Survivors. J Child Psychol Psychiat, 21, 163-73.

Kupst, M., \& Schulman, J. (1988). Long-term Coping with Pediatric Leukemia: A SixYear Follow-up Study. Journal of Pediatric Psychology, 13(1), 7-22.

Kupst, M., \& Richardson, C. (1995). Family Coping with Pediatric Leukemia: Ten Years After Treatment. Journal of Pediatric Psychology, 20(5), 601-17. 
Lavigne, J., \& Faier-Routman, J. (1993). Correlates of Psychological Adjustment to Pediatric Physical Disorders: A Meta-Analytic Review and Comparison with Existing Models. Developmental and Behavioral Pediatrics, 14(2), 117-23.

Mulhern, R. A. (1989). Social Competence and Behavioral Adjustment of Children Who Are Long-Term Survivors of Cancer. Pediatrics, 83(1), 18-25.

Parsons, S., \& Brown, A. (1998). Evolution of Quality of Life of Childhood Cancer Survivors: A Methodological Conundrum. Medical and Pediatric Oncology Supplesment, 1, 46-53.

Patenaude, A., \& Kupst, M. (2005). Psychosocial Functioning in Pediatric Cancer. Journal of Pediatric Psychology, 30(1), 9-27.

Sarason, I., Levine, H., Basham, R., \& Sarason, B. (1983). Assessing social support: The social support questionnaire. Journal of Personality and Social Psychology, 44, $127-130$.

Silver, E., Stein, R., \& Bauman, L. (1999). Sociodemographic and Condition-Related Characteristics Associated with Conduct Problems in School-aged Children with Chronic Health Conditions. Arch Pediatr Adolesc Med, 153, 815-820.

Spirito, A., Stark, L., \& Tyc, V. (1994). Stressors and Coping Strategies Described During Hospitalization by Chronically Ill Children. Journal of Clinical Child Psychology, 23(3), 314-22.

Spirito, A., Stark, L., \& Williams, C. (1988). Development of a Brief Coping Checklist for Use with Pediatric Populations. Journal of Pediatric Psychology, 13(4), 55574. 
Spirito, A., Stark, L., \& Gil, K. (1995). Coping with Everyday and Disease-Related Stressors by Chronically Ill Children and Adolescents. J Am Child Adolsc Psychiatry, 34(3), 283-90.

StataCorp. (2011). Stata Statistical Software. College Station, TX: StataCorp LP. Tyc, V., \& Mulhern, R. (1995). Chemotherapy-Induced Nausea and Emesis in Pediatric Cancer Patients: An Analysis of Coping Strategies. Journal of Pain and Symptom Management, 10(5), 338-47.

U.S. Census Bureau. (2011). American Community Survey: Median Household Income 5Year Estimates. Retrieved January 7, 2013, from American Fact Finder: http://factfinder2.census.gov

Zebrack, B., \& Chesler, M. (2002). Quality of Life in Childhood Cancer Survivors. Psycho-Oncology, 11, 132-41.

Zebrack, B., Zeltzer, L., Whitton, J., Mertens, A., Odom, L., Berkow, R., et al. (2002). Psychological Outcomes in Long-Term Survivors of Childhood Leukemia, Hodgkins's Disease, and Non-Hodgkin's Lymphoma: A Report From the Childhood Cancer Survivor Study. Pediatrics, 110(1), 42-52.

Zeltzer, L. (2009). Psychological Status in Childhood Cancer Survivors: A Report From the Childhood Cancer Survivor Study. Journal of Clinical Oncology, 27(14), 2396-2404.

Zeltzer, L., Qian, L., \& Leisenring, W. (2008). Psychosocial Outcomes and HealthRelated Quality of Life In Adult Childhood Cancer Survivors: A Report from the Childhood Cancer Survivor Study. Cancer Epidemiol Biomarkers Prev, 17, 435446. 


\section{CHAPTER 7: STRENGTHS, LIMITATIONS, AND CONCLUSIONS}

\subsection{Strengths and Limitations}

While this study provides valuable information on stressors and coping in pediatric cancer survivors, several limitations must be noted. First, since two aims of the study involved strictly cross sectional data, limited inferences can be made about these aims in relation to family, diagnosis, and treatment characteristics in relation to coping changes over time. Secondly, the initial survey for each participant was not necessarily completed on their first visit to the FACT clinic; therefore, the ability to make generalizations was limited regarding stressors experienced for cancer survivors at the same time point of completion of treatment. Furthermore, while much of the data was gathered from medical records, a portion of the household structure data was selfreported by the child life specialist and the social worker, which can introduce recall bias. However, the child life specialist and the social worker both agreed on all information they knew about the same child. Moreover, Kidcope surveys were attempted with only $58 \%$ of the population that attends FACT clinic, which limits the generalizability of the results since those participants and their families who chose to complete the Kidcope survey may be different from those who chose not to complete it. Demographic or treatment data were not collected for those who did not participate since obtaining that information required a signed HIPAA authorization. Additionally, information on medical late effects of cancer diagnosis or treatment was not collected, which could have contributed to their coping abilities. Thus, appropriate long term follow-up needs to include assessments of both psychosocial and potential physical factors that may be contributing to distress. Finally, consistent with many studies of childhood cancer, the 
participants in this study were all attending the same follow-up clinic. It is difficult to know, therefore, whether the results obtained apply to all childhood cancer survivors.

Although there are limitations to this study, there are also several notable strengths. When considering the longitudinal component of the study, the proposed study was the first sample of childhood cancer survivors evaluated with the Kidcope survey longitudinally. Other longitudinal studies have been conducted on coping but with smaller sample sizes and different coping measures used. Additionally, this study measured household factors as well as medical diagnosis and treatment related factors when examining coping. Previous studies using the Kidcope survey primarily examined demographic and diagnosis factors and not household structure or cancer treatment factors. Furthermore, despite its small contribution, this study was able to make inferences regarding racial differences in coping. Previous studies have been conducted in primarily Caucasian populations and have not examined race with respect to coping.

\subsection{Conclusions}

This research served to identify risk factors associated with coping, which can be used to identify childhood cancer survivors who may need more intervention than others and thus guide health care professionals in their preventative recommendations for both the childhood cancer survivor and their families. Efforts to implement interventions are essential to promote one's ability to better cope with the stresses associated with cancer.

Research on intervention programs survivors of childhood cancer is limited. A possible intervention could include group psychotherapy focused on decreasing withdrawal coping strategies and increasing the utilization of approach coping strategies. Clinicians working with distressed survivors of childhood cancer could explicitly address 
painful memories and cognitions about the former illness, as well as beliefs about the future, to foster processing and integration of the illness experience and to support the development of a positive outlook on the future. Further research is needed to develop evidence-based psychological interventions for childhood cancer survivors.

Attending to the way patients think about their illness history and their future and how they manage stress should be a part of routine follow-up care. The identification of perceived stressors and coping responses has important implications for the long-term mental health of childhood cancer survivors. The American Cancer Society (2012) reported that follow-up care to date has not implemented the regular use of questionnaires for survivors or parents to assess the late effects of cancer on coping as a mediator that can impact adjustment outcomes. The use of questionnaires at long term follow-up clinics allows repeated standardized measures collected from the same individuals across time, providing critical longitudinal data for assessment of the late effects of cancer treatment. Employing the Kidcope questionnaire as a screening tool would enable identification of those patients with limited coping strategies at their disposal or who rate their coping strategies as ineffective. When clinicians are able to recognize ineffective coping strategies, they may be able to assist the patient in replacing them with more effective strategies, improving long-term psychosocial outcomes.

An additional area of future research would be to study the relationship between parent and child coping. Investigating the correlation between parent and child coping may reveal important information about how interventions could be tailored to help children and their families cope with medical and emotional stressors associated with childhood cancer. Overall, this research identified areas that could be a focus of follow- 
up programs in order to provide an increased understanding for how patients and their families should be supported in order to minimize the psychosocial consequences of disease and treatment. Moreover, by providing a brief survey, such as the Kidcope, clinicians will begin to bridge the gap between research and clinical practice and examine more systematically the variety of coping styles which children and adolescents can bring to any given situation. 


\section{REFERENCES}

Adewale, A., Hayduk, L., \& Estabrooks, C. (2007). Understanding Hierarchical Linear Models. Nursing Research, 56(4s), s40-s46.

Aldridge, A., \& Roesch, S. (2007). Coping and Adjustment in Children with Cancer: A Meta-Analytic Study. Journal of Behavioral Medicine, 30(2), 115-29.

Altshuler, J., \& Ruble, D. (1989). Developmental Changes in Children's Awareness of Strategies for Coping with Uncontrollable Stress. Child Development, 60, 13371349.

American Cancer Society. (2012). Cancer Facts and Figures 2012. Atlanta: American Cancer Society.

Baker, J., \& Succop, P. B. (2001). Adolescent Girl's Coping With an STD: Not Enough Problem Solving and Too Much Self-Blame. J Pediatr Adolesc Gynecol, 14, 8588.

Band, E., \& Weisz, J. (1988). How to Feel Better When it Feels Bad: Children's Perspectives on Coping with Everyday Stress. Developmental Psychology, 24(2), 247-53.

Berger, Z., \& Dalton, L. (2011). Coping With a Cleft II: Factors Associated With Psychosocial Adjustment of Adolescents With a Cleft Lip and Palate and Their Parents. Cleft Palate-Craniofacial Journal, 48(1), 82-90.

Blount, R. (2008). Evidence-Based Assessment of Coping and Stress in Pediatric Psychology. Journal of Pediatric Pscyhology, 33(9), 1021-1045. 
Blount, R., Landolf-Fritsche, B., \& Powers, S. (1991). Differences Between High and Low Coping Children and Between Parent and Staff Behaviors During Painful Medical Procedures. Journal of Pediatric Psychology, 16(6), 795-810.

Boman, K. (2000). Long-Term Coping in Childhood Cancer Survivors: Influence of Illness, Treatment, and Demographic Background Factors. Acta Paediatr, 89, $105-111$.

Boman, K., \& Bodegard, G. (1995). Psychological Long-Term Coping with Experience of Disease and Treatment in Childhood Cancer Survivors. Acta Pardiatr, 12, 1395-402.

Bryant, R. (2003). Managing Side effects of Childhood Cancer Treatment. Journal of Pediatric Nursing, 18(2), 113-25.

Bull, B., \& Drotar, D. (1991). Coping with Cancer in Remission: Stressors and Strategies Reported by Children and Adolescents. Journal of Pediatric Psychology, 16(6), $767-82$.

Campbell, L. K., Scaduto, M., Van Slyke, D., Niarhos, F., Whitlock, J. A., \& Compas, B. E. (2008). Executive Function, Coping, and Behavior in Survivors of Childhood Acute Lymphocytic Leukemia. Journal of Pediatric Psychology, 34(3), 317-327.

Cheng, S.-T., \& Chan, A. M. (2003). Factorial Structure of the Kidcope in Hong Kong Adolescents. The Journal of Genetic Psychology, 164(3), 261-266.

Compas, B. (1987). Coping With Stress During Childhood and Adolescence. Psychological Bulletin, 101, 393-403.

Compas, B. E. (1993). Children and Disasters. New York: Plenum Press. 
Compas, B., \& Malcarne, V. F. (1988). Coping with stressful events in older children and young adolescents. Journal of Consulting and Clinical Psychology, 56(3), 405411.

Compas, B., Connor-Smith, J., Saltzman, H., Thomsen, A., \& Wadsworth, M. (2001). Coping with Stress During Childhood and Adolescence: Problems, Progress, and Potential in Theory and Research. Psychological Bulletin, 127, 87-127.

Corner, J. (2001). Care in Context. Boston: Wiley-Blackwell.

Donaldson, D., Prinstein, M., Danovsky, M., \& Spirito, A. (2000). Patterns of Children's Coping With Life Stress: Implications for Clinicians. American Journal of Orthopsychiatry, 70(3), 351-359.

Edgar, K., \& Skinner, T. (2003). Illness Representations and Coping as Predictors of Emotional Well-Being in Adolescents with Type 1 Diabetes. Journal of Pediatric Pscyhology, 28(7), 485-93.

Eiser, C., HIll, J., \& Vance, Y. (2000). Examining the Psychological Consequences of Surviving Childhood Cancer: Systematic Review as a Research Methos in Pediatric Psychology. Journal of Pediatric Psychology, 25(6), 449-60.

Folkman, S., \& Lazarus, R. (1986). Stress process and depressive symptomology. Journal of Abnormal Psychology, 95, 107-113.

Frank, N., Blount, R., \& Borwn, R. (1997). Attributions, Coping, and Adjustment in Children with Cancer. Journal of Pediatric Psychology, 22(4), 563-576.

Friedman, D. L., Whitton, J., \& Leisenring, W. (2010). Subsequent Neoplasms in 5-Year Survivors of Childhood Cancer: The Childhood Cancer Survivor Study. J Natl Cancer Inst, 102, 1083-1095. 
Garralda, M., \& Rangel, L. (2004). Impairment and Coping in Children and Adolescents with Chronic Fatigue Syndrome: A Comparative Study with Other Paediatric Disorders. Journal of Child Psychology and Psychiatry, 45(3), 543-552.

Gold, J., Mahrer, N., \& Treadwell, M. (2008). Psychosocial and Behavioral Outcomes in Children with Sickle Cell Disease and Their Healthy Siblings. Journal of Behavioral Medicine, 31, 506-16.

Gold, J., Treadwell, M., \& Weissman, L. (2008). An Expanded Transactional Stress and Coping Model for Siblings of Children with Sickle Cell Disease: Family Functioning and Sibling Coping, Self-Efficacy, and Perceived Social Support. Child: Care, Health, and Development, 34(4), 491-502.

Gortmaker, S., \& Walker, D. W. (1990). Chronic Conditions, Socioeconomic Risks, and Behavioral Problems in Children and Adolescents. Pediatrics, 85(3), 267-76.

Gray, R. (1992). Psychologic Adaption of Survivors of Childhood Cancer. Cancer, 70, 2712-2713.

Greenberg, H., Kazak, A., \& Meadows, A. (1989). Psychologic Functioning in 8-to-16year-old Cancer Survivors and Their Parents. J Pediatr, 114, 488-93.

Grylli, V., Wagner, G., \& Hafferl-Gattermayer, A. (2005). Disturbed Eating Attitudes, Coping Styles, and Subjective Quality of Life in Adolescents with Type 1 Diabetes. Journal of Psychosomatic Research, 65-72.

Haase, J. e. (1994). Experiences of Completing Cancer Therapy: Children's Perspectives. Oncology Nursing, 21, 1483-1492. 
Holen, S., Lervag, A., Waaktaar, T., \& Ystgaard, M. (2012). Exploring the Associations Between Coping Patterns for Everyday Stressors and Mental Health in Young Schoolchildren. Journal of School Psychology, 167-193.

Holmquist, L. (2002). Treatment, Age, and Time-Related Predictors of Behavioral Outcome in Pediatric Brain Tumor Survivors. J Clin Psychol Med, 9, 315-21.

Howlander, N., Noone, A., \& Krapcho, M. (2012). SEER Cancer Statistics Review, 19752009. Bethesda, MD: National Cancer Institute.

Jeney-Gammon, P., Daugherty, T., Finch, A., Belter, R., \& Foster, K. (1993). Children's Coping Styles and Report of Depressive Symptoms Following A Natural Disaster. The Journal of Genetic Psychology, 154(2), 259-267.

Kadan-Lottick, N. S., Robinson, L. L., Gurney, J. G., \& Neglia, J. P. (2002). Childhood Cancer Survivors' Knowledge About Their Past Diagnosis and Treatment. Journal of the Americal Medical Association, 287(14), 1832-1839.

Kahn, J. (2011). Multilevel Modeling: Overview and Applications to Research in Counseling Psychology. Journal of Counseling Psychology, 58(2), 257-271.

Kahn, J. H. (2011). Multilevel Modeling: Overview and applications to research in counseling psychology. Journal of Counseling Psychology, 58(2), 257-271.

Kazak, A. (2005). Evidence-Based Interventions For Survivors of Childhood Cancer and Their Families. Journal of Pediatric Psychology, 30(1), 29-39.

Kazak, A., Barakat, L., Meeske, K., Gallagher, P., Cnaan, A., \& Stuber, M. (2001). Posttraumatic stress in survivors of childhood cancer and their mothers: development and validation of the Impact of Traumatic Stressors Interview Schedule (ITSIS). Journal of Clinical Psychology Medicine, 8, 307-323. 
Kazak, A., Meeske, K., \& Barakat, L. (1997). Posttraumatic Stress, Family Functioning, and Social Support in Survivors of Childhood Leukemia and Their Mothers and Fathers. Journal of Consulting and Clinical Psychology, 65(1), 120-9.

Kazak, A., Penati, B., Boyer, B. H., Brophy, P., \& Johnson, K. (1996). A randomized controlled prospective outcome study of a psychological and pharmacological intervention protocol for procedural distress in pediatric leukemia. Journal of Pediatric Psychology, 21, 615-631.

Khairkar, P., Malhotra, S., \& Marwaha, R. (2010). Growing up with the families of BThalassaemia Major Using An Accelerated Longitudinal Design. Indian J Med Res, 132, 428-437.

Koocher, G., \& O'Malley, J. (1981). The Damocles Syndrome: Psychosocial Consequences of Surviving Childhood Cancer. New York: McGraw-Hill.

Koocher, G., O'Malley, J., \& Gogan, J. (1979). Psychological Adjustment Among Pediatric Cancer Survivors. J Child Psychol Psychiat, 21, 163-73.

Kupst, M., \& Richardson, C. (1995). Family Coping with Pediatric Leukemia: Ten Years After Treatment. Journal of Pediatric Psychology, 20(5), 601-17.

Kupst, M., \& Schulman, J. (1988). Long-term Coping with Pediatric Leukemia: A SixYear Follow-up Study. Journal of Pediatric Psychology, 13(1), 7-22.

Lavigne, J., \& Faier-Routman, J. (1993). Correlates of Psychological Adjustment to Pediatric Physical Disorders: A Meta-Analytic Review and Comparison with Existing Models. Developmental and Behavioral Pediatrics, 14(2), 117-23.

Lazarus, R. (1993). Coping Theory and Research: Past, Present and Future. Psychosomatic Medicine, 55, 234-47. 
Lazarus, R., \& Folkman, S. (1984). Stress, Appraisal, and Coping. New York: Springer.

Li, H., Chung, O. K., \& Ho, K. Y. (2011). Coping Strategies Used by Children Hospitalized with Cancer: An Exploratory Study. Psycho-Oncology, 20(9), 969976.

Maas, C., \& Hox, J. (2005). Sufficent sample sizes for multilevel modeling. Methodology: European Journal of Research Methods for the Behavioral and Social Sciences, 85-92.

Madan-Swain, A., Sexson, S., \& Brown, R. (1993). Family Adaption and Coping Among Siblings of Cancer Patients and Their Brothers and Sisters, and Nonclinical Controls. The American Journal of Family Therapy, 21(1), 60-70.

Meeske, K., Patel, S., \& Palmer, S. (2007). Factors Associated with Health-Related Quality of Life in Pediatric Cancer Survivors. Pediatr Blood Cancer, 49, 298-305.

Menard, S. (2000). Coefficients of Determination for Multiple Logistic Regression Analysis. The American Statistician, 54(1), 17-24.

Michel, G., Rebholz, C., \& al., e. (2010). Psychological Distress in Adult Survivors of Childhood Cancer: The Swiss Childhood Cancer Survivor Study. J Clin Oncol, 28(10), $1740-1748$.

Miller, R., Sabin, C., \& Goldman, C. (2000). Coping Styles in Families with Haemophilia. Psychology, Health and Medicine, 5(1), 1-12.

Mulhern, R. A. (1989). Social Competence and Behavioral Adjustment of Children Who Are Long-Term Survivors of Cancer. Pediatrics, 83(1), 18-25.

Netemeyer, R. G., Bearden, W. O., \& Sharma, S. (2003). Scaling Procedures: Issues and Applications. Thousand Oaks: Sage Publications. 
Noll, R., Bukowski, W., \& Davies, W. (1993). Adjustment in the Peer System of Adolescents with Cancer: A Two-Year Study. Journal of Pediatric Psychology, 18(3), 351-64.

Papadatou, D., Giannopoulou, I., \& Bitsakou, P. (2012). Adolescents' Reactions After a Wildfire Disaster in Greece. Journal of Traumatic Stress, 25, 57-62.

Parsons, S., \& Brown, A. (1998). Evolution of Quality of Life of Childhood Cancer Survivors: A Methodological Conundrum. Medical and Pediatric Oncology Supplesment, 1, 46-53.

Patenaude, A., \& Kupst, M. (2005). Psychosocial Functioning in Pediatric Cancer. Journal of Pediatric Psychology, 30(1), 9-27.

Pereda, N., Forns, M., \& T, K. (2009). Use of the Kidcope to Identify Socioeconomically Diverse Spanish School-Age Children's Stressors and Coping Strategies. Child: Care, Health and Development, 1-10.

Peterson, L. (1989). Coping by Children Undergoing Stressful Medical Procedures: Some Conceptual, Methodological, and Therapeutic Issues. Journal of Counsulting and Clinical Psychology, 57(3), 380-387.

Peugh, J. (2010). A Practical Guide to Multilevel Modeling. Journal of School Psychology, 48, 85-112.

Pretzlik, U., \& Sylva, K. (1999). Paediatric Patients' Distress and Coping During Medical Treatment: A Self-Report Measure. Arch Dis Child, 81, 525-27.

Prinstein, M., LaGreca, A., \& Vernberg, E. (1996). Children's Coping Assistance: How Parent's, Teachers, and Friends Help Children Cope After a Natural Disaster. Journal of Clinical Child Psychology, 25(4), 463-475. 
Recklitis, C., Diller, L., \& Najita, J. (2006). Suicide Ideation in Adult Survivors of Childhood Cancer: A Report from the Childhood Cancer Survivor Study. J Clin Oncol, 24(24), 3852-3857.

Reid, G., Dubow, E., \& Carey, T. (1995). Differential and situational differences in coping among children and adolescents with diabetes. Journal od Applied Developmental Psychology, 16, 529-554.

Rodgers, C., Norville, R., Tayle, O., Poon, C., Hesselgrave, J., Gregurich, M. A., et al. (2012). Children's Coping Strategies for Chemotherapy-Induced Nausa and Vomiting. Oncology Nursing Forum, 39(2), 202-209.

Rudolph, K., Denning, M., \& Weisz, J. (1995). Determinants and Consequences of Children's Coping in the Medical Setting: Conceptualization, Review and Critique. Psychological Bulletin, 118(3), 328-57.

Salama, C., Morris, M., \& Armistead, L. (2013). Depressive and Conduct Disorder Symptoms in Youth Living with HIV: The Independent and Interactive Roles of Coping and Neuropsychological Functioning. AIDS Care, 25(2), 160-168.

Sanger, M., Copeland, D., \& ER, D. (1991). Psychosocial Adjustment Among Pediatric Cancer Patients: A Multidimensional Assessment. Journal of Pediatric Psychology, 16(4), 463-74.

Sarson, I., Levine, H., Basham, R., \& Sarason, B. (1983). Assessing social support: The social support questionnaire. Journal of Personality and Social Psychology, 44, 127-130. 
Sawyer, M., Antoniou, G., \& Toogood, I. (2000). Childhood Cancer: A 4-Year Prospective Study of the Psychological Adjustment of Children and Parents. Journal of Pediatric Hematology/Oncology, 22(3), 214-220.

Schultz, K., Ness, K., \& Whitton, J. (2007). Behavioural and Social Outcomes in Adolescent Survivors of Childhood Cancer: A Report from the Childhood Cancer Survivor Study. J Clin Oncol, 25(24), 3649-3656.

Seo, J. (2010). Psychosocial Aspects of Childhood Cancer Survivors. Korean Journal of Pediatrics, 53(4), 471-76.

Seo, J. J. (2010). Psychosocial Aspects of Childhood Cancer Survivors. Korean Journal of Pediatrics, 53(4), 471-476.

Servitzoglou, M., Papadatou, D., \& Tsiantis, I. (2008). Psychosocial Functioning of Young Adolescent and Adult Survivors of Childhood Cancer. Support Care Cancer, 16, 29-36.

Shafer, D. (1993). Developmental Psychology: Childhood and Adolescence. Belmont: Brooks Cole Publishing.

Silver, E., Stein, R., \& Bauman, L. (1999). Sociodemographic and Condition-Related Characteristics Associated with Conduct Problems in School-aged Children with Chronic Health Conditions. Arch Pediatr Adolesc Med, 153, 815-820.

Smith, K., Ackerson, J., \& Blotcky, A. (1989). Reducing Distress During Invasive Medical Procedures: Relating Behavioral Interventions to Preferred Coping Style in Pediatric Cancer Patients. Journal of Pediatric Psychology, 14, 405-19.

Spirito, A., Francis, G., \& Overholser, J. (1996). Coping, Depression, and Adolescent Suicide Attempts. Journal of Clinical Child Psychology, 25(2), 147-55. 
Spirito, A., Stark, L., \& Gil, K. (1995). Coping with Everyday and Disease-Related Stressors by Chronically Ill Children and Adolescents. J Am Child Adolsc Psychiatry, 34(3), 283-90.

Spirito, A., Stark, L., \& Grace, N. (1991). Common Problems and Coping Strategies Reported in Childhood and Early Adolescence. Journal of Youth and Adolescence, 20(5), 531-44.

Spirito, A., Stark, L., \& Tyc, V. (1994). Stressors and Coping Strategies Described During Hospitalization by Chronically Ill Children. Journal of Clinical Child Psychology, 23(3), 314-22.

Spirito, A., Stark, L., \& Williams, C. (1987). Coping in Children and Adolescents:

Development of a Brief Scale. Washington, D.C.: The Fifth Annual Conference of the Society of Behavioral Medicine.

Spirito, A., Stark, L., \& Williams, C. (1988). Development of a Brief Coping Checklist for Use with Pediatric Populations. Journal of Pediatric Psychology, 13(4), 55574.

Stallard, P., Velleman, R., \& Langsford, J. (2001). Coping and Psychological Distress in Children Involved in Road Traffic Accidents. British Journal of Clinical Psychology, 40, 197-208.

Stata Corp LP. (2011). Stata Structural Equation Modeling Reference Manual. College Station: Stata Press.

StataCorp. (2011). Stata Statistical Software. College Station, TX: StataCorp LP. 
Tyc, V., \& Mulhern, R. (1995). Chemotherapy-Induced Nausea and Emesis in Pediatric Cancer Patients: An Analysis of Coping Strategies. Journal of Pain and Symptom Management, 10(5), 338-47.

U.S. Census Bureau. (2011). American Community Survey: Median Household Income 5Year Estimates. Retrieved January 7, 2013, from American Fact Finder: http://factfinder2.census.gov

Vernberg, E., \& al., e. (1996). Prediction of Posttraumatic Stress Symptoms in Children After Hurricaine Andrew. Journal of Abnormal Psychology, 105, 237-348.

Vigna, J., Hernandez, B., Kelley, M., \& Gresham, F. (2010). Coping Behavior in Hurricaine-Affected African American Youth: Psychometric Properties of the Kidcope. Journal of Black Psychology, 36(1), 98-121.

Weigers, M. (1998). Self-Reported Worries Among Long-Term Survivors of Childhood Cancer and Their Peers. Journal of Psychosocial Oncology, 16(2), 1-24.

Woltman, H., Feldstain, A., MacKay, C., \& Rocchi, M. (2012). An Introduction to Hierarchical Linear Modeling. Tutorials in Quantitative Methods for Psychology, 8(1), 52-69.

$\mathrm{Yu}, \mathrm{C}$. (Evaluating cutoff criteria of model fit indices for latent variable models with binary and continuous outcomes). 2002. Univeristy of California, Los Angelos: Doctoral dissertation.

Zebrack, B. (2001). Health-Related Worries, Self-Image, and Life Outlooks of LongTerm Survivors of Childhood Cancer. Health and Social Work, 26(4), 245-256.

Zebrack, B., \& Chesler, M. (2002). Quality of Life in Childhood Cancer Survivors. Psycho-Oncology, 11, 132-41. 
Zebrack, B., Zeltzer, L., Whitton, J., Mertens, A., Odom, L., Berkow, R., et al. (2002). Psychological Outcomes in Long-Term Survivors of Childhood Leukemia, Hodgkins's Disease, and Non-Hodgkin's Lymphoma: A Report From the Childhood Cancer Survivor Study. Pediatrics, 110(1), 42-52.

Zebrack, B., \& Isaacson, S. (2012). Psychosocial Care of Adolescent and Young Adult Patients with Cancer and Survivors. Journal of Clinical Oncology, 1-7.

Zeltzer, L. (2009). Psychological Status in Childhood Cancer Survivors: A Report From the Childhood Cancer Survivor Study. Journal of Clinical Oncology, 27(14), 2396-2404.

Zeltzer, L., Qian, L., \& Leisenring, W. (2008). Psychosocial Outcomes and HealthRelated Quality of Life In Adult Childhood Cancer Survivors: A Report from the Childhood Cancer Survivor Study. Cancer Epidemiol Biomarkers Prev, 17, 435446. 
APPENDICES 


\title{
APPENDIX A: HIPAA Authorization \& Consent to Participate Forms
}

\author{
Medical University of South Carolina (MUSC) \\ Health Insurance Portability and Accountability Act (HIPAA) \\ Authorization to Use or Disclose
}

Protected Health Information (PHI) for Research Purposes

\section{Assessment of Coping Pediatric Oncology Patients Using the Kidcope Interview}

HIPAA is a federal law that requires the protection of information that can identify you. Protected Health Information includes information that pertains to your past, present or future physical and mental health conditions, or the provision of health care. You are being asked to sign this Authorization because you are in the research study listed above.

The researchers agree to protect your protected health information by using and disclosing it only as permitted by you in the Authorization and as directed by state and federal law.

\section{A. What is the purpose of the use and/or disclosure of your protected health information?}

Your child/adolescent is being asked to volunteer for a research study. This research is sponsored by the Medical University of South Carolina. The purpose of this study is to investigate your child's/adolescent's perceptions of stresses related to his/her illness and treatment, and his/her reported use of coping strategies specific to these stresses, in order to provide effective interventions and support as needed and to monitor adjustment over the course of the illness. This study will utilize the Kidcope checklist, an established tool designed to identify specific coping strategies children and adolescents are using to cope with events/situations that they perceive as stressful related to their illness, and investigate the effectiveness of such a screening tool. Your child/adolescent is being asked to participate in this study because they are/were a cancer patient who is/was treated at the Medical University of South Carolina. The investigator in charge of this study is Michelle Vandermaas.

\section{B. What protected health information will be used or disclosed?}

You may be asked for health-related information relevant to the study. Your child's/adolescent's name and date of birth will be collected on the survey. Additional information will be collected from your child's/adolescent's chart including medical diagnosis, treatment and dates of diagnosis and completion of treatment. Researchers will also generate new information about your child/adolescent as a result of the research questionnaire. The information that will be used or disclosed to others is the responses generated from the Kidcope Checklist. All information will be anonymous and will not be able to be linked back to your child. Results presented will be in terms of a group based on several factors such as type of stressor identified on the survey, coping strategies used, medical diagnosis, demographics or related household factors.

\section{Who will disclose your protected health information?}

The researchers and staff of the Medical University of South Carolina who are involved in this research study will disclose your medical/health information for this study.

\section{Who will receive your protected health information?}


Your protected health information may be used or shared with others outside of MUSC for purposes directly related to the conduct of the research. Once this information leaves MUSC, we cannot guarantee that it will be protected by this authorization.

- Federal and state agencies and MUSC committees that have authority over the research, such as:

0 The Institutional Review Board (IRB) that oversees human research at the MUSC

o Office of Human Research Protections (OHRP)

- Clinical staff not involved in the study who may become involved in your care if it is potentially relevant to treatment

- Parents of research subjects ages 16 up to 18 years of age. Parents of minors $<16$ may receive information without authorization from the child.

\section{E. Do you have to sign this authorization?}

You do not have to sign this authorization. If you choose not to sign the authorization, it will not affect your treatment, payment or enrollment in any health plan or affect your eligibility for benefits. You will not be allowed to participate in the research study.

\section{F. If you sign the Authorization, can you change your mind?}

You have the right to withdraw your authorization to allow MUSC to use or share your protected health information collected for this research study. Protected health information that has already been used or disclosed cannot be withdrawn. Your protected health information may still be used and disclosed if you have an adverse event. Once authorization is withdrawn and you are no longer participating in the study, no more protected health information will be collected. If you want to withdraw your permission, you must do so in writing to the investigator. The investigator's address is:

Michelle Vandermaas

Medical University of South Carolina

165 Ashley Avenue

PO Box 250329

Charleston, SC 29425

If you withdraw your authorization, you will not be allowed to participate in the research study.

G. You have a right to see and copy the information described on this authorization form.

H. Authorization:

You authorize Michelle Vandermaas and her staff, your doctors and other health care providers to use and disclose your protected health information for the purposes described above.

$\begin{array}{llll}\text { Signature of Participant } & \text { Date } & \text { *Name of Participant }\end{array}$

\section{Privacy Notice:}

You have been given a copy of the Privacy Notice that describes the practices of MUSC regarding your protected health information. Please initial here:

If you have any questions or concerns about your privacy rights, you should contact MUSC's Privacy Officer at (843) 792-8744.

You will be given a signed copy of this form. 


\title{
Medical University of South Carolina CONSENT TO BE A RESEARCH SUBJECT
}

\author{
Assessment of Coping Pediatric Oncology Patients Using the Kidcope Interview
}

\begin{abstract}
A. PURPOSE AND BACKGROUND:
My child/adolescent is being asked to volunteer for a research study. This research is sponsored by the Medical University of South Carolina. The purpose of this study is to investigate my child's/adolescent's perceptions of stresses related to his/her illness and treatment, and his/her reported use of coping strategies specific to these stresses, in order to provide effective interventions and support as needed and to monitor adjustment over the course of the illness. This study will utilize the Kidcope checklist, an established tool designed to identify specific coping strategies children and adolescents are using to cope with events/situations that they perceive as stressful related to their illness, and investigate the effectiveness of such a screening tool. My child/adolescent is being asked to participate in this study because they are/were a cancer patient who is/was treated at the Medical University of South Carolina. The investigator in charge of this study is Michelle Vandermaas. This study is being done at the Medical University of South Carolina and will involve approximately 200 volunteers.
\end{abstract}

\section{B. PROCEDURES:}

If you agree for your child/adolescent to participate in this study, the following will happen:

1. My child/adolescent will be administered the Kidcope checklist using a semi-structured interview format. My child/adolescent will begin will begin by identifying something that has been a problem recently related to his/her illness or treatment. Next he/she will identify feelings associated with this problem, and the strength of these feelings. Questions relating to coping strategies used and the perceived efficacy of each will follow. My child/adolescent will only be completing one survey at this visit.

2. Information on your diagnosis and treatment will be collected from your medical record.

\section{DURATION:}

Participation in this study will take about 45 minutes to an hour.

\section{RISKS/DISCOMFORTS:}

My child/adolescent may choose to participate in which he/she will decide what issues to discuss with the Child Life Specialist conducting the interview. I understand that this interview is completely child directed and that topics discussed may cause minimal discomfort to my child/adolescent. There is also a risk of breach of confidentiality since name and date of birth are being collected on the survey.

\section{E. BENEFITS:}

The benefit of having my child/adolescent participate in the Kidcope interview includes possible early identification of trouble coping, and timely, individually-tailored interventions.

\section{F. COST:}

Your child/adolescent will not be charged for any of the study procedures.

\section{G. COMPENSATION:}

Your child/adolescent will not be paid for participating in this study.

\section{H. ALTERNATIVES:}

The alternative is to not participate.

Results of this research will be used for the purposes described in this study. This information may be published, but your child/adolescent will not be identified. Information that is obtained concerning this research that can be identified with your child/adolescent will remain confidential to the extent possible within State and Federal law. The investigators associated with this study, the sponsor, and the MUSC 
Institutional Review Board for Human Research will have access to identifying information. All records in South Carolina are subject to subpoena by a court of law.

In the event that your child/adolescent is injured as a result of participation in this study, you should immediately take your child/adolescent to the emergency room of the Medical University Hospital, or in case of an emergency go to the nearest hospital, and tell the physician on call that your child/adolescent is in a research study. They will call your child's/adolescent's study doctor who will make arrangements for your child's treatment. If the study sponsor does not pay for your child's/adolescent's treatment, the Medical University Hospital and the physicians who render treatment to your child/adolescent will bill your insurance company. If your insurance company denies coverage or insurance is not available, you will be responsible for payment for all services rendered to your child.

Your child's/adolescent's participation in this study is voluntary. Your child/adolescent may refuse to take part in or stop taking part in this study at any time. You should call the investigator in charge of this study if you decide to do this. Your decision not to take part in the study will not affect your child's/adolescent's current or future medical care or any benefits to which your child/adolescent is entitled.

The investigators and/or the sponsor may stop your participation in this study at any time if they decide it is in your child's/adolescent's best interest. They may also do this if your child/adolescent does not follow the investigator's instructions.

\section{Volunteers Statement}

I have been given a chance to ask questions about this research study. These questions have been answered to my satisfaction. If I have any more questions about my participation in this study or study related injury, I may contact Michelle Vandermaas MS, CCLS (843/792/1380). I may contact the Medical University of SC Hospital Medical Director (843/792-9537) concerning medical treatment.

If I have any questions, problems, or concerns, desire further information or wish to offer input about my child's/adolescent's rights as a research subject in this study, I may contact the Medical University of SC Institutional Review Board for Human Research IRB Manager of the Office of Research Integrity Director at (843) 792-4148. This includes any questions about my rights as a research subject in this study. I agree to participate in this study.

I have been given a copy of this form for my own records.

If you wish to participate, you should sign below.

Signature of Participant Date

*Name of Participant Date

Signature of Person Obtaining Consent Date

*12-17 years of age:

"My participation has been explained to me, and all of my questions have been answered. I am willing to participate.”

Signature:

Age: Date of Birth: 
Demographic \& Household Information:

ID \#

Last Name:

First Name:

Date of Birth: l Date of Death:

Gender: Male Female Zip Code:

Race/Ethnicity: White Black Other Siblings: Yes No

Household structure: Both Parents Mother Father Grandparent

Diagnosis \& Treatment Information:

Diagnosis:

Date of diagnosis: l- -

Chemotherapy: Yes No Radiation: Yes No

Surgery to remove tumor: Yes No Port __ Pic/Central Line

Bone Marrow Transplant: Yes No Date:

Off treatment date:

Relapse date:

$2^{\text {nd }}$ off treatment date: 


\section{APPENDIX C: Kidcope Questionnaires}

\section{Kidcope Questionnaire}

Date:

Name:

Age:

Grade:

\section{Date of Birth:}

Think about something that bothered you when you were sick. Please describe the problem or situation below.

1. Did/does this situation make you nervous?

not at all a little somewhat pretty much very much

2. Did/does this situation make you sad?

not at all a little somewhat pretty much very much

3. Did/does this situation make you angry or mad?

not at all a little somewhat pretty much very much

4. Did/does this situation make you afraid?

not at all a little somewhat pretty much very much

5. Compared to all other problems that you've had, how much does this one bother you?

not at all a little somewhat pretty much much If this is not the worst problem, what would be the worst problem? 


\section{(Adolescent Version)}

Please read each item below and circle which phrase applies. Then answer both questions to the right of each item, circling the best answer.

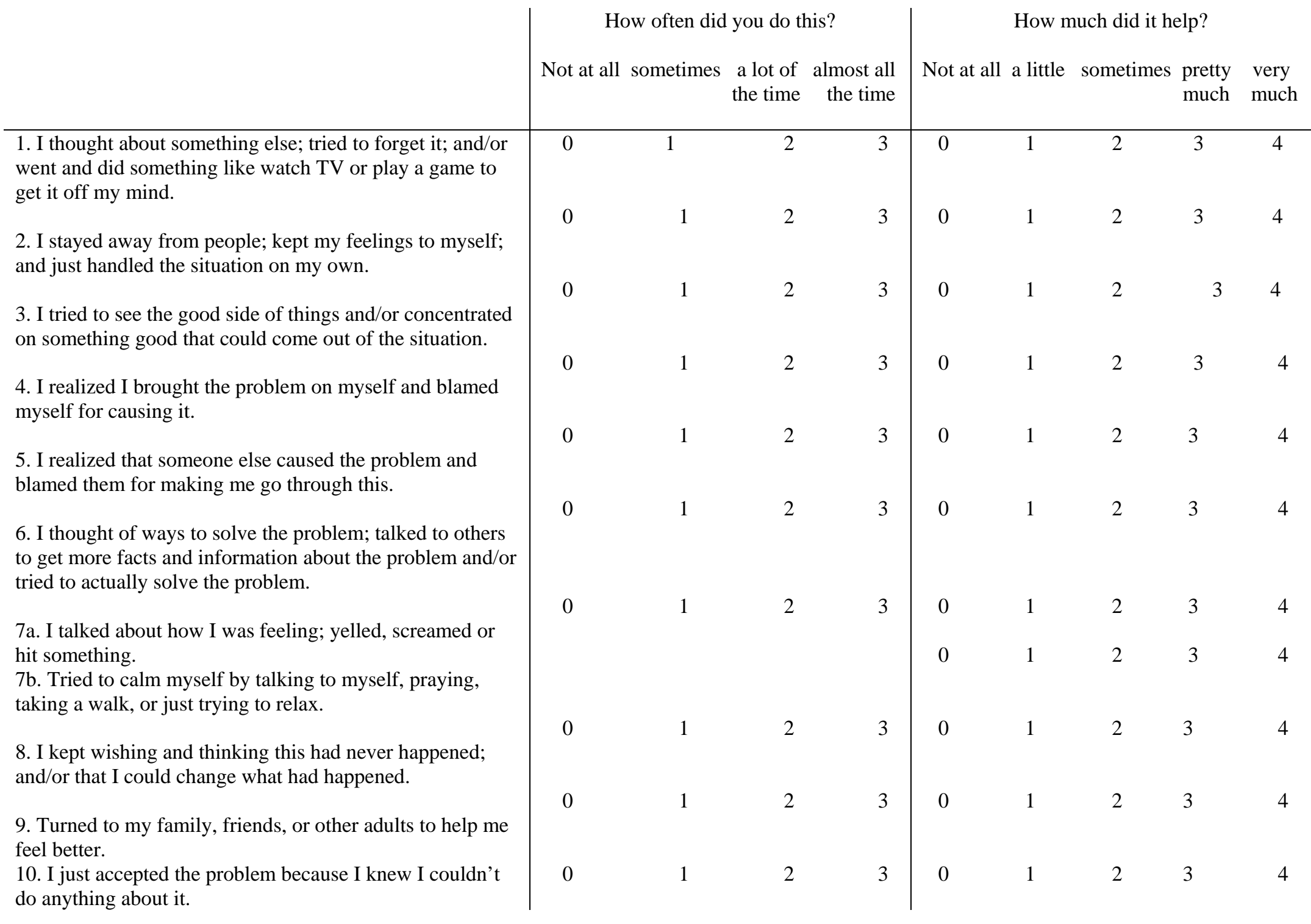




\section{(Younger Version)}

Think about the problem you described. Did you use any of the following ways to deal with the problem? How well did they work for you?

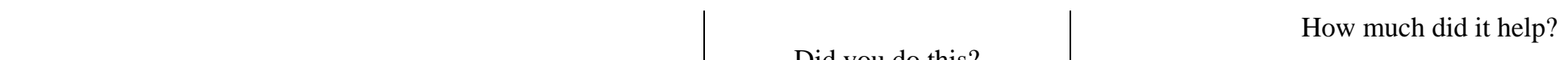

1. I just tried to forget it.

2. I did something like watch TV or played a game to forget it.

3. I stayed by myself.

4. I kept quiet about the problem.

5. I tried to see the good side of things.

6. I blamed myself for causing the problem.

7. I blamed someone else for causing the problem.

8. I tried to fix the problem by thinking of answers.

9. I tried to fix the problem by doing something or talking to someone.

10. I yelled, screamed, or got mad.

11. I tried to calm myself down.

12. I wished the problem had never happened.

13. I wished I could make things different.

14. I tried to feel better by spending time with others like family, grownups, or friends.

15. I didn't do anything because the problem couldn't be fixed.
How much did it help?

Not at all a little a lot

Y

Yes

0

No

2

Yes

Yes

Yes

Yes

Yes

Yes

Yes

Yes

Yes

Yes

Yes

Yes

Yes
0

1

0

0

0

0

0

0

0

0

0

0

0

1

2 


\section{APPENDIX D: Stressor Coding}

\section{Cancer-Related Stressors:}

\section{Chemotherapy}

- Getting sick and throwing up

- Chemo-sick, weak, tired

- One of the chemo's I am taking

- Getting mouth sores and not being able to eat or drink anything. Also, getting sick bothers me because most of the times I get sick is in the middle of the night and when I get sick it makes my mouth sores burn and sting.

- Chemo

- Throwing up

- I had to use the restroom a lot in the hospital; I thought the chemo was pee since it was yellow in color.

- Food tasted like metal when I was on chemo

- When I used to have to get chemo treatment, why was I always sick?

- The nights while on therapy

- Not knowing how I am going to react to the chemo. You hear about all the side effects but you don't know which ones you will have

- Taking medicine and then throwing up.

\section{Surgery}

- Surgeries made me worry because I didn't understand why I had to go to sleep when I wasn’t sleepy

- Surgery on my neck

- My scars

- Nervous that I would wake up during surgery

- When I was put to sleep for surgery I kind of remembered and felt it and came out of the anesthesia

- Scar-hard to buy clothes and bathing suits

- Surgery while I am asleep I am oblivious to what is happening

- Going into my body.

- Having tubes in mouth; being asleep and being cut open.

- When I couldn't move after surgery

- Having a scar.

- Having tubes up my nose and other places such as my mouth. 
- I hate the shots

- Getting shots

- Needles

- The butterfly shot scared me the most because I am afraid of needles

- When the needles went into my arm

- When they poked me with a needle

- Needle sticks

- Having to get shots everyday

- I was scared because the doctors were always poking me and I had to get a lot of shots

- Shots at the same time in two legs bothered me.

- Getting stuck.

\section{Hair loss}

- Losing hair

- When my hair had come out

- People's ignorance, getting looks

- When I went through chemotherapy I didn't have any hair and kids used to tease me

- Hair loss-I shaved my head to keep it from making a mess when it falls out. Sometimes I wear a hat but not usually. It doesn't bother me too much now because I am used to being bald.

- When I lost my hair and a lot of people made fun of me

- When my hair fell out I was scared

- The hardest thing was losing my hair and not being able to cover it up. Seeing how sick I was, this was a minor medical point but to a high school sophomore this was a big deal. I felt like as long as I looked fairly normal I could still fit in with my friends and peers. When I lost my hair, I didn't feel normal anymore. Sure, wearing a hat and having understanding friends helped some, but the stares I got from strangers during a trip to the mall or Wal-Mart was enough to remind me I didn't quite fit in.

- I was nervous when they took my port in and out

- The worst part was having two operations done on my port

- Port, hurt when accessed.

- Port access 
- Blood draw

- The blood work

- Hated getting blood drawn

- Lots of blood tests

- IV

- I hate having to get IV's because they miss and have to stick me again and again. Everyday they have to draw blood.

- Blood transfusions, it wasn't my blood

- Take blood

- At night I would get blood drawn when I was asleep sometimes

- Drawing blood from my finger

\section{Hospital}

- Going to the hospital

- Staying in the hospital all the time

- I hate when you are in the hospital and none of your friends understand how bad you feel. They say things like 'you're so lucky you missed a test today.' They don't understand that you want to take that test or do home work. Anything is better than the hospital

- When I had to stay in the hospital when I had a fever.

- When I had to stay in the hospital extra days, I had to stay in the hospital on Easter.

- What bothered me most about my sickness is that I had to go to the hospital for every little thing.

- Laying in bed all the time

- Coming to clinic every week

- Having to stay at the hospital for long periods of time

- The doctors came in the middle of the night

- Having to see all the doctors

- My friend Ashley was in the hospital and I went to see her and the sight got me a little upset.

- Being sick most of the time and having to be in bed a lot.

\section{Painful procedures}

- $\quad$ Painful procedures, i.e. endoscopy

- Spinal taps and bone marrow asp.

- Spinal taps, tests on my leg (sticks \& shocks)

- Back sticks 
- Having weird feeling; the medicine I would take would make me hungry and eat weird things

- Taking medicine everyday and having people watch me take the medicine and the taste of the medicine

- $\quad$ Taking 4 pills every day

- Medicine

- The medicine-aggravating because I did not know what the medicine was for

- Being sick most of the time and having to take medicine.

- The medicine tastes bad.

\section{Radiation}

- The radiation stunting my growth

- Radiation on my neck

- Radiation-held down to table with face mask and being by yourself

- When I had radiation it made the hair above my left ear not grow

\section{Pain}

- My stomach has been bothering me; chest hurts too

- The numbing of my hand has bothered me

- Stomach problems, scared I have stomach ulcers

- Pains

- The pain-my stomach

- My stomach, heart hurts a little

Fear of cancer recurrence

- Thinking about it coming back

- Worrying

- Cancer-when I thought it would come back

- Doctors talking about my cancer possibly coming back

- I think I might have brain damage or something else. I think I might have cancer again. 
Not being able to participate in activities

- Not being able to do all the stuff I was used to doing. Like playing softball, swimming, hanging out with friends and just being a normal kid.

- Not being able to participate in outdoor activities because I am on oxygen

- Not being able to go swimming in the lake

- Not being able to go to school and meet new people.

- Not being able to see my friends while I was in the hospital

- The way I walk bothers me. I guess my limp bothers me because I am around people I don't know. I guess I'm bothered because I walk slower, different and cannot run.

- Missing summer because I spent it at the hospital

- Not being able to play sports

- I can't play football because I have one kidney.

- Could not do anything with friends.

- Being weak. Not being able to dance or just walk somewhere if I wanted

- In high school I wasn't allowed to play sports due to my portacath

\section{Thoughts of death}

- Thought I was going to die

- Wondering if I was ever going to get better; wondered if I was going to die

- Afraid of going to sleep-that I wouldn't be able to wake up again

- Thinking about people or myself dying from cancer

- Remembers dying and coming back to life-saw dead grandparents.

- My friends dying from cancer 


\section{Having cancer in general}

- Having a brain tumor

- It keeps coming back even though I have already had chemo and radiation

- My weight loss and my eyesight. I cannot even see out of my left eye. I am doing everything to gain weight but I am still losing.

- Sick with cancer

- My stomach got big and the doctors kept telling me my stomach almost exploded

- Looking back it bothers me because I wasn't the only one suffering. My parents thought I might die. Can't believe all they had to go through.

- Just the fact that I had cancer. I went to the hospital with a minor stomach ache and I came out with this

- The situation about my illness is when I was 2 years old with cancer and I didn't know everything about what was going on so when I was in this room when nobody could stay the night with me I used to cry and cry until I fell asleep. Now I am 14 years old and trying to keep myself from HIV, smoking, AIDS and other things that will cause cancer because it's hard to deal with and it causes really bad pain.

- The thing that bothers me most is when people ask me if I am deaf. Also at the point they ask why do I talk like I do. It hurt really badly when people don't understand what you are really going through in your life.

- Would rather he lost his sense of smell rather than his hearing

- I was scared because I only have one kidney left and I am afraid to lose the last one because something bad might happen.

- Getting treatment and being really weak

- Having cancer

- That my friend might tell everyone I had cancer

- If I lose another kidney.

- Have very vivid memories of cancer. Worry about restrictions on my life in the future because of cancer.

- Bothered that no one told him he was sick.

- Deep inside I feel like sometimes I can’t get over it and I just cry. My mom doesn't want me to go on anything and says 'you're fine'. She is crazy and won't do anything to see that I need help.

- Alarming doctors played the biggest blow, not to my physical health but to my mental health. Impersonal contact with health professionals has made me shrewd to the whole experience. MUSC is far better than the competition in this regard, but as far as I am concerned the whole industry needs a kick in the pants. 


\section{Non-Cancer-Related Stressors:}

\section{School}

- A combination event led to overall problems at school and at home

- Hard school work

- I failed $7^{\text {th }}$ grade

- Tests at school

- My grades

- Spanish is hard

- My teacher is a racist sending all black people to the silent lunch table and to the back of the line.

- Teacher stole my cell phone

- Math-multiplication

- Report due on Tuesday, not even done with the notes.

- Homework

- Pop quiz

- School-trying to make everything fit. I had to make up 5 days from the hurricane.

- Teacher got me kicked out of school

- Kids picking on me

- The kids in my class that bother me

- I get mad when people call me retarded because I am in LD classes

- People ask my why and how I got cancer and I tell them and they are like you don't fit with us

- When people call me or my sister names; a lot of people picking on my sister

- Former friends/drugs etc. If I smoke it may cause cancer, but I am afraid I might try it.

- Pick fights, ganged up on

- Being made fun of at school and my reactions

- Peer pressure

- Bullies in school

- Busy body people

- Being in front of a lot of people

- When I am in a play in front of a bunch of people

- Getting in front of people to spell 
- A combination event led to overall problems at school and at home

- Family problems

- Dad doesn’t come around a lot; buys drugs instead of giving my mom money

- Sister bothers me

- My brother makes fun of me

- Billy-Mom's boyfriend

- Brother going to college

- New stepmom and younger brother

- My dad is away from home a lot

- Divorced parents

- Brothers and sisters

- My stepmom

- My stepmom got my dad locked up (he is out now) but he cant even go to the house without an officer being with him so I am staying with my sister

- Not being able to see real dad. Don't go places with stepdad. Getting into trouble at home with brother.

- When my sister was in the hospital.

- Brother and Dad.

- Cousin.

- When Dad left.

- Does not like when mom goes on a trip.

\section{Friends/family deaths}

- My brother died

- The passing away of my friends

- A dream that my grandma passed away (she passed away last Thanksgiving)

- Saying goodbye to friends, losing a loved one

- Friend killed in a car accident

- Grandmother dying

- Death in the family

- Friend that died in the hospital

- I didn't know what to say to my Grandma when she was about to die. Wish I could have talked to her.

- Grandfather died.

- Dog died

- Animals die 
- Stuck in the middle of two of my best friends who hate each other

- Some of my friends that I have aren't nice to me

- Friend talked behind my back

- One of my best friends has gotten grouchy

- Play drums in front of friends

- Friends fight sometimes.

\section{Not having any friends}

- Meeting new people

- Making friends

- No friends at school

\section{Other}

- Dark

- Anxiety attacks

- Lightening and thunder

- Bugs/Spiders

- Basketball 